\title{
LANDFILL GAS EXTRACTION AND PURIFICATION TECHNIQUES
}

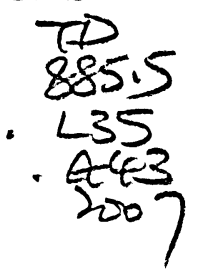

by

Samuel Gebrehawariat

B.Sc., Alemaya University, Ethiopia, July 1987

Research Project

Presented to Ryerson University

In Partial Fulfillment of the Requirements for the degree of Master of Engineering

In the Program of

Civil Engineering 
UMI Number: EC53564

\section{INFORMATION TO USERS}

The quality of this reproduction is dependent upon the quality of the copy submitted. Broken or indistinct print, colored or poor quality illustrations and photographs, print bleed-through, substandard margins, and improper alignment can adversely affect reproduction.

In the unlikely event that the author did not send a complete manuscript and there are missing pages, these will be noted. Also, if unauthorized copyright material had to be removed, a note will indicate the deletion.

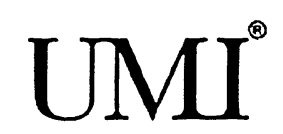

UMI Microform EC53564

Copyright 2009 by ProQuest LLC

All rights reserved. This microform edition is protected against unauthorized copying under Title 17, United States Code.

ProQuest LLC

789 East Eisenhower Parkway

P.O. Box 1346

Ann Arbor, MI 48106-1346 


\section{Author's Declaration}

I hereby declare that I am the sole author of this research project.

I authorize Ryerson University to lend this research project to other institutions or individuals for the purpose of scholarly research.

I further authorize Ryerson University to reproduce this research project by photocopying or by other means, in total or in parts, at the request of other institutions or individuals for the purpose of scholarly research. 


\section{Borrower's Page}

Ryerson University requires the signatures of all persons using or photocopying this research paper. Please sign below and give address and date.

1.

2.

3.

4.

5.

6.

7.

8.

9.

10.

11.

12.

13.

14.

15.

16.

17.

18.

19.

20. 


\title{
LANDFILL GAS EXTRACTION AND PURIFICATION TECHNIQUES
}

\author{
M. Eng., Civil Engineering, 2007 \\ Samuel Gebrehawariat \\ Civil Engineering Program \\ Ryerson University \\ Toronto, Ontario, Canada, 2007
}

\begin{abstract}
Landfill Gas (LFG) is mainly composed of methane and carbon dioxide and some other compounds like hydrogen sulphide, water vapor, etc. in trace level. The gas is, basically, generated as an end product of anaerobic decomposition of solid wastes containing organic matter. Studies indicate that LFG production ranges between 0.05 and $0.40 \mathrm{~m}^{3}$ of LFG per kilogram of solid waste (Ham, 1989). There are a number of different ways of collecting gas from landfills. The main part of the collection system includes vertical extraction wells and/or horizontal trenches; headers and piping system; and blower and compressor for creating pressure gradient so that the gas flow is induced. Purification of LFG is important whereby the gas is upgraded to biomethane with relatively higher energy value. There are a number of available techniques designed to upgrade LFG to biomethane by removing the impurities such as $\mathrm{CO}_{2}, \mathrm{H}_{2} \mathrm{~S}$, moisture, etc.
\end{abstract}

Generally, the paper discusses landfill gas generation, gas extraction and purifications techniques. Compositions of LFG and gas generation processes are discussed. Inline with this, different models for estimating the rate of LFG generation are analyzed. Landfill gas generation model of U.S. EPA along with other common quantifying models are explored. The study of LFG extraction and collection systems includes design considerations for LFG collection schemes, gas capture augmenting techniques, and the prediction of gas collection efficiency. An in depth assessment of purification processes of LFG along with upgrading of the LFG to biomethane of different grades is carried out. The discussion on gas purification methods is conducted in accordance with the type of LFG composition, level of treatment required, quality of LFG expected, and the final application of the LFG and biomethane. 


\section{Acknowledgement}

I would like to express my gratitude to my supervisor, Dr. Mostafa Warith, for his guidance and support throughout my study period and also during my research project. I would also like to thank Dr. Grace Luk and Dr. Michael Chapman of civil engineering program for being part of the examining committee members, reviewing my research project and forwarding valuable comments for the enhancement of my project.

I am grateful for all the support I received from Mary Neelands of School of Graduate Studies, civil engineering program. It has been a great pleasure to be in the civil engineering program and to have such wonderful professors and faculty members.

I am indebted to my wife, Salem, and my children, Sesiny and Senay, for their love, patience and support throughout the accomplishment of my studies. I am thankful to my parents for all the encouragement and love I received, and still receiving, throughout all these years. I owe my friends, Gebremichael Afewerki and his wife Freweini Habtai, dearly for being my family while I was away from my family. 


\section{TABLE OF CONTENT}

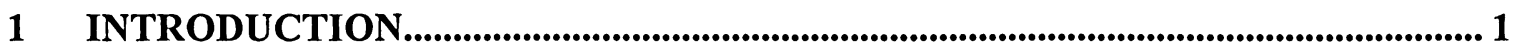

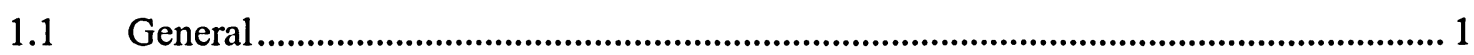

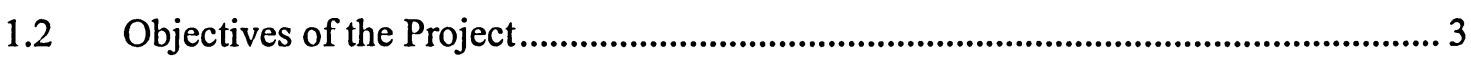

2 LANDFILL GAS GENERATION _....................................................................................... 5

$2.1 \quad$ Solid Waste and Their Disposal................................................................................... 5

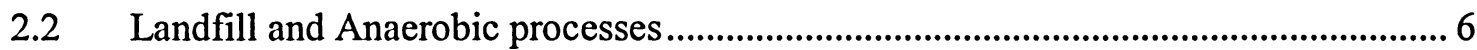

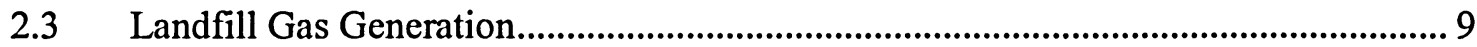

$2.4 \quad$ Factors Affecting LFG Generation ......................................................................... 12

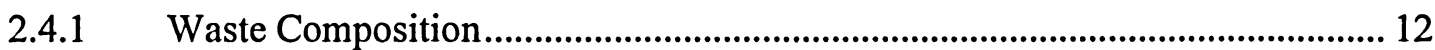

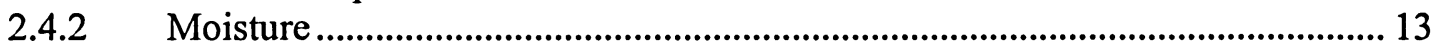

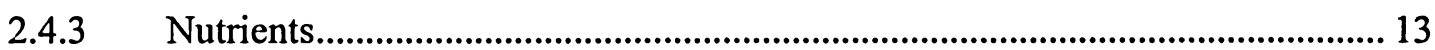

2.4.4 Temperature and $\mathrm{pH}$................................................................................... 14

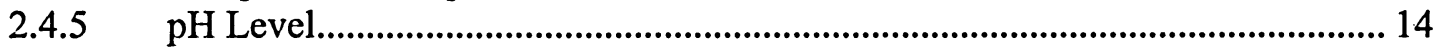

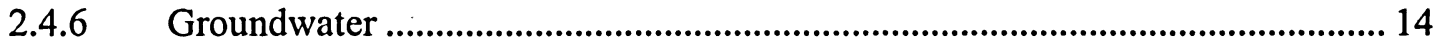

2.5 Composition of LFG ..................................................................................... 15

3 MODELING OF LFG EMISSION AND GENERATION …........................................... 16

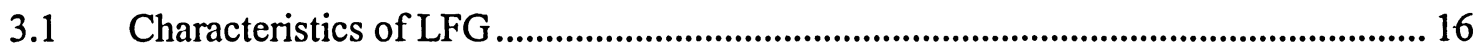

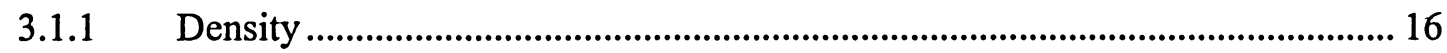

3.1.2 Viscosity ….............................................................................................. 17

3.1.3 Solubility ................................................................................................ 17

3.1.4 Moisture Content ........................................................................................... 18

3.1.5 Heat Value Content.......................................................................................... 18

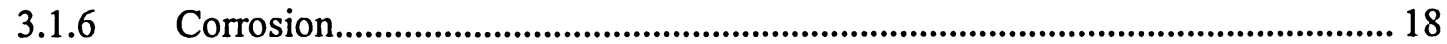

3.1.7 Important Chemical Characteristics of LFG....................................................... 19

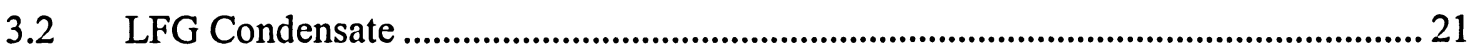

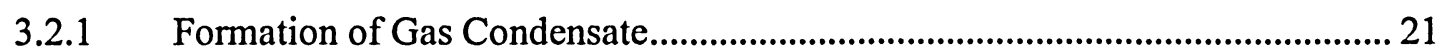

3.2.2 Features of the Condensate ............................................................................. 21

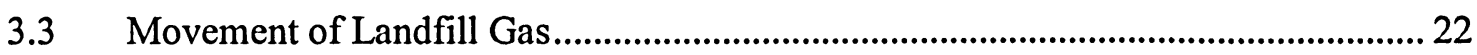

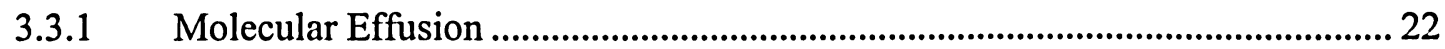

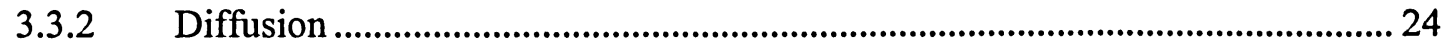

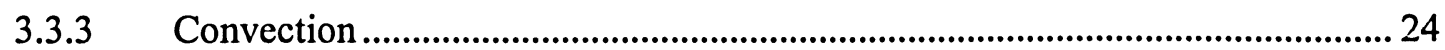

3.4 Factors Affecting LFG Transport Mechanism........................................................ 25

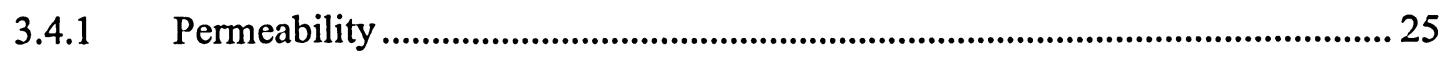

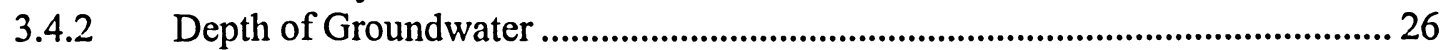

3.4.3 Waste Type and Condition.............................................................................. 27

3.4.4 Landfill Cap and Liner Systems ................................................................... 28

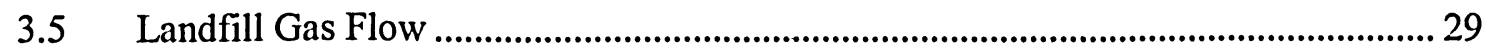




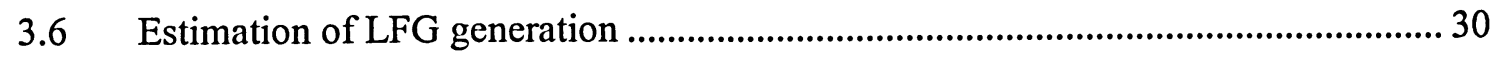

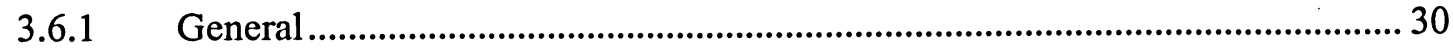

3.6.2 Scholl Canyon Model ....................................................................................... 32

3.6.3 LandGEM (EPA Landfill Gas Emission Model) .................................................. 36

3.6.4 LFGGEN (Landfill Gas Generation Model).......................................................... 39

3.7 LFG Collection Efficiency............................................................................................... 44

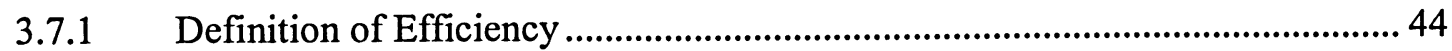

3.7.2 Mass Balance of Methane Pathways..................................................................... 46

3.7.3 Empirical Methane Generation Model................................................................. 52

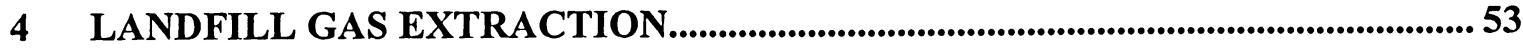

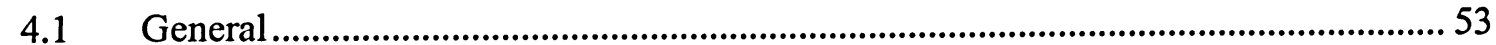

4.2 Assessment of Gas Production............................................................................... 53

4.2.1 Pre-Installation Assessment.............................................................................. 54

4.2.2 Modeling of LFG and Methane Production........................................................ 54

4.2.3 Pumping Test for LFG .................................................................................. 55

4.3 Atmospheric and Landfill Pressures ....................................................................... 56

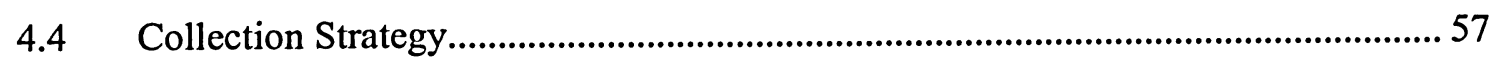

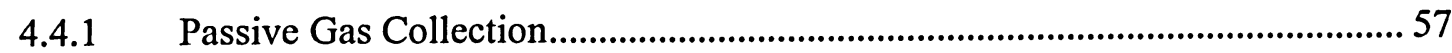

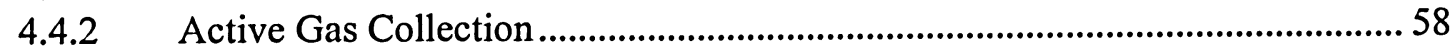

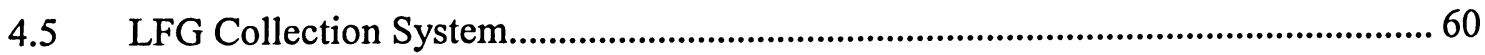

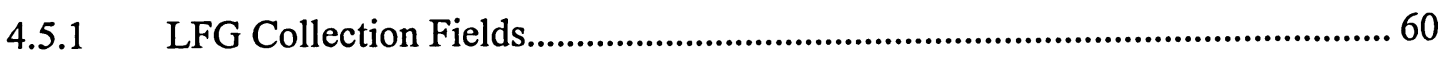

4.5.2 Collection Piping .............................................................................................. 62

4.5.3 Condensate Drop-Out and Disposal System......................................................... 64

4.5.4 Blower System and Related Appurtenances ............................................................6 66

4.5.5 LFG Utilization and Flaring Facility ............................................................... 67

4.6 Radius of Influence of Extraction Wells................................................................. 71

4.7 Design Considerations for LFG Extraction System.................................................... 74

4.7.1 Stage-1: Assessment and Investigation................................................................. 74

4.7.2 Stage-2: Design Stage .................................................................................... 76

4.7.3 LFG Collection Wells ...................................................................................... 76

4.7.4 Extraction Well Construction .......................................................................... 77

4.7.5 Spacing and Number of Wells ................................................................................ 77

4.7.6 Equipment for Gas Flow Transport .................................................................... 78

4.7.7 Condensate Control System................................................................................. 81

5 PURIFICATION OF LANDFILL GAS ........................................................................ 83

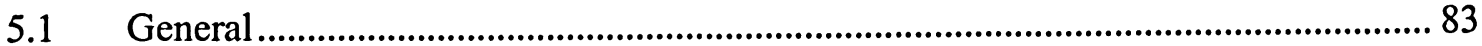

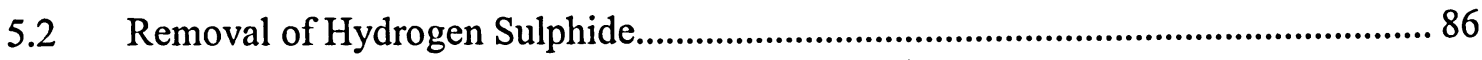

5.2.1 Air/Oxygen Injection ................................................................................... 86

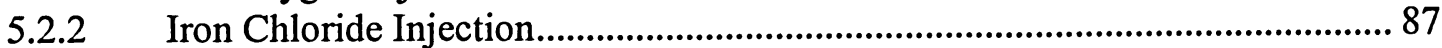

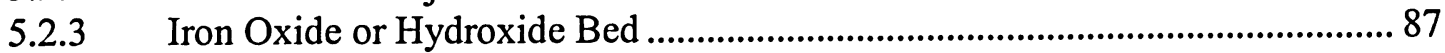

5.2.4 Activated Carbon Sieve ................................................................................. 88

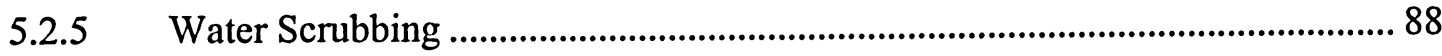


5.2.6 Biological Filter ................................................................................. 89

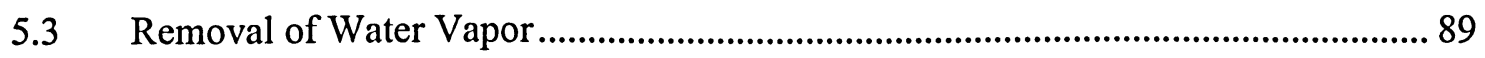

$5.4 \quad$ Particulate Removal ........................................................................................... 91

$5.5 \quad$ Removal of Carbon Dioxide ............................................................................. 91

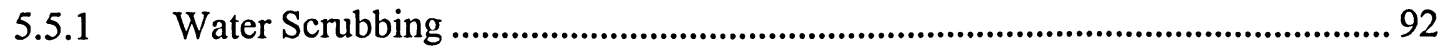

5.5.2 Pressure Swing Adsorption..................................................................... 93

5.5.3 Chemical Scrubbing with Polyethlylene Glycols ........................................... 94

5.5.4 Cryogenic Separation............................................................................... 94

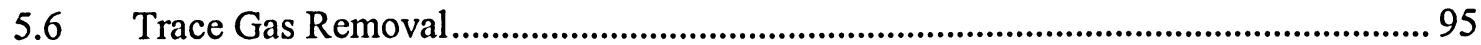

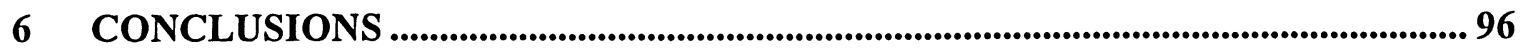

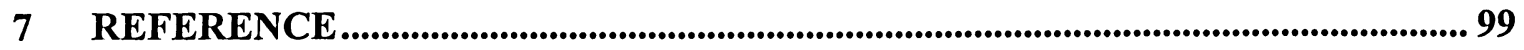




\section{List of Tables}

Table 2.1: Typical constituents and composition of LFG............................................................ 15

Table 3.1: Suggested k Value Ranges for Corresponding Annual Precipitation......................... 34

Table 3.2: Suggested Lo Values by organic waste content ............................................................ 35

Table 3.3: Values for methane generation rates $(k)$......................................................................... 38

Table 3.4: Values for the Potential Methane Generation Capacity $(L o)$...................................... 39

Table 4.1: Comparison of various gas collection systems .............................................................. 59

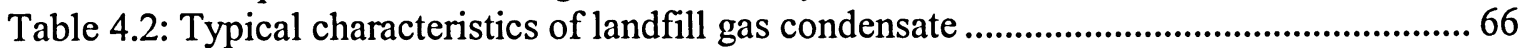

Table 4.3: LFG classification according to the level of treatment.................................................6 68

Table 4.4: LFG utilization based on its grade...............................................................................6 69

Table 4.5: Stack emissions after landfill gas combustion.............................................................. 70

Table 5.1: Purification steps and utilization of sewer and landfi1 gases ..................................... 85

\section{List of Figures}

Figure 2-1: Composition of U.S. municipal solid waste by-product and non-product categories, 2001 (Source: US EPA 2003) ...................................................................................................... 6

Figure 2-2: Multi-Step Methanogenesis in Anaerobic Digestion................................................... 8

Figure 2-3: LFG Production Phases............................................................................................... 11

Figure 3-1: Typical LFG Generation Curve (using Scholl Canyon Model)............................... 36

Figure 3-2: Typical Four-Stage Process of LFG production curve for LFGGEN ....................... 44

Figure 3-3: Schematics of methane pathways within landfill........................................................46

Figure 4-1: Typical horizontal gas collection trench (Profile-View)............................................ 60

Figure 4-2: Typical horizontal gas collection trench (Cross-Section) ............................................ 61

Figure 4-3: Typical vertical gas collection well .............................................................................. 61

Figure 4-4a: Ring Main LFG collection network .........................................................................6 63

Figure 4-4b: Multiple Header Main LFG collection network $\quad$..........................66

Figure 4-4c: Single Main with outfield Regulation collection network $\quad$..................66

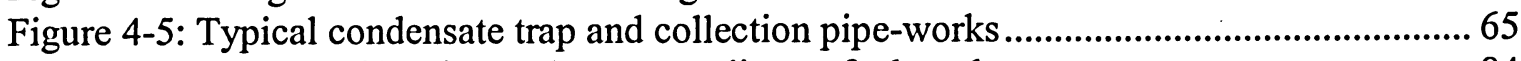

Figure 5-1: LFG classification and use according to fuel grade................................................. 84 
List of Abbreviations

$\begin{array}{ll}\text { CNG } & \text { Compressed Natural Gas } \\ \text { GAC } & \text { Granular Activated Carbon } \\ \text { GHG } & \text { Greenhouse gas } \\ \text { LFG } & \text { Landfill gas } \\ \text { LNG } & \text { Liquefied Natural Gas } \\ \text { MSW } & \text { Municipal Solid Waste } \\ \text { NMOC } & \text { Non-Methane Organic Compounds } \\ \text { U.S.EPA/EPA } & \text { United States Environmental Protection Agency } \\ \text { US.ACE } & \text { United States Army Corps of Engineers } \\ \text { VOC } & \text { Volatile Organic Compounds } \\ \text { WC } & \text { Water column (unit measure of pressure head in imperial } \\ & \text { method) }\end{array}$

\section{List of Unit Conversion Factors}

a. Length

\begin{tabular}{|l|c|c|c|}
\hline \multicolumn{1}{|c|}{ From/To } & M & $\mathbf{m m}$ & $\mathbf{k m}$ \\
\hline inch (in.) & 0.0254 & 25.4 & $2.54 \mathrm{E}-05$ \\
\hline foot (ft) & 0.3048 & 304.8 & $3.048 \mathrm{E}-04$ \\
\hline yard (yd) & 0.9144 & 914.4 & $9.144 \mathrm{E}-04$ \\
\hline mile (mi) & 1,609 & $1,609,000$ & 1.609 \\
\hline
\end{tabular}

b. Volume

\begin{tabular}{|l|c|c|}
\hline \multicolumn{1}{|c|}{ From/To } & $\mathrm{m}^{3}$ & 1 \\
\hline Cubic foot $\left(\mathrm{ft}^{3}\right)$ & 0.02832 & 28.32 \\
\hline gallon US & 0.003785 & 3.785 \\
\hline gallon Imp. (Imp gal) & 0.004546 & 4.546 \\
\hline acre-foot (ac-ft) & 1,233 & $1,233,000$ \\
\hline
\end{tabular}

c. Flow

\begin{tabular}{|l|c|c|c|}
\hline \multicolumn{1}{|c|}{ From/To } & $\mathrm{M}^{\mathbf{3} / \mathrm{s}}$ & $\mathrm{1} / \mathrm{s}$ & $\mathrm{m}^{\mathbf{3}} / \mathrm{hr}$ \\
\hline Cubic foot/second (cfs) & 0.02831 & 28.31 & 40.77 \\
\hline million gallon/day (MGD) & 0.04381 & 43.81 & 63.09 \\
\hline Gallon (US)/minute (gpm) & 0.00006309 & 0.06309 & 0.09086 \\
\hline acre-foot per day (ac-ft/day) & 0.01427 & 14.27 & 20.55 \\
\hline
\end{tabular}


d. Pressure

\begin{tabular}{|l|c|c|c|c|c|}
\hline \multicolumn{1}{|c|}{ From/To } & Pa & $\mathbf{k P a}$ & $\mathbf{a t m}$ & $\mathbf{m m ~ H 2 0}$ & $\mathbf{k g} / \mathbf{c m}^{2}$ \\
\hline bar & $1.00 \mathrm{E}+05$ & 100 & 0.9869 & 10,200 & 1.0204 \\
\hline \begin{tabular}{l|c|c|c|c} 
pounds per square \\
foot (psf)
\end{tabular} & 47.88 & 0.04788 & $4.725 \mathrm{E}-04$ & 4.884 & $4.886 \mathrm{E}-04$ \\
\hline pounds per square inch (psi) & 6894 & 6.894 & 0.06805 & 703.3 & 0.07035 \\
\hline feet water (ft H2O) & 2,986 & 2.986 & 0.02948 & 304.6 & 0.03047 \\
\hline millimeters mercury (mm Hg) & 133.3 & 0.1333 & 0.001316 & 13.60 & 0.001360 \\
\hline
\end{tabular}

e. Power

\begin{tabular}{|l|c|c|c|}
\hline \multicolumn{1}{|c|}{ From/To } & $\begin{array}{c}\text { Watt } \\
\text { (W) }\end{array}$ & $\begin{array}{c}\text { Kilowatt } \\
\text { (kW) }\end{array}$ & $\begin{array}{c}\text { Horsepower } \\
\text { (hp) }\end{array}$ \\
\hline foot pound f/sec (ft-lbf/s) & 1.355 & 0.001355 & 0.001816 \\
\hline BTU/hour (BTU/hr) & 0.2929 & 0.0002929 & 0.0003926 \\
\hline
\end{tabular}

\section{f. Viscosity}

\begin{tabular}{|c|c|c|}
\hline From/To & $\begin{array}{c}\text { Pascal-Second } \\
\text { (Pa-s) }\end{array}$ & $\begin{array}{c}\text { Centipoise } \\
\text { (cP) }\end{array}$ \\
\hline pound f-second/sq. $\mathrm{ft}\left(\mathrm{lbf}-\mathrm{s} / \mathrm{ft}^{2}\right)$ & 47.88 & 47,880 \\
\hline
\end{tabular}

g. Kinematic Viscosity

\begin{tabular}{|c|c|c|}
\hline From/To & $\begin{array}{c}\text { Square meter/second } \\
\left(\mathrm{m}^{2} / \mathrm{s}\right)\end{array}$ & $\begin{array}{c}\text { Centistoke } \\
(\mathrm{cS})\end{array}$ \\
\hline square feet/second $\left(\mathrm{ft}^{2} / \mathrm{s}\right)$ & 0.09290 & $9.290 \mathrm{E}+04$ \\
\hline
\end{tabular}

h. Velocity

\begin{tabular}{|l|c|c|}
\hline \multicolumn{1}{|c|}{ From/To } & $\begin{array}{c}\text { Meter/second } \\
(\mathbf{m} / \mathbf{s})\end{array}$ & $\begin{array}{c}\text { Kilometer/hour } \\
(\mathbf{k m} / \mathbf{h r})\end{array}$ \\
\hline feet/second (fps) & 0.3048 & 1.097 \\
\hline miles/hour (mph) & 0.4470 & 1.609 \\
\hline
\end{tabular}




\section{INTRODUCTION}

\subsection{GENERAL}

Landfill Gas (LFG) mainly contains methane and carbon dioxide and some other compounds like hydrogen sulphide, water vapor, etc. in trace level. They are basically generated as end products of physiochemical and biochemical process of solid wastes, containing organic matter. The process basically takes place within organic wastes placed inside landfills in which anaerobic decomposition occurs in the absence of oxygen. The main and essential actors in the generation of LFG are anaerobic microorganisms, principally bacteria; by the mechanism of biodegradation of the organic wastes they release methane, carbon dioxide, etc. from the wastes. Short-term studies done on full-size landfills, using data from LFG extraction tests, indicate a range of LFG production between 0.05 and $0.40 \mathrm{~m}^{3}$ of LFG per kilogram of waste placed into a landfill (Ham (1989).

When landfill gas is escapes uncontrollably from the generation area (landfill) or from its storage; it can pose a potential for hazard. It is destructively explosive in air at concentrations between 5 and 15\%. Several cases of landfill methane gas explosions have been reported (Stone, 1978). Uncontrolled discharge of LFG to the atmosphere gives way to environmentally potent compounds including volatile organic compounds (VOC), nitrogen oxides (NOs), methane, carbon dioxide, odorous compounds like hydrogen sulphide, etc. However, proper extraction and utilization of LFG using technologies of landfill gas-to-energy brings benefits in the form of energy, environmental protection, \& economic returns, air quality improvements, odor reductions, and creating jobs within the locality. 
Basically, LFG-to-energy technologies include landfill gas generation, extraction facility, collection systems, and purification and gas utilization systems. Although waste management practices including waste reduction, reuse, recycling, etc. help in reducing the amount of organic wastes placed in landfills; using landfills for disposing organic wastes from municipal, agricultural, and industrial sources will continue for the foreseeable future, ultimately generating landfill gas. The generation of LFG on top of other factors depends to certain degree on design and construction of the landfills, whether the system is operated in aerobic or anaerobic processes.

In a typical anaerobic operated landfill, the organic wastes decomposes to yield a landfill gas, which is a mixture of methane and carbon dioxide and also some other components with trace level. Methane is the essential component of LFG, which is one of the essential renewable energy sources. The landfill gas control system enables the collection and treatment of landfill gas, while preventing uncontrolled migration of LFG to the atmosphere and surrounding areas. Such an objective can be achieved using proper LFG extraction technologies comprised of collection wells, piping systems and appurtenances established at the landfill site.

Generally, a properly planned and constructed landfill incorporates landfill gas control and recovery system. Bored wells and horizontal trenches assist in the extraction and recovery of LFG within the active gas generation zone of the landfill. The LFG withdrawn from the extraction wells is collected at a central point by means of an underground network of pipes called the gas collection header. The central point of collection system includes a compressing unit that provides suction and also compression of the LFG prior to use or purification or storage. 
LFG has carbon dioxide and water vapor with variable concentrations and also a number of other trace gases like hydrogen sulphide that necessitate removal, where a high grade fuel is anticipated. The presence of moisture content in the LFG affects the collection of LFG through the piping network system by blocking the flow of gas to the extraction wells. Carbon dioxide in reaction with water vapor creates carbonate and bicarbonates, which have acidic characteristics. Besides, water vapor reacts with hydrogen sulphide yielding sulfuric acid, which is corrosive. Apart from creating carbonate and bicarbonates, carbon dioxide which is inert gas, reduces the energy value of LFG, while simply occupying space within LFG. As a consequence, LFG collected from the landfill may require purification and scrubbing process out of those impurities.

\subsection{OBJECTIVES OF THE PROJECT}

The main objective of this project paper is to study landfill gas extraction and purifications technologies. Different techniques and approaches of extraction and purification of LFG will be assessed. In line with this, composition of the gas and LFG generation processes are discussed. The section where LFG generation is discussed covers gas generation processes and mathematical models used for quantifying LFG generated during the life time of landfill and also at any relevant time in the life of landfill. The United States Environmental Protection Agency (EPA) landfill gas generation modeling technique along with other common methods of estimating LFG emission will be explored.

The discussion on LFG extraction method will include design considerations for LFG collection schemes, gas capture augmenting techniques, models for quantity of gas that could be captured, and also gas capture efficiency will be investigated. 
There are different methods available for purifying and treating landfill gas in the market. They vary mainly depending on the type of LFG composition, level of treatment required, quality of end-product required, and use of the final application of LFG. Therefore, this project paper covers LFG purification systems according to the required quality and application of the LFG or methane.

Moreover, the paper undertakes a brief assessment on design and construction of landfills in conjunction with anaerobic decomposition processes of solid wastes containing organic matter. 


\section{LANDFILL GAS GENERATION}

\subsection{SOLID WASTE AND THEIR DISPOSAL}

Documents show that historically solid waste was taken for granted and as its name implies it was just a waste. However, nowadays it has become a subject of enormous concerns. The main disposal methods of solid wastes include landfills, material recovery facilities, incineration systems, etc. Pfeffer (1992) in his book "Solid Waste Management Engineering" defines solid waste as any solid material in the material flow pattern that is rejected by society. Its sources include rejected solid materials originating from domestic and residential areas, commercial and institutional, construction demolition, street refuse, dead animals, industrial solid wastes, agricultural residues, etc. Industrial solid waste has distinctive characteristics, which are typical to a specific industry and as a result they are not usually considered as part of municipal waste stream. They are handled separately and treated usually within the premises of the industry outside the control of municipal waste.

According to "Statistics Canada, 2005", household garbage accounts for $40 \%$ of the solid waste generated in Canada. The annual solid waste generated in Canada per person amounts to $383 \mathrm{~kg}$ in year 2002. Households continue to generate more solid waste, and the majority of it ends up in landfill sites.

The United States Environmental Protection Agency (USEPA) categorizes solid waste as products, food scraps, and miscellaneous inorganic wastes. Yard trimmings are grouped as non-product municipal solid waste (MSW), according to the EPA classification.

Based on EPA classifications, typical MSW classified as product and non-product wastes in 2001 in the United States of America are given in Figure 2.1. 


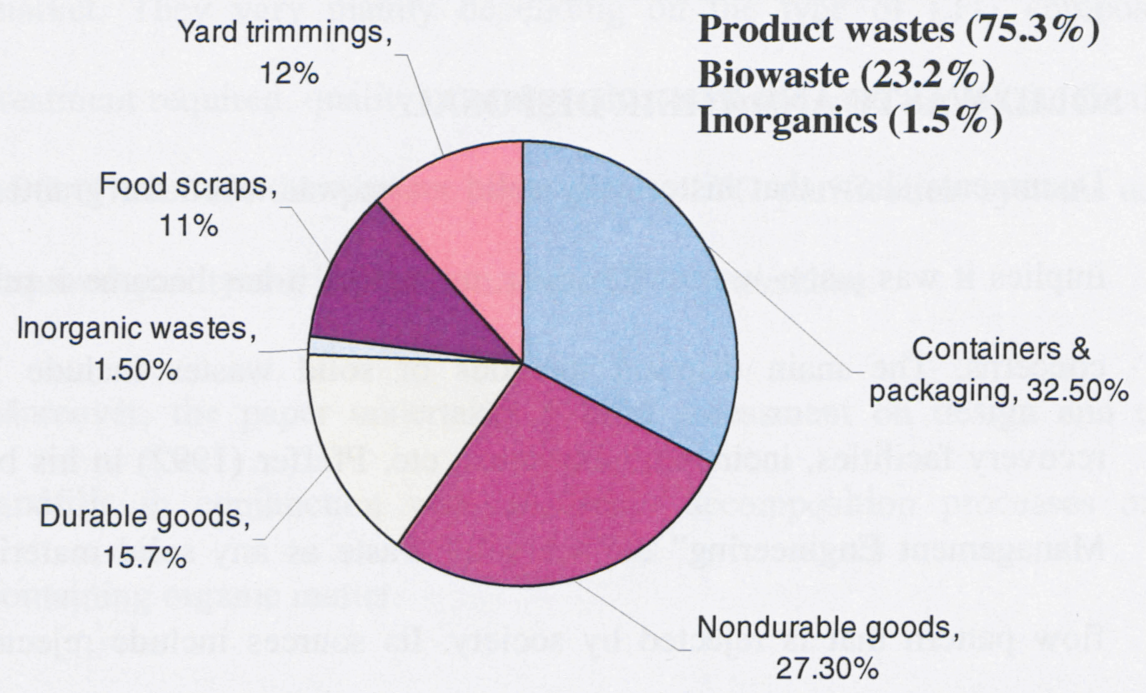

Figure 2-1: Composition of U.S. municipal solid waste by-product and non-product categories, 2001 (Source: US EPA 2003)

Although, tremendous efforts and investments are directed in waste reduction, recycling, and reuse, a substantial amount of solid wastes still find their way into landfills and incinerators. In 2002, (Statistics Canada, 2005) the residential component of Canada's waste was estimated at just over 12 million tones, a $6.8 \%$ increase from 2000. An estimated 2.5 million tones, or about one-fifth of the residential total, were recycled or otherwise diverted, a 17\% increase from 2000. The remainder, about 9.5 million tones, was disposed of in landfills or incinerated. Hence, still considerable quantities of solid wastes are dumped in landfills, with some burned in incinerators.

\subsection{LANDFILL AND ANAEROBIC PROCESSES}

Landfill provides an atmosphere for a good solid waste management system for a municipal waste stream. A landfill, which is designed, constructed and operated in a right way, offers an environmentally sound disposal system of solid wastes that cannot 
be reduced, recycled, composted, combusted, or processed in some other fashion. Besides, landfills are used for disposing left over from recycling, composting, combustion or other facilities used for processing wastes.

According to US EPA 2003 solid waste takes about 30 years or more of process time to get decomposed in landfills. During the initial stage of placement of solid wastes in landfill, the air held within the waste material gives way to an aerobic environment. Aerobic microorganisms quickly consume the oxygen, producing carbon dioxide, water, residual organics, and heat (Ham, et al., 1979). When the oxygen starts getting depleted as a result of the consumption by the aerobic microbes, the landfill is transformed into a second phase, which is anaerobic processes, facilitated by anaerobic bacteria that are acid-forming. The anaerobic bacteria hydrolyze and ferment the complex organics mainly carbohydrates, lipids and proteins and as a result they form fatty acids, alcohols, carbon dioxide, ammonia, and hydrogen. The microorganisms involved are anaerobic and facultative anaerobic fermenting bacteria such as Bacillus, Clostridium, and Enterobacteria (Parametrix, Inc., 1987)

During the process of acid formation, carbon dioxide production peaks, while hydrogen production begins (Schumacher, 1983). Peaks of as much as $90 \%$ carbon dioxide by volume have been reported to occur 11 to 40 days after solid waste placement (Boyle, 1977). The characteristic phases of anaerobic decomposition of landfill refuse are illustrated in Figure 2-2.

When the refuse is totally depleted of oxygen, a third phase begins in which methaneforming bacteria become dominant. Methanogenic bacteria are obligate anaerobes, meaning that any oxygen will destroy their activity. Actually, two complex microbiological processes take place during methane generation: 
1. Organic acids and alcohols are converted into acetate, hydrogen, and carbon dioxide.

2. Methanogenic bacteria produce methane from the products of process are of the following types:

a. methanogens that reduce carbon dioxide to methane (hydrogen as the reducing agent), and

b. methanogens that decarboxylate acetate to methane and carbon dioxide.

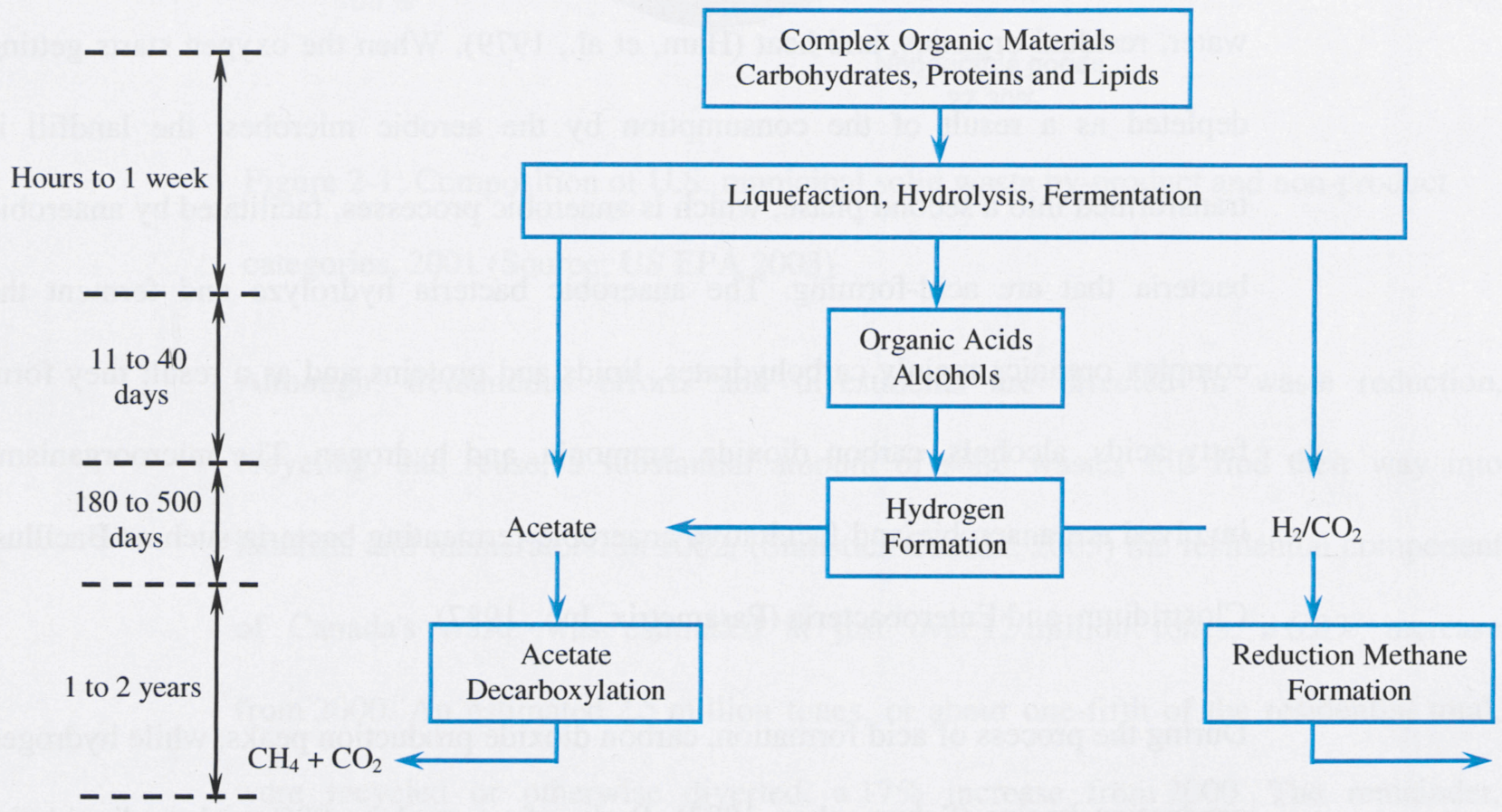

Figure 2-2: Multi-Step Methanogenesis in Anaerobic Digestion

(Source: Zehnder, 1978, mentioned in Parametrix, Inc., 1987, Solid Waste landfill design Manual; and Boyle, 1977)

The fraction by volume of methane increases, with a concurrent decrease in carbon dioxide and hydrogen. This third phase has been observed to occur between 180 and 500 days after solid waste placement (Boyle, 1977).

The fourth phase of landfill gas generation occurs one to two years after refuse placement. In this final phase, gas production and composition approach steady-state 
conditions, with methane ranging from $50 \%$ to $70 \%$ and carbon dioxide from $30 \%$ to $50 \%$.

\subsection{LANDFILL GAS GENERATION}

It is common knowledge that it is the organic portion of the solid waste that gives way to generation of LFG. LFG generation process and rate are governed by the microbial processes (Christensen, 1989). These processes in turn are dependent on the prevalent environmental conditions, including human interactions and influences.

LFG generation capacity of a landfill is determined primarily by the nature and composition of waste contained within. This is due to the very reason that LFG is generated as a result of decomposing organic wastes. However, there are a number of other factors, which also control the rate by which LFG is produced. Such parameters include;

- moisture and nutrient contents;

- bacterial composition and content;

- $\mathrm{pH}$ level and temperature; and

- site-specific design and operations

As McBean et al., 1995 put it; moisture plays a primary limiting role in the rate of waste decomposition. The moisture conditions within the landfill are dependent on many conditions and factors. Nutrients like nitrogen and phosphorus are essential to the growth of microorganisms that are necessary for fermentation reactions of the waste. $\mathrm{pH}$ level and temperature affect the microbial growth and activity. Design and construction of landfills and how they are operated; including cover material and filling 
methodology govern the way moisture moves within the landfill and through the waste matter (Reinhart, 1996). Along with the other factors moisture content dictates the microorganisms, which generate LFG. As a result, it influences the total LFG produced and also the rate at which it is produced. Hence, controlling the movement of moisture, affects microbial activity and ultimately LFG production. The current trend in landfill designs and construction is towards Landfill Bioreactor Technology (LBT) systems, which augment the amount of water contacting the waste, to rapidly stabilize the wastes (Reinhart, 1996). With the help of this approach, initially large quantity of LFG can be generated, with an abrupt decline in generation rate after few years of the landfill life. The potential LFG generation rate of a landfill is determined, in a basic analysis, by the size and age of the waste volume, type of the waste, and moisture content within the landfill.

Farquhar and Rovers (1995) predicted generation of gas in a landfill for typical municipal solid waste (MSW) in the 1970s. It has been observed that throughout the lifetime of a landfill, there exist four distinct phases of LFG production. Figure 2-3 shows LFG production corresponding to the prevailing phases.

The time extent and coverage of the phases is generally based on a number of parameters, such as waste type and composition, moisture, nutrient availability for bacterial growth, bacterial population, $\mathrm{pH}$ level, etc. The generation of methane, the essential constituent of LFG, commences just at the end of second phase when the available oxygen in the landfill is depleted. Its production shows exponential growth during the third phase, showing a peak growth in this stage. Basically, methane production growth through this phase is facilitated due to the absence of oxygen, in which case anaerobic process is prevalent. On phase four, the generation rate is steady; 
yielding constant production. Phase four lasts 8 to 40 years depending on many factors as discussed previously.

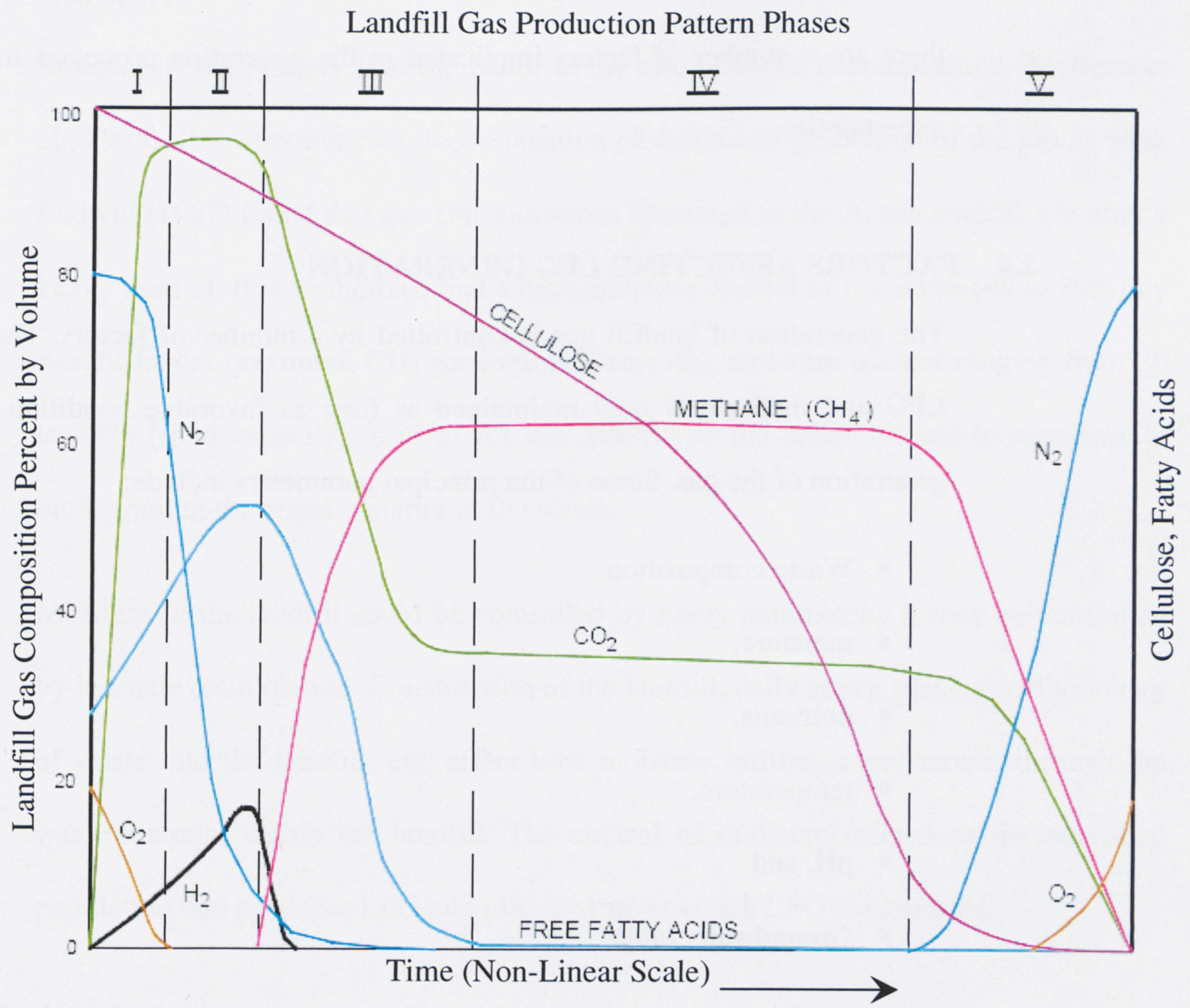

\begin{tabular}{|c|c|c|}
\hline Phase & Condition & Time Frame - Typical \\
\hline I & Aerobic & Hours to 1 Week \\
\hline II & Anoxic & 1 to 6 Months \\
\hline III & Anaerobic, Methanogenic, Unsteady & 3 Months to 3 Years \\
\hline IV & Anaerobic, Methanogenic, Steady & 3 to 40 Years \\
\hline V & Anaerobic, Methanogenic, Declining & 1 to 40 ${ }^{+}$Years \\
\hline Total & & $\mathbf{1 0}^{+}$to $\mathbf{8 0}^{+}$Years \\
\hline
\end{tabular}

Figure 2-3: LFG Production Phases

Source: Farquhar and Rover, 1973; as modified by Augenstein and Pacey, 1991.

The organic content of the waste steam, which is placed into the landfill, influences to a large extent the production range of LFG. Short-term studies done on full-size landfills, 
using data from LFG extraction tests, indicate a range of LFG production between 0.05

and $0.40 \mathrm{~m}^{3}$ of LFG per kilogram of waste placed into a landfill (Ham, 1989). The exact determination of LFG generated from a landfill is difficult; due to the fact that there are a number of factors implicated in the generation processes involving many uncertainties.

\subsection{FACTORS AFFECTING LFG GENERATION}

The generation of landfill gas is controlled by a number of factors. The formation of LFG and methane is only maintained as long as favorable condition exists for the generation of the gas. Some of the principal parameters include:

- Waste composition

- moisture,

- nutrients,

- temperature,

- $\mathrm{pH}$, and

- Groundwater table

\subsubsection{Waste Composition}

According to Environment Canada (1996), the maximum potential volume of LFG is dependent on the quantity and type of organic content within the landfill mass. Waste composition is the most important factor in assessing the LFG generation potential of a site. The overall proportion of organic content within the waste stream affects the amount of landfill gas generated. Besides, the type of organic matter and its readily biodegradability also plays a major role in the production of the gas. It is certain that there exist many materials which are toxic or inhibitory to gas producing microorganisms and that these could find their way into sanitary landfills (Farquhar et 
al., 1973). Gas production could be affected because of the toxic substances present within the waste material.

\subsubsection{Moisture}

Moisture is the primary limiting factor in the rate of waste decomposition (McBean et al., 1995). It is important for decomposition of waste and generation of the gas as well. Ludwig (1967) found that gas concentrations increased in the Azusa landfill site after a heavy rainfall. It is recognized that a high moisture content of the waste (60 to $80 \%$ ) by weight favors maximum $\mathrm{CH}_{4}$ generation. Generally, moisture content ranging from 30 to $45 \%$ (field capacity) is ideal for the activity of the anaerobic microorganisms in biodegrading the organic matter in the waste.

Moisture in the landfill could be controlled by many parameters. It may be controlled by leachate recirculation. Construction of the landfill, daily cover, placing methodology of waste into the landfill, etc. affect how moisture infiltrates and moves through the waste material within the landfill. The control of moisture influences the microbial population that produces LFG and also the rate at which LFG is generated.

\subsubsection{Nutrients}

The type and quantity of nutrients in the landfill influences the volume of gas generated from microbial processes and the composition of the generated gases. Microorganisms, whether aerobic, anaerobic or facultative, in landfill require certain nutrients for growth. Such nutrients include carbon, hydrogen, oxygen, nitrogen, and phosphorous. Besides, they need some other elements in small amounts including sodium, potassium, sulfur, calcium and magnesium. Ramaswamy (1972) found that gas production rates could be changed by varying the amounts of $\mathrm{N}_{2}, \mathrm{P}$, and $\mathrm{K}$ in the refuse. Macronutrients, 
specifically the available C:N:P (Carbon : Nitrogen : Phosphorus) ratio in the waste, available for bacterial activity, should be in the magnitude of 100-200:10:1.

\subsubsection{Temperature and $\mathrm{pH}$}

The predominance of the type of bacteria within a landfill is influenced by temperature in the landfill, which in turn affects the overall rate of LFG generation. Temperature within the landfill differs horizontally and also vertically along the depth of the landfill. It is primarily affected by the prevailing climatic conditions, compaction and density of waste, depth variations, microbial biochemistry, waste chemistry, moisture content of the waste, etc. Generally, $\mathrm{CH}_{4}$ generation is enhanced in landfills with warm temperatures. A drop in microbial activity and gas production is observed at temperatures of $10^{\circ} \mathrm{C}$ and below. A temperature ranging between 30 to $41^{\circ} \mathrm{C}$ is the optimum range for anaerobic bacteria (Kotze et al., 1969). It is reported that the typical temperature inside landfills during aerobic decomposition ranges between 29 and $60^{\circ} \mathrm{C}$.

\subsection{5 pH Level}

Solid wastes in landfill have a widely varying $\mathrm{pH}$; though municipal solid wastes usually have a $\mathrm{pH}$ in the range of 5 to 9 . Mainly, biological processes within the landfill control the $\mathrm{pH}$ of the waste in the landfill. Usually, a $\mathrm{pH}$ of 6.5 to 8.0 is observed in the landfill during methane formation. Optimum $\mathrm{pH}$ value favorable for biological activity, good biodegradation and satisfactory LFG generation is in the range of 6 to 8. (Skinner, 1968).

\subsubsection{Groundwater}

The depth of water table and its seasonal variation affect the anaerobic microbial activity within the landfill and which in turn affects LFG generation rate of from the waste. It is a customary to design and construct landfills with bottom liners so as to 
prevent the intrusion of groundwater into landfills and protect its contact with the waste matter and leachate. If the groundwater comes into contact with the waste, air from the water will enter the waste and aerobic degradation can ensue, preventing the formation of LFG. Besides, in the presence of water in the waste gas movement will be hampered within the saturated zone.

\subsection{COMPOSITION OF LFG}

The microbial population, moisture content of the waste and biodegradation of solid wastes influence the composition and constituents of the landfill gas. The main and essential constituent of LFG is methane. Methane is usually generated in a ratio of 50:50 with carbon dioxide. Apart from methane and carbon dioxide, other chemical constituents of LFG are also generated, as shown on Table 2.1 below.

Table 2.1: Typical constituents and composition of LFG

\begin{tabular}{|c|c|c|}
\hline \multirow[t]{2}{*}{ Constituents } & \multicolumn{2}{|c|}{ Concentration in LFG } \\
\hline & Range & Average \\
\hline Methane & 35 to 60 percent & 47.4 \\
\hline Carbon dioxide & 35 to 55 percent & 47.0 \\
\hline Nitrogen & 0 to 20 percent & 3.7 \\
\hline Oxygen & 0 to 2.5 percent & 0.8 \\
\hline Water vapor & 1 to 10 percent & NA \\
\hline Paraffin hydrocarbons & NA & 0.1 \\
\hline Aromatic-cyclic hydrocarbons & NA & 0.2 \\
\hline Hydrogen & NA & 0.1 \\
\hline Hydrogen sulphide & 1 to $1,700 \mathrm{ppmv}$ & 0.01 \\
\hline Carbon monoxide & NA & 0.1 \\
\hline Trace compounds & NA & 0.5 \\
\hline
\end{tabular}

$\mathrm{NA}=$ not available. ppmv $=$ parts per million by volume.

(Source: Ham et. al, 1979; and Doorn et al., 1995)

The oxygen and nitrogen levels shown in the table below are not products of decomposition; but rather the result of intrusion of air to the landfill and LFG through many mechanisms (Ham et. al, 1979). 


\section{MODELING OF LFG EMISSION AND GENERATION}

\subsection{CHARACTERISTICS OF LFG}

Landfill gas is generated as soon as MSW is placed in the landfill. However, methane does not occur simultaneously with the production of LFG. The production of methane as part of the LFG requires lag time. Landfill gas composition is a result of a complex biological process involving the breakdown (decomposition) of organic materials.

\subsubsection{Density}

The density of LFG is variable and it is dependent on the proportion of gas components contained within, and also on the stage of anaerobic decomposition. Landfill gas is a mixture and usually its components do not split into layers. It is generally accepted that the greater the waste density, the higher the theoretical yield of LFG per unit volume of void space available.

A mixture of $10 \%$ hydrogen (density $0.08 \mathrm{~kg} / \mathrm{m}^{3}$ ) and $90 \%$ carbon dioxide (1.98 $\mathrm{kg} / \mathrm{m}^{3}$ ), as typically produced during the early stages of degradation will be denser than air $\left(1.29 \mathrm{~kg} / \mathrm{m}^{3}\right)$. A mixture of $60 \%$ methane $\left(0.72 \mathrm{~kg} / \mathrm{m}^{3}\right)$ and $40 \%$ carbon dioxide, as is typical of a mature anaerobic landfill gas, will be slightly lighter than air (Environmental Agency, UK, 2002).

The most common densities of LFG are as follows:

- Methane $\left(\mathrm{CH}_{4}\right) \quad=0.72 \mathrm{~kg} / \mathrm{m}^{3}$

- $\mathrm{LFG}\left(\right.$ Composite gas $\left.{ }^{\mathrm{i}}\right)=1.07 \mathrm{~kg} / \mathrm{m}^{3}$

\footnotetext{
${ }^{\mathrm{i}}$ Composite gas is another name for LFG with all its constituent gases.
} 


\subsubsection{Viscosity}

The resistance of a fluid to a flow as a result of its internal friction is called viscosity of the fluid. The resistance to flow is expressed as a coefficient of dynamic (or absolute) viscosity and it implies to the force required to move a unit area a unit distance.

The approximate dynamic viscosity of $\mathrm{CH}_{4}$ and composite gas at $0^{\circ} \mathrm{C}$ and 1 atmosphere of pressure is given as follows:

$$
\begin{array}{ll}
\text { - } \mu \text { of } \mathrm{CH}_{4} & =1.04 \times 10^{-5} \mathrm{~N} \cdot \mathrm{sec} \cdot \mathrm{m}^{-2} \\
\text { - } \mu \text { of Composite gas: } & =1.15 \times 10^{-5} \mathrm{~N} \cdot \mathrm{sec} \cdot \mathrm{m}^{-2}
\end{array}
$$

\subsubsection{Solubility}

A large number of the components of LFG can dissolve in aqueous media, which include landfill leachate and condensate. The extent to which a compound enters into solution, under equilibrium conditions, is affected by many factors including temperature, prevailing pressures and chemical interactions between the compound and the aqueous media. When the liquid containing the dissolved gasses is subjected to changes in temperature, pressure or mechanical agitation, could result in degassing.

Methane is slightly soluble in water, $35 \mathrm{ml}$ methane/l water at $17^{\circ} \mathrm{C}$ (about $4 \mathrm{mg} / \mathrm{l}$ ) (Budvaris, 1989). Carbon dioxide is more soluble in water $\left(1.45 \mathrm{~kg} / \mathrm{m}^{3}\right.$ of water), forming bicarbonate and carbonate ions. This disparity in solubility is partially responsible for observed variations in bulk gas composition. The aqueous media found in the landfill including leachate and condensate act as vehicles for transportation of dissolved methane. It is prudent to consider risk assessment of methane migration and emission with the help of leachate and condensate. Accumulation of methane in 
confined areas should be monitored in situations where there is the possibility of methane migration by leachate and condensates.

\subsubsection{Moisture Content}

Temperature and pressure influence the amount of moisture that can be contained in the gas and the condition could be saturated or undersaturated. Food and garden as part of the organic solid waste provide the highest moisture input in the landfill. As a consequence, the average municipal solid waste has a moisture content of about $25 \%$. Additional moisture to the landfill contents could originate from rainfall, surface and groundwater infiltration.

\subsubsection{Heat Value Content}

The calorific value of methane is $35.9 \mathrm{MJ} / \mathrm{m}^{3}$ (1000 BTU/scf), while the concentrated mixture of the composite gas, LFG, has is a fuel value of $18-22 \mathrm{MJ} \mathrm{m}^{-3}(\sim 500 \mathrm{BTU} / \mathrm{cft})$ (Spokas et al., 2005). The LFG calorific value is about half that of natural gas. Methane is highly flammable that forms explosive mixtures with air when present between the concentration limits of 5 to $15 \% \mathrm{v} / \mathrm{v}$, at $20^{\circ} \mathrm{C}$ and 1 atmosphere pressure. For methane to ignite, the minimum oxygen content required in the air is approximately $14 \%$ (by volume).

\subsubsection{Corrosion}

Landfill gas has a number of constituents, with some of them being potentially corrosive. It is wise to consider this corrosive nature of the components in the LFG during planning and designing of gas collection and treatment systems. Corrosion hastens the wear on plant facilities and equipment, reducing the effective life of gas collection and/or control facilities. 
When dissolved in water, carbon dioxide forms carbonic acid, which can corrode a range of metals. On top of this, condensate will be acidic, with a $\mathrm{pH}$ in the range 3 to 6.5 as a result of the dissolved carbon dioxide and acidic trace compounds. Such aqueous solution can corrode a range of metals. Moreover, water vapor and hydrogen sulphide can react to form an acid, $\mathrm{H}_{2} \mathrm{SO}_{4}$, which is corrosive as well.

\subsubsection{Important Chemical Characteristics of LFG}

There are a number of factors influencing the composition of LFG, among which waste type and the stage of decomposition play a vital role. The amount of LFG produced is generally a function of the type, extent and rate of decomposition. The major components of $\mathrm{LFG}$ are $\mathrm{CH}_{4}, \mathrm{CO}_{2}, \mathrm{NMOC}$ and water vapor.

\section{A. Methane $\left(\mathrm{CH}_{4}\right)$}

$\mathrm{CH}_{4}$ (methane) makes the major constituent of LFG. It is lighter than air, colorless and odorless. Mainly, the flammable characteristic of LFG is attributed to the presence of $\mathrm{CH}_{4}$. It can be asphyxiant if present in high concentrations without $\mathrm{O}_{2} \cdot \mathrm{CH}_{4}$ is explosive at about 5 to $15 \%$ by volume in air.

\section{B. Carbon Dioxide}

Another major constituent of $\mathrm{LFG}$ is $\mathrm{CO}_{2}$ (carbon dioxide). $\mathrm{CO}_{2}$ is heavier than air, colorless, and odorless. $\mathrm{CO}_{2}$ can be a simple asphyxiant and health hazard if present in high concentrations.

\section{Water Vapor}

Gas created during the decomposition of organic compounds typically includes between 4 and 7 percent by volume of water vapor. Temperatures are typically elevated over ambient during biological decomposition and increase the evaporation of water 
into the LFG. Water vapor content of LFG will depend on the system temperature and pressure and could be saturated under landfill conditions.

\section{Non-Methane Organic Compounds (NMOC)}

Many minor constituents are present in LFG at low concentrations. Trace gases are produced by the complex interaction of the physical, chemical, and biological processes occurring within the waste. LFG contains a variety of NMOC including (USACE, 1995):

- benzene,

- toluene,

- ethylbenzene,

- vinyl chloride,

- dichloromethane,

- trichloroethylene,

- 1,2,-cis dichloroethylene, and

- tetrachloroethylene.

These compounds are widely used in industry and are found in common household products or used in their manufacture.

\section{E. Others}

Hydrogen is produced during waste decomposition, particularly during initial anaerobic conversion of mixed organic acids to acetic acid. Significant amounts of hydrogen are later consumed in the formation of $\mathrm{CH}_{4}$. Hydrogen is flammable between 4 and $74 \%$, by volume, in air. There are a number of other constituents of LFG, which are found in trace levels. 


\subsection{LFG CONDENSATE}

\subsubsection{Formation of Gas Condensate}

As the gas undergoes changes in temperature and pressure, condensate forms in the collection systems. LFG condensate accumulates in gas collection systems and gas processing systems. When LFG moves through the collection system, the gas cools and the various constituents condense out of the gas. Mainly, the condensed material is composed of water, organic compounds, and traces of in-organics. The organic compounds are generally not soluble in water and separate into aqueous and hydrocarbon phases, though the solubility parameter is dependent on the concentration of hydrocarbons.

Condensates are also generated in the gas energy and processing plants. Condensate production could happen as a result of natural or artificial cooling of the gas, or it could simply be through physical processes such as expansion.

\subsubsection{Features of the Condensate}

The type and quality of gas condensate is dependent on the following factors:

- age and quality of refuse in the landfill,

- amount of moisture or liquid in the landfill,

- temperature differences,

- landfill size and configuration,

- type of liner and/or cover materials, and

- climatic conditions.

Some published data show that the aqueous phase of LFG condensate generally passes the Toxicity Characteristic Leaching Procedure (TCLP) regulatory limits (USACE, 1995). If a non-aqueous phase liquid is present in the condensate, this fraction has been found to fail ignitability testing. Landfills that have been operating principally as a municipal landfill are rarely found to have a non-aqueous phase fraction. 
Based on the limited condensate data which are available, it is likely that the hydrocarbon or organic phase of the condensate is ignitable and, thus, should be considered hazardous (US EPA, 2003). Ignitable wastes are those with a flash point below $60^{\circ} \mathrm{C}$.

\subsection{MOVEMENT OF LANDFILL GAS}

Due to the nature of the landfill design and construction and also because of the waste types and their composition, gas movement through the waste and soil is difficult to predict and are usualy very complicated. The path of least resistance governs the movement of the gas through the waste and the surrounding soils. Weather conditions affect rate of gas migration. When barometric pressure is falling outside the landfill, gas moves away from the landfill into the surrounding areas. While the rise of barometric pressure outside the landfill will keep the gas within the landfill, until pressure balance occurs.

The nature of the specific transport mechanism depends on the type of waste (solid or liquid) exposed to the atmosphere. Several physical mechanisms describe the behavior of volatile compounds as they may be released into the atmosphere from a landfill. The transport may occur by the three principal mechanisms namely molecular effusion, diffusion, and convection.

\subsubsection{Molecular Effusion}

Basically, molecular effusion occurs at the surface boundary between the landfill and the atmosphere. Effusion is the process by which diffused gas releases from the top of the landfill, when the material gets compacted but not covered. The principal release mechanism for dry solids is direct exposure of the waste vapor phase to the ambient atmosphere. Any volatile liquid constituents, which coats the soil surface would be 
released according to Raoult's Law, which predicts the release rate based on the vapor pressure of the compounds present (USACE, 1995). Raoult's Law describes that the vapor-pressure depression of a constituent is directly proportional to the concentration of particles in solution.

It implies that the partial vapor pressure of a constituent in a gaseous mixture is equal to the mole fraction of that constituent in the solution times the vapor pressure of the pure constituent, which is a function of temperature.

Raoult's Law is expressed as follows:

$$
P_{v}=X_{i}^{*} P_{o}
$$

where,

$$
\begin{aligned}
& P v=\text { partial pressure of a compound in gaseous mixture, atm } \\
& X i=\text { concentration of compound in solution, mole fraction } \\
& P o=\text { vapor pressure of the compound in pure state, atm }
\end{aligned}
$$

Liquid molecules that possess sufficient kinetic energy are projected out of the main body of a liquid at its free surface and pass into vapor. The pressure exerted by this vapor is known as the vapor pressure.

The vapor pressure of a given compound is the single most significant factor affecting the performance of an off-gas collection system. The vapor pressure of water at $20^{\circ} \mathrm{C}$ is $0.34 \mathrm{KN} / \mathrm{m}^{2}$. In general, compounds which exhibit vapor pressure greater than $0.5 \mathrm{~mm}$ $\mathrm{Hg}$ are appropriate for off-gas collection. Wind speed affects the release rate of LFG from the surface. 


\subsubsection{Diffusion}

The variations in gas concentration between different locations gives way to diffusion. During diffusion, gas flows from area of high concentration to low concentration. Usually, the concentration of a volatile constituent in the LFG is higher than that of the surrounding atmosphere. Hence, LFG will migrate to a lower concentration area, which is towards the ambient air. Wind often serves to keep the surface concentration at or near zero, which renews the concentration gradient between the surface and the landfill on a continuing basis and, thus, promotes the migration of vapors to the surface. Landfill caps like geomembrane affect the diffusion process by isolating the gas migration between the landfill and the surrounding atmosphere.

The density of the vapor influences the rate of diffusion. However, concentration gradient within the gas system overcomes these density differences, especially when small density differences are exhibited. Specific compounds exhibit different diffusion coefficients that are essential for the transport mechanism.

Diffusion can be an important element in lateral migration of methane. However, its effect is minimal where naturally occurring pressures are, high within the landfill or when an induced exhaust system is used to increase the landfill pressure gradient (Moore 1979, Schumacher 1983).

\subsubsection{Convection}

Pressure gradient between the landfill and the surrounding atmosphere plays a significant role in the migration of LFG, in which case the gas tends to flow from high pressure gradient to the lower pressure gradient. This type of gas flow due to pressure gradients is called convective flow. Basically, convective flow of gas has more control over the gas flow direction and magnitude as compared to the other two transport 
mechanisms. Pressure of the gas is developed within the landfill as a result of the production of vapors from biodegradation processes, chemical reactions within the landfill, compaction effects, or methane production at the lower regions of the landfill that pushes the vapors toward the surface. Variations in depth of water table could give rise to small pressure gradients with the effect of either pushing the gas out or drawing the material in. Changes in barometric pressure at the surface of the landfill can also have an impact on the convective flow of gas.

The rate of gas movement is generally more influenced by convection rather than by diffusion. For a particular gas, convective and diffusive flow may be in opposing directions, resulting in an overall tendency toward cancellation. However, in most cases of LFG gas recovery, diffusive and convective flows occur in the same direction.

\subsection{FACTORS AFFECTING LFG TRANSPORT MECHANISM}

The migration of the gas, flow direction and transport mechanism is affected by gas permeability of the landfill matter; groundwater depth; type and condition within the waste; moisture content within the landfill; and landfill liner and cap systems.

\subsubsection{Permeability}

The rates of gas flow and gas recovery are greatly influenced by the permeability distribution of the waste matter and landfill materials. Uniform gas flow pattern and large values of gas permeability are exhibited in coarse-grained waste materials. By contrast, fine-grained refuses are characterized by small values of gas permeability and gas flow patterns which are primarily restricted to macropores or secondary permeability zone such as fractures.

A coefficient of permeability, $k$, is often used to describe the rate of discharge of fluid under laminar-flow conditions and at a standard temperature (usually $20^{\circ} \mathrm{C}$ ) through a 
unit cross-sectional area of a porous medium under a unit hydraulic gradient. The LFG permeability is a function of both its intrinsic (ki) and relative (kr) permeabilities.

The intrinsic permeability coefficient, $\mathrm{ki}$, is a measure of the ease with which a porous medium can transmit LFG, water, or other fluid through its media. The intrinsic permeability is specific for each landfill, and is a function only of the porous medium. The dimensions, in length squared, may be expressed in units of darcies: 1 darcy = $9.87 \times 10^{-9} \mathrm{~cm}^{2}$. The relative permeability (kr) is a dimensionless number and is expressed as a fraction of the maximum permeability value that the medium can exhibit for a given fluid.

\subsubsection{Depth of Groundwater}

The surface of the water table acts as a no-flow boundary for gases within the unsaturated zone. As a result, it is generally used to estimate the thickness of the zone of extraction from which a gas can be removed. The depth to groundwater as well as seasonal variations need to be evaluated during design process to evaluate the well construction requirements as well as the potential for water table upwelling (i.e., the upward rise of the water table toward extraction well). The potential rise in the water table that can occur at a location is expressed as an equivalent water column height (in $\left.\mathrm{cm}_{2} \mathrm{O}\right)$. The limit of upwelling, $\mathrm{z}(\mathrm{cm})$ can thus be calculated as:

$$
h_{\text {rise }}=1033 *\left(1-P_{r}\right)
$$

Where,

$$
\begin{array}{ll}
\mathrm{h}_{\text {rise }}= & \text { increase in the water table surface, } \mathrm{cm} \text { of water } \\
\mathrm{P}_{\mathrm{r}}= & \begin{array}{l}
\text { pressure reading as a function of the radial distance from the } \\
\text { vertical extraction well, atm }
\end{array}
\end{array}
$$


Upwelling is not a significant concern in more permeable formations, as the applied vacuum will have little influence. In less permeable formations, however, upwelling can be significant and should be quantified for efficient gas system design and operation.

\subsubsection{Waste Type and Condition}

Landfills are heterogeneous in their type of waste and physical conditions. As a result, it is common to observe that anaerobic decomposition (mainly acid phase), and some aerobic decomposition along with methanogenic degradation occurring simultaneously. These occurrences affect gas flow and gas recovery rates during gas collection operation.

The porosity of solid wastes within the landfill is expressed as a ratio of the void volume to the total volume of the porous medium. It is a measure of the fraction of void space in the material. Usually, these pores are occupied by gas, water, and/or bacteria. Waste porosity can be calculated from the volume of void space and bulk volume of the waste material.

$$
n=\frac{V_{V}}{V_{T}}
$$

Where,

$$
\begin{aligned}
& \mathrm{n}=\text { waste porosity, dimensionless } \\
& V v=\text { volume of void space }\left(\mathrm{m}^{3}\right) \\
& V_{T}=\text { bulk volume of particle including solid and waste component }\left(\mathrm{m}^{3}\right)
\end{aligned}
$$

Alternatively, porosity can also be calculated from the bulk density and particle density, as given on equation $3-4$, below.

$$
n=1-\frac{B_{D}}{P_{D}}
$$


where,

$$
\begin{aligned}
& \mathrm{n}=\quad \text { waste porosity, dimensionless } \\
& B_{D}=\text { bulk density of the waste, } \mathrm{kg} / \mathrm{m}^{3} \\
& P_{D}=\text { density of the particle, } \mathrm{kg} / \mathrm{m}^{3}
\end{aligned}
$$

Generally, waste porosity of landfills ranges from 0.04 to 0.10 . Gas permeability within the waste in the landfill is influenced by the moisture content of the wastes. Moisture occupies pore space of the wastes, thereby computing with gas and its migration flow. Hence, moisture reduces the flow and pathway of the gas through the landfill, ultimately decreasing gas recovery rates.

\subsubsection{Landfill Cap and Liner Systems}

Landfill caps provide the benefit of the final closure of the landfills. They improve LFG collection system by allowing maximum recovery of LFG from all portions of the landfill. A properly constructed landfill cap consisting of geomembrane will exclude the inflow of air from surrounding area to the landfill, especially during active gas collection system. Therefore, higher operating vacuum can be applied to the gas collection system without danger of overdrawing the gas. Hence, the effective radius of influence of each well is increased implying to the use of fewer wells per unit area.

Landfill liners are made up of materials with low permeability, including compacted clay liners, geomembranes, and geosynthetic clay liners. Landfill liners assist in preventing the intrusion of water and inflow of air from the subsurface into the landfill and to the LFG collection system especially during active collection system. 


\subsection{LANDFILL GAS FLOW}

In systems where a natural or induced pressure gradient occurs, convective mechanisms will be the primary means of gas flow (Schumacher, 1983). Hence, the means by which methane (LFG) is removed from a landfill is by producing a pressure or concentration sink to which the gas will flow. Darcy's Law has been used to characterize the flow of gas through the refuse (Findikakis and Leckie, 1979).

Under the assumption that the production of LFG and its removal by convective means are happening simultaneously, Darcy's Law for radial flow of landfill toward a recovery well may be expressed mathematically using the following equation.

$$
V r=-k * \frac{d h}{d l}
$$

Where,

$$
\begin{aligned}
& \mathrm{Vr}=\quad \text { apparent gas velocity at distance " } 1 ",(\mathrm{~m} / \mathrm{sec}) \\
& \mathrm{k}=\quad \text { permeability coefficient, }(\mathrm{m} / \mathrm{sec}) \\
& 1=\quad \text { radial distance from the recovery well, }(\mathrm{m}) \\
& \mathrm{h}=\quad \text { hydraulic head, }(\mathrm{m}) \\
& \mathrm{dh} / \mathrm{dl}=\text { hydraulic (pressure) gradient at distance " } 1 " .
\end{aligned}
$$

The negative sign indicates that flow is of decreasing hydraulic head toward the recovery well.

With:

$$
h=\frac{p}{\gamma}+z
$$

Where,

$$
\begin{aligned}
& \mathrm{p}=\quad \text { total pressure at distance } " 1 ",\left(\mathrm{~N} / \mathrm{m}^{2)}\right. \\
& \gamma=\quad \text { specific weight of the gas, }\left(\mathrm{N} / \mathrm{m}^{3}\right) \\
& \mathrm{z}=\quad \text { elevation above some arbitrary datum, (m) } \\
& 29
\end{aligned}
$$


Darcy's Law applies only to laminar flow; that is, the resistive forces of viscosity predominate. Reynold's number is usually used to check the laminar flow.

$$
\operatorname{Re}=\rho * \frac{V * D}{\mu}
$$

Where,

$$
\begin{aligned}
& \mathrm{Re}=\text { Reynold's number, dimensionless } \\
& \mu=\text { absolute viscosity of the fluid, }\left(\mathrm{Pa} \cdot \mathrm{sec} / \mathrm{m}^{2}\right) \\
& \rho=\text { density of the fluid, }\left(\mathrm{kg} / \mathrm{m}^{3}\right) \\
& V=\text { velocity of flow, }(\mathrm{m} / \mathrm{sec}) \\
& D=\text { mean grain diameter of the porous medium, (m) }
\end{aligned}
$$

According to previous works laminar flow occurs when the Reynold's number is in the range of 1 to 10 . This indicates that Darcy's law applies only to very slowly moving fluids (water and gas). Maximum velocity, V, at the refuse/recovery well interface was found to be in order of $0.3 \mathrm{~cm} / \mathrm{sec}$ (Campbell et. al., 1991).

\subsection{ESTIMATION OF LFG GENERATION}

\subsubsection{General}

The estimation of LFG emission is very important from the point of pollution prevention and gas capture and collection systems. Apart from assessing the impact of LFG emission on the environment, the estimation of LFG generation lends itself in devising a proper control measure of the emission.

LFG emissions differ from one site to another. They are influenced by a number of factors both controllable and uncontrollable. There are many parameters that make 
estimation difficult and unpredictable, because of the inherent uncertainty using isolated samples to predict total generation rates over long periods (Ham et al., 1979).

There are different models available for estimating LFG emission. Broadly, these prediction tools are categorized as modeling and measurements. The simplest prediction tool is modeling, which requires validation using actual measurements of gas emissions. Modeling involves a thorough study of a number of parameters. Mainly the model should include waste composition, method of disposal, moisture content, and also future trends and predictions. Besides, information on landfill design and construction, method of LFG collection and management are essential for realistic estimation of LFG generation and emission.

Depending on the type of model used, it is expected that the estimated or computed gas yield and generation rate could also vary. The most important input parameter that is common to all models is the quantity of decomposable waste that is considered. Another important factor is the assumed lag time between the placement of waste and the beginning of the anaerobic decomposition or methanogenic phase within the waste mass (Augenstein, 1991).

Therefore, it is prudent to use a simple model, with fewer parameters, which can be more reasonably assigned according to the specific site conditions. The predictive success of any model is dependent mostly on the degree of accuracy needed, the reliability of the input data, the experience of the individual analyzing the data, and the degree of similarity between the subject site and other sites which have been successfully modeled (Zison, 1990). Here in this paper the most commonly used models will be discussed. Such models include;

- Scholl Canyon model, 
- LandGEM (EPA Landfill Gas Emission Model),

- LFGGEN (Landfill Gas Generation Model)

These models are used for estimating LFG emission from municipal solid waste landfills. Emissions are projected over time using mainly first-order decomposition. The most popular model is EPA's first order decay model that is used in evaluating potential gas production.

\subsubsection{Scholl Canyon Model}

The Scholl Canyon Model assumes that methane generation is a function of first-order kinetics. The empirical, first-order decay model most widely accepted and used by industry and regulatory agencies, including the U.S. EPA, is Scholl Canyon Model. The main assumption of the model is that there is a certain fraction of biodegradable material in the landfill per unit of time. The parameters of this model are empirically determined by fitting the empirical data to the model to account for variations in the refuse moisture content and other landfill conditions. The gas production rate is assumed to be at its peak upon initial placement after a negligible lag time during which anaerobic conditions are established and decreases exponentially (first-order decay) as the organic content of the waste is consumed. The model is expressed by the following equation.

$$
Q_{C H 4}=L o^{*} R^{*}\left(e^{-k c}-e^{-k t}\right)
$$

Where:

$\mathrm{Q}_{\mathrm{CH} 4}=$ methane generation rate at time $\mathrm{t},\left(\mathrm{m}^{3} / \mathrm{yr}\right)$

Lo $=$ potential methane generation capacity of the waste, $\left(\mathrm{m}^{3} / \mathrm{Mg}\right)$

$\mathrm{R}=$ average annual acceptance rate of waste, $(\mathrm{Mg} / \mathrm{yr})$

$\mathrm{k}=\mathrm{CH} 4$ generation rate constant, $(1 / \mathrm{yr})$ 
$\mathrm{c}=$ time since landfill closure, $(\mathrm{yr})$ (i.e. $\mathrm{c}=0$ for active landfill)

$\mathrm{t}=$ time since initial waste placement, $\mathrm{yr}$.

The model could be further refined by dividing the landfill into smaller sub-masses to account for the landfill age over time. If a constant annual acceptance rate (R) is assumed, the methane generated from the entire landfill is maximum at the time of landfill closure. Lag time due to the establishment of anaerobic conditions could also be incorporated into the model by replacing "c" with "c + lag time" and " $t$ " by " $t+$ lag time". The lag time before which anaerobic conditions are established may range from 200 days to several years (USEPA, 1978). The refined Scholl Canyon Model equation then takes the following form:

$Q=2 * k * L o * R *\left(e^{-k(t-\operatorname{lag}))}\right)$

Where:

$$
\begin{aligned}
& Q=\text { LFG generation rate at time } t,\left(\mathrm{~m}^{3} / \mathrm{yr}\right) \\
& \text { Lo = potential methane generation capacity of the waste, }\left(\mathrm{m}^{3} / \mathrm{Mg}\right) \\
& \mathrm{R}=\text { average annual acceptance rate of waste, }(\mathrm{Mg} / \mathrm{yr}) \\
& \mathrm{k}=\mathrm{CH} 4 \text { generation rate constant, }(1 / \mathrm{yr}) \\
& \mathrm{t}=\text { time since initial waste placement, }(\mathrm{yrs}) \\
& \text { lag = time to reach anaerobic conditions, }(\mathrm{yrs})
\end{aligned}
$$

It is a common practice to assume that the LFG generated is composed of fifty percent methane and fifty percent carbon dioxide so that the total LFG produced is basically equal to twice the quantity of methane calculated from Equation 3-8.

The Scholl Canyon Model is also simple to understand and apply. Equation 3.9 is the basis for the U.S. EPA's LFG Emissions Model (LandGEM). The Scholl Canyon 
Model predicts LFG production over time as a function of the LFG generation constant (k), the methane generation potential (Lo), and the historic waste filling records and future waste projections at a site. The U.S. EPA assigns default values for each of these parameters for a conservative preliminary site assessment. However, these input parameters must be selected with knowledge of the specific site conditions and geographic location.

The methane generation rate constant $(\mathrm{k})$ represents the first-order biodegradation rate at which methane is generated following waste placement. This constant is affected by nutrient availability, temperature, $\mathrm{pH}$ and moisture content within the landfill. Moisture within the landfill acts as a vehicle in transporting nutrients and bacteria. The moisture content within a landfill is influenced by the moisture content of the waste, type of material for daily cover and its permeability, leachate collection system, infiltration of precipitation through the landfill cover, etc. Typical values of " $k$ " range from 0.02 for dry sites to 0.07 for wet sites. The default value used by the U.S. EPA for sites with greater than $625 \mathrm{~mm}$ of precipitation per year is 0.05 (U.S. EPA, 1994). Suggested ranges and recommended parameter assignment for the rate constant, (k), are given on Table 3.1.

Table 3.1: Suggested k Value Ranges for Corresponding Annual Precipitation

\begin{tabular}{cccc}
\hline Annual Precipitation & \multicolumn{3}{c}{ Range of k Values } \\
\cline { 2 - 4 } & Relatively Inert & $\begin{array}{c}\text { Moderately } \\
\text { Decomposable }\end{array}$ & $\begin{array}{c}\text { Highly } \\
\text { Decomposable }\end{array}$ \\
\hline$<250 \mathrm{~mm}$ & 0.01 & 0.02 & 0.03 \\
$>250$ to $<500 \mathrm{~mm}$ & 0.01 & 0.03 & 0.05 \\
$>500$ to $<1000 \mathrm{~mm}$ & 0.02 & 0.05 & 0.08 \\
$>1000 \mathrm{~mm}$ & 0.02 & 0.06 & 0.09 \\
\hline
\end{tabular}

(Source: Conestoga, 2004, Handbook for the Preparation of Landfill Gas to Energy Projects, The World Bank) 
"Lo" value is dependent on the composition of the waste, and in particular, the fraction of organic matter present. Its value is estimated based on the carbon content of the waste, the biodegradable carbon fraction, and a stoichiometric conversion factor. Typical methane values for this parameter range from $125 \mathrm{~m}^{3} /$ tone of waste to 310 $\mathrm{m}^{3} /$ tonne of waste.

The default assignment of "Lo" already recognizes that there is a mixture of decomposable organic wastes and inorganic wastes being deposited in a typical fill site. If there is good data regarding waste quantities and types, it may be possible to refine the modeling assessment using the following as guideline parameter assignments for the Lo factor. It would be necessary to make the overall LFG generation assessment a sum of the curves generated for the various types of waste.

Table 3.2: Suggested Lo Values by organic waste content

\begin{tabular}{ccc}
\hline Waste Categorization & $\begin{array}{c}\text { Minimum "Lo" } \\
\text { Value }\end{array}$ & $\begin{array}{c}\text { Maximum "Lo" } \\
\text { Value }\end{array}$ \\
\hline Relatively Inert Waste & 5 & 25 \\
Moderately Decomposable Waste & 140 & 200 \\
Highly Decomposable Waste & 225 & 300 \\
\hline
\end{tabular}

(Source: Conestoga, 2004, Handbook for the Preparation of Landfill Gas to Energy Projects, The World Bank)

Figure 3.1 illustrates the LFG generation curve, with emphases on peak LFG generation rate and first order generation rate constant. The LFG computation and its production curve is produced using the Scholl Canyon Model. The U.S. EPA default values $\left(k=0.05, L o=170 \mathrm{~m}^{3}\right.$ of methane per tone of waste) for a landfill site with a constant fill rate of 500,000 tones per year for 25 years (from 1990 to 2015) are used for creating those curves. The graph shows two curves, the theoretical total amount of 
LFG produced and the LFG collected assuming a typical collection system efficiency of $75 \%$ as the U.S. EPA suggests.

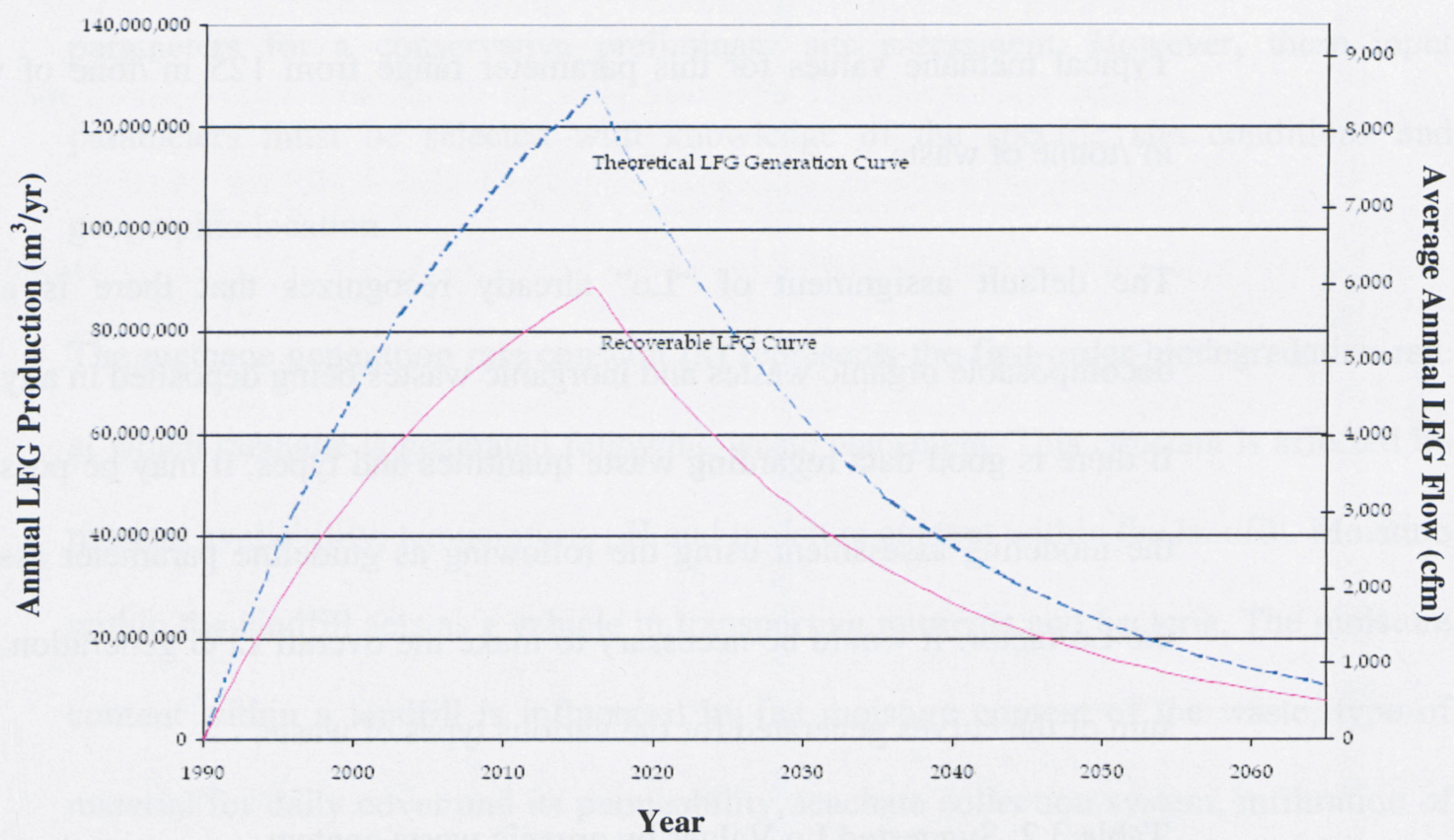

Figure 3-1: Typical LFG Generation Curve (using Scholl Canyon Model)

(Source: Conestoga, 2004, Handbook for the Preparation of Landfill Gas to Energy Projects, The World Bank)

\subsubsection{LandGEM (EPA Landfill Gas Emission Model)}

The Landfill Gas Emissions Model (LandGEM) is a model developed by U.S. EPA for estimation of emission rates for total landfill gas, methane, carbon dioxide, nonmethane organic compounds, and other individual air pollutants from municipal solid waste landfills. The model, LandGEM, uses landfill-site-specific data to estimate LFG emissions. If site specific data are not available, then default parameters of the model can be used. The two default parameters used by the model are CAA defaults and inventory defaults (U.S. EAP, 2005).

CAA Defaults: The CAA defaults are based on requirements for MSW landfills laid out by the Clean Air Act (CAA), including the NSPS/EG and NESHAP. This set of 
default parameters yields conservative emission estimates and can be used for determining whether a landfill is subject to the control requirements of the NSPS/EG or NESHAP.

Inventory Defaults: With the exception of wet landfill defaults, the inventory defaults are based on emission factors in the U.S. Environmental Protection Agency's (EPA's) Compilation of Air Pollutant Emission Factors (AP-42). This set of defaults yields average emissions and can be used to generate emission estimates for use in emission inventories and air permits in the absence of site-specific test data.

LandGEM is based on a first-order decomposition rate for quantifying emissions from the decomposition of solid wastes in MSW landfills. Model defaults are based on empirical data from U.S. landfills. Field test data can also be used in place of model defaults when available. The model uses the following first-order decomposition rate equation to estimate annual emissions over a specified time period.

$$
\left.Q_{C H 4}=\sum_{i=1}^{n} \sum_{j=0.1}^{1} k L_{o}\left(\frac{M_{i}}{10}\right) e^{-k t_{i j}}\right)
$$

where

$\mathrm{Q}_{\mathrm{CH} 4}=$ annual methane generation in the year of the calculation $\left(\mathrm{m}^{3} /\right.$ year $)$

$\mathrm{i}=1$ year time increment

$\mathrm{n}=$ (year of the calculation) - (initial year of waste acceptance)

$\mathrm{j}=0.1$ year time increment

$k=$ methane generation rate $\left(\right.$ year $\left.^{-1}\right)$

$L o=$ potential methane generation capacity $\left(\mathrm{m}^{3} / \mathrm{Mg}\right)$

$\mathrm{Mi}=$ mass of waste accepted in the ith year $(\mathrm{Mg})$

$\mathrm{tij}=$ age of the $\mathrm{jth}$ section of waste mass Mi accepted in the ith year (decimal years) 
The Methane Generation Rate, $k$, determines the rate of methane generation for the mass of waste in the landfill. The higher the value of $k$, the faster the methane generation rate increases and then decays over time. Basically, the value of $k$ is a function of the following landfill and solid waste conditions:

- Moisture content of the waste mass,

- Availability of the nutrients for microorganisms that break down the waste to form methane and carbon dioxide,

- $\mathrm{pH}$ of the waste mass, and

- Temperature of the waste mass.

The five built-in $k$ values used by the model are given in Table 3.3. Locations with rainfall less than 25 inches per year are considered Arid Areas in the model. The default $k$ value is the CAA $k$ value for conventional landfills $\left(0.05\right.$ year $\left.^{-1}\right)$.

Table 3.3: Values for methane generation rates $(k)$

\begin{tabular}{ccc}
\hline Default Type & Landfill Type & $\begin{array}{c}K \text { Value } \\
\left(\text { year }^{-1}\right)\end{array}$ \\
\hline CAA & Conventional & 0.05 (default) \\
CAA & Arid Area & 0.02 \\
Inventory & Conventional & 0.04 \\
Inventory & Arid Area & 0.02 \\
Inventory & Wet (Bioreactor) & 0.7 \\
\hline
\end{tabular}

(Source: U.S. EPA, 2005)

The Potential Methane Generation Capacity, $L_{o}$, is dependent only on the type and composition of solid waste placed within the landfill. The higher the cellulose content of the waste, the higher the value of $L_{o}$. Table 3.4 below, gives the five $L_{o}$ values used by LandGEM. The default $L_{o}$ value is the CAA $L_{o}$ value for conventional landfills, 170 $\mathrm{m}^{3} / \mathrm{Mg}$ 
Table 3.4: Values for the Potential Methane Generation Capacity (Lo)

\begin{tabular}{ccc}
\hline Emission Type & Landfill Type & $\begin{array}{c}\text { Lo Value } \\
\left(\mathbf{m}^{\mathbf{3}} / \mathbf{M g}\right)\end{array}$ \\
\hline CAA & Conventional & 170 (default) \\
CAA & Arid Area & 170 \\
Inventory & Conventional & 100 \\
Inventory & Arid Area & 100 \\
Inventory & Wet (Bioreactor) & 96 \\
\hline
\end{tabular}

(Source: U.S. EPA, 2005)

LandGEM is the most popular model used for estimation of methane emission rates. The model is simple and straightforward in its application. Although, the landfill categorization like conventional, arid area, wet bioreactor take into account the moisture content during selection of $L o$ and $K$ values; LandGEM does not consider direct measurement of moisture content of the landfill refuse. Site-specific composition of waste is not taken into account. Besides, the model ignores lag time between the first placement of waste into the landfill and the initial methane generation.

\subsubsection{LFGGEN (Landfill Gas Generation Model)}

LFGGEN model is used not only in estimation of methane generation rates and yield but it is also used for sizing equipment for landfill gas collection and combustion facilities. The gas generation model, LFGGEN, is developed by CH2M HILL. The model yields results similar to other landfill gas generation rate estimation models (Emcon, 1980). The model has been used to estimate landfill gas generation rates as the basis of design for more than 20 landfill gas collection systems in the United States (CH2M HILL, 2002).

The organic fraction of the solid waste within the landfill and the part that is readily biodegradable by anaerobic bacteria is important factor in using the model in estimating the total yield of gas and generation rate from unit mass of MSW. If sitespecific data with regards to organic fraction are not available to use as inputs to the 
model, the waste stream is assumed to have an inert material content of between 25 percent and 35 percent by weight (CH2M HILL, 2002). Of the decomposable organic fraction of the refuse that contributes to gas production, the readily decomposable portion has been assumed to be between 25 percent and 45 percent by weight, and the moderately decomposable portion has been assumed to be between 50 percent and 70 percent by weight. In case of site specific data are missing, default values corresponding to typical U.S. MSW are provided.

Songohuga (1969) reported that maximum LFG generation occurs in landfills under saturated conditions of $60 \%$ moisture content (by weight) or grater. Moisture content is considered an important determinant of the rate of gas generation in landfills. The anaerobic organisms that produce landfill gas function most actively in an aqueous environment. Typically, moisture varies from 15 to $40 \%$ during placement of waste into landfill (Tchobanoglous, 1977). The peak rate of gas production, the rate of increase in gas production to the peak rate, and the length of the period of peak gas production are assumed to vary in direct proportion to the moisture content of the wastes.

The modeling approach followed in LFGGEN is to develop a unit curve representing gas generation rate, plotted against time. During modeling, disposal of refuse is assumed to occur in annual increments. As shown in Figure 3.2, the unit curve is modeled as a four-stage process, as described below (CH2M HILL, 2002).

Stage 1: Lag Phase: A lag phase occurs during which methanogenic bacteria cannot compete with aerobic and other organisms in the refuse. The refuse is purged of oxygen during this phase and methanogenic bacteria are established. The lag phase is assumed to be 6 months long. The gas generation rate is computed as zero during the lag phase. 
Stage 2: Rising Phase: Methane generation increases until a peak generation rate is reached. The rate is assumed to increase linearly with time to the peak generation rate over a relatively short time period (typically 2 to 5 years). The length of the rising phase and the peak methane generation rate are functions of the refuse composition and moisture content. The peak methane generation rate varies between 0.08 and 0.20 standard cubic feet (SCF) of methane per pound of wet refuse per year for typical MSW.

For modeling purposes, the maximum possible methane generation rate is taken as 0.20 SCF per pound per year, and is adjusted downward for the moisture content and composition of the refuse using the following equation:

$$
Q_{\text {peak }}=0.2 *\left(\frac{M C}{60}\right) * \frac{\left(0.763 * \frac{R E D F R A C}{0.35}+0.38 * \frac{M O D F R A C}{0.61}\right)}{(0.763+0.38) * \frac{O R G F R A C}{0.71}}
$$

where,

Qpeak $=\quad$ peak methane generation in SCFM per pound of refuse in place (wet weight basis)

MC: $\quad$ moisture content of the refuse (percentage wet weight basis)

ORGFRAC: fraction of the refuse that is organic material

REDFRAC: fraction of ORGFRAC that is readily decomposable

MODFRAC: fraction of ORGFRAC that is moderately decomposable

The length of the rising phase is assumed to be a minimum of 2 years, adjusted upward in inverse proportion to the ratio of the moisture content to the maximum moisture content of 60 percent. The length of the rising phase is computed as follows:

$$
T R I S E=2 y r *\left(\frac{M C}{60}\right)
$$

where, 
TRISE is the time from placement of waste until the end of the rising phase

During the rising phase, the methane generation rate is computed using the following equation:

$$
Q=Q_{\text {peak }} * \frac{(T-T L A G)}{(T R I S E-T L A G)}
$$

where,

$$
\begin{array}{ll}
\mathrm{Q}= & \text { methane generation rate in SCFM per pound of refuse at time } \mathrm{T} \\
\mathrm{TLAG}= & \begin{array}{l}
\text { lag time from placement of waste }=0.5 \mathrm{yr}, \text { (as described } \\
\text { previously) }
\end{array}
\end{array}
$$

Stage 3: Stable Phase: The peak generation rate is maintained in a nutrient-limited steady-state for a number of years. The length of time of the stable phase is a function of the composition and moisture content of the waste.

The length of the stable phase is assumed to be a minimum of 5 years, adjusted upward in inverse proportion to the ratio of the moisture content to the maximum moisture content of 60 percent. The length of the stable phase is computed as follows:

$$
\text { PLATENED }=5 *\left(\frac{M C}{60}\right)
$$

Where,

$$
\text { PLATEND }=\text { length of the stable phase }
$$

During the stable phase, the methane generation rate is maintained at Qpeak.

Stage 4: Declining Phase: The declining phase, which constitutes most of the length of the unit methane generation versus time curve, is modeled by an exponential decay equation that approaches zero asymptotically. The equation was derived from a 
statistical analysis of observations of gas generation from decomposing MSW in a laboratory-controlled anaerobic environment (Hartz, 1980).

The equation that describes the gas generation rate at any time $\mathrm{T}$ during the stable phase is:

$$
Q=A P^{-k}
$$

where,

$$
\begin{array}{ll}
\mathrm{Q}= & \begin{array}{l}
\text { methane generation rate in SCRM per pound of refuse at time } \mathrm{T} \\
\mathrm{A}=
\end{array} \\
\mathrm{P}= & \begin{array}{l}
\text { empirical factor } \\
\text { cumulative cubic feet of methane per pound of wet refuse that } \\
\text { have been produced at time } \mathrm{T}
\end{array} \\
\mathrm{K}= & \text { rate constant found equal to } 1.5 \text { (in Hartz's experiments). }
\end{array}
$$

In Hartz' experiments, the empirical factor " $A$ " was found to be 0.06388 for MSW with typical U.S. composition maintained at a moisture content of 35 percent. The factor "A" is adjusted for actual moisture content and actual refuse composition using the following equation:

$$
A=0.06388 *\left(\frac{M C}{35}\right) * \frac{\left(0.763 * \frac{R E D F R A C}{0.35}+0.38 * \frac{M O D F R A C}{0.61}\right)}{(0.763+0.38) * \frac{\text { ORGFRAC }}{0.71}}
$$

Finally, the end results obtained from LFGGEN model include percentage of total methane produced. 


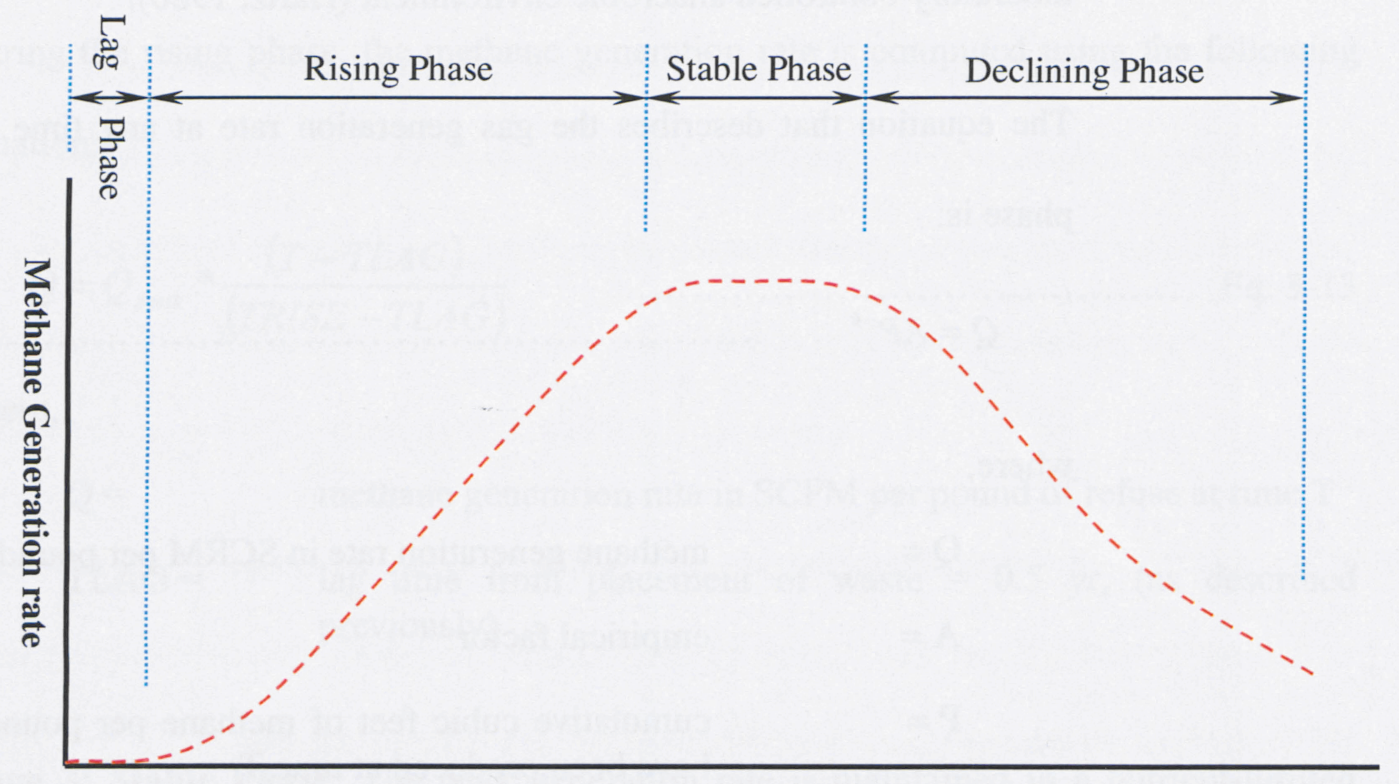

Time from Placement

Figure 3-2: Typical Four-Stage Process of LFG production curve for LFGGEN

\subsection{LFG COLLECTION EFFICIENCY}

\subsubsection{Definition of Efficiency}

LFG collection efficiency is essential in quantifying the effectiveness of emission control measures and it is also an important measure of the potential of a landfill for energy recovery works. Collection efficiency of LFG can be defined differently by different users based on the purpose of the quantification. Efficiency with respect to the objective of energy recovery system is defined as the ratio of the gas collected to gas generated within the landfill. Spokas et al., (2005) conducted extensive field measurements at three landfill sites to elucidate the total methane balance and provide field measurements to quantify these pathways.

The methane production rates, based on the works of Spokas et al., (2005), was estimated by considering the relative mass balance of methane that is recovered, 
emitted, oxidized by methanotrophic bacteria, laterally migrated, or temporarily stored within the landfill volume. Other researchers used the empirically modeled gas generation (eg. using LandGEM) for calculating gas efficiency against the direct measurement of collected gas.

Practical measures of collection efficiency are lacking and as a result, a default efficiency of 75\% (as proposed by U.S. EPA) based on surveys of industry estimates is commonly used (Huitric L.R. and Kong D., 2006). However, measurements of actual emissions on some landfills, though few, show that higher efficiencies ranging from 85 to $98 \%$ have been observed.

Hence, the gas collection efficiency from a landfill can be computed as follows:

$$
E=\frac{G_{c}}{G_{g}}
$$

where,

$$
\begin{array}{ll}
E= & \text { gas collection efficiency } \\
G c= & \text { gas collected/recovered }^{\mathrm{ii}} \\
G g= & \text { gas generated from landfill }
\end{array}
$$

Different researchers and designers of gas collection systems consider the generated gas volume $(G g)$ differently. Some of them consider the empirical gas generation model from landfill as estimation of the generated gas. This methane generation model uses a first order kinetics including the variables of mainly waste inputs, climate variables, decay factor, etc (Blaha et al., 1999).

\footnotetext{
ii Gas recovered is measured from recovery well meters

iii Gas generated is a measure of either using empirical methane generation model or generation rate measure using mass balance equation
} 
Usually, the results of the model are compared to actual recovery trends, and model parameters adjusted through the period of active gas extraction so that projections are consistent with actual recovery data. Accordingly, gas recovery efficiencies have been typically estimated to be in the range of $50-75 \%$, based on measured gas extraction rates divided by modeled gas generation rates (Spokas et al., 2005).

The other method identifies the pathways of methane within the landfill and their summation produces the total or net gas generation. This method applies a mass balance of the methane pathways.

\subsubsection{Mass Balance of Methane Pathways}

Mass balance system considers actual gas recovery efficiencies based on identification and quantification of all methane pathways as given in Figure 3-2.

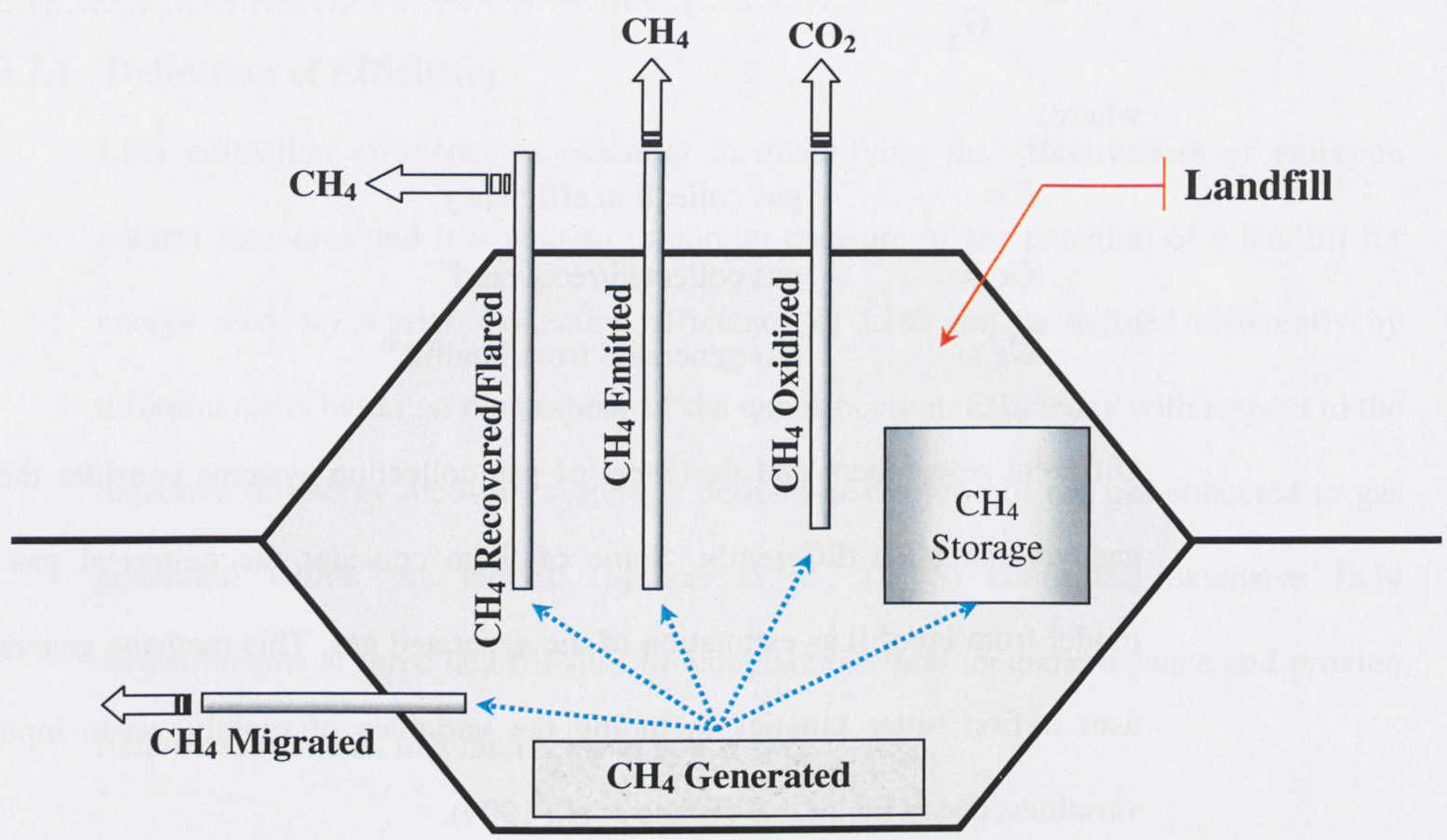

Figure 3-3: Schematics of methane pathways within landfill 
Bogner and Spokas, (1993) partitioned methane generated in landfills into methane recovered, emitted to the atmosphere, oxidized by methanotrophs, laterally migrated, and internally stored in the landfill volume, as given below:

$\mathrm{CH}_{4}$ generated $=\mathrm{CH}_{4}$ emitted $+\mathrm{CH}_{4}$ oxidized $+\mathrm{CH}_{4}$ recovered (flared) $+\mathrm{CH}_{4}$ migrated $+\Delta \mathrm{CH}_{4}$ storage

There are several factors which affect the overall collection efficiency of a landfill gas extraction system, which can vary from about 50 to over 90 percent (USEPA, 1996). The permeability of the landfill's cover layer will determine how much of the landfill gas generated will escape to the atmosphere; however, a portion of the landfill gas will escape through the cover of even the most tightly constructed and controlled collection system. Well spacing and depth, which are determined by economic and other site specific factors, also affect collection efficiency, as can bottom and side liners, leachate and water level, and meteorological conditions.

\section{Emitted Methane}

Direct measurements of landfill methane emissions vary over seven orders of magnitude (0.0004-4000 $\left.\mathrm{g} \mathrm{m}^{-2} \mathrm{~d}^{-1}\right)$ (Bogner et al., 1997). There are several methods for measuring emissions of methane over the surface of landfill. Tregoures et al. (1999) (cited by Huitric and Kong, 2006 and Spokas et al., 2005) compared several direct and indirect methane emission measurement methods including thermography, flux chambers, tracers, eddy correlation, mass balance, etc. They noted that eddy correlation is unsuitable because of spatial variability of emissions; thermography is in development stage; tracer gas method requires comprehensive plume coverage; flux chamber require hundreds of measurements, etc. Flux chamber techniques will be discussed in this paper. 


\section{Flux Chamber Method}

Methane flux density is measured using static recirculating chamber from many small areas of landfill surface $\left(0.25 \mathrm{~m}^{2}\right)$. A pump with flow rate of $101 / \mathrm{min}$ is used in this approach. The pump is used to circulate the enclosed chamber headspace to an outside loop. The rate of $\mathrm{CH}_{4}$ enrichment in the loop is measured periodically using a laboratory gas chromatograph that is transported in a utility vehicle around the site (Tregoures et al., 1999). Resulting surface flux density is calculated from the change in chamber $\mathrm{CH}_{4}$ concentration with time, chamber volume, and area. Surface flux is computed using the following equation:

$$
F l u x=\frac{V}{A}\left(\frac{\Delta C}{\Delta t}\right)
$$

where,

$$
\begin{array}{ll}
\text { Flux }= & \text { surface flux } \\
V=\quad \text { chamber volume } & \text { surface area } \\
A=\quad & \text { methane concentration with time }
\end{array}
$$

The unit of measurement of methane flux density is " $\mathrm{g} \mathrm{CH} \mathrm{CH}_{4}^{-2} \mathrm{~min}^{-1}$ ". Measured emissions of $\mathrm{CH}_{4}$ at chamber locations are the result of complex biological, chemical, and physical processes occurring within landfill cover soils, and there can be difficulties in the extrapolation of chamber measurements for large landfill areas (Spokas et al., 2005). Chamber fluxes were measured on a $20 \times 20 \mathrm{~m}$ grid pattern and spatially interpolated using inverse distance weighing.

\section{Methane Oxidized}


The oxidation of methane is carried out by methanotrophic bacteria found with the landfill cover. Methanotrophic bacteria are a physiologically unique group of microorganisms distinguished by their ability to use methane as sole source of carbon and energy (Wise et al., 1999), and they are a class of methylotrophic bacteria that possess a specific enzyme (methane monooxygenase), which allows them to oxidize $\mathrm{CH}_{4}$ to methanol. Ultimately methanol is further degraded and oxidized to $\mathrm{CO}_{2}$. It is has been reported during field works that an appreciable amount (10-100\%) of the methane present in the landfill cover is oxidized by indigenous methanotrophs.

Methane oxidation is determined using a stable carbon isotope technique. Since there is a preferential oxidation of ${ }^{12} \mathrm{C}$ over ${ }^{13} \mathrm{C}_{\text {in }} \mathrm{CH}_{4}$ by the methanotrophs (De Visscher et al., 2004), it is possible to determine the oxidized fraction by quantifying the change in $\delta^{13} \mathrm{C}$ of $\mathrm{CH}_{4}$ between the anaerobic zone and the surface. It should be noted that this may be regarded as a conservative estimate. Anaerobic zone gas is collected from recovery headers and wells, while static flux chambers along selected transects can be used for gas reflecting $\mathrm{CH}_{4}$ oxidation. The static flux chambers may also provide additional point measurements of $\mathrm{CH}_{4}$ emissions.

\section{Methane Recovered}

The measurement of methane recovered could be done by mass flow measurements from vertical wells or horizontal trenches of active recovery system. The mass of $\mathrm{CH}_{4}$ recovered is the most accurately quantified pathway of the $\mathrm{CH}_{4}$ balance (Spokas et al., 2005).

\section{Methane Migrated}

Lateral migration of gas within a cell can be controlled using different systems including geomembranes, compacted clay layers, and liners. Once a system reaches 
steady state, flow through a combination of barriers is controlled by the slowest diffusion rate. Diffusive flux, among other transport mechanisms, can be considered for lateral movement of gas within the landfill. Transmission of gas molecules through a polymer structure is through permeation. For HDPE geomembrane of $1.5 \mathrm{~mm}$ membrane thickness, the polymer liner will only allow $0.58 \mathrm{~cm}^{3} \mathrm{CH}_{4} \mathrm{~m}^{-2} \mathrm{~d}^{-1}$ at $1 \mathrm{~atm}$ pressure to pass through (Lim, 1995). This is equivalent to $400 \mu \mathrm{g} \mathrm{CH}_{4} \mathrm{~m}^{-2} \mathrm{~d}^{-1}$ per 1.5 mm of thickness. Under the assumption that the cell has a cubic shape; the area of the four sides and bottom were summed and multiplied by the permeation rate above to estimate $\mathrm{CH}_{4}$ migration.

\section{Methane Change in Storage}

Change in $\mathrm{CH} 4$ storage is perhaps the most difficult term of the balance to quantify (Spokas et al., 2005). The parameter is a function of several interdependent variables including:

- creation of additional void space due to decomposition of the waste,

- settlement as a result of increased void space,

- levels of leachate amount in the landfill,

- difference in the extraction efficiencies,

- changes in the amount of dissolved $\mathrm{CH}^{4}$ in leachate, and

- temperature and barometric pressure changes.

All of these factors may yield to different amount of $\mathrm{CH}_{4}$ gas contained within the airfilled porosity of the landfill. Change in storage is estimated from the temporal changes in $\mathrm{CH}_{4}$ concentrations from gas sampling wells or, if they are not available, from the changing $\mathrm{CH}_{4}$ concentrations in the main header from the gas recovery system. 
Therefore, the change in methane storage can be calculated as follows (Spokas et al., 2005):

$$
\begin{aligned}
& \Delta S_{C H 4}=(\Delta A) V \Phi_{a i r} \\
& \Delta S_{C H 4}=\text { change in storage } \\
& \Delta \mathrm{A}=\quad \text { change in methane concentration within the waste }\left(\mathrm{kgm}^{-3}\right) \\
& \mathrm{V}=\quad \text { total landfill volume }\left(\mathrm{m}^{3}\right) \\
& \phi_{\text {air }}=\quad \text { air filled porosity (0.2) }
\end{aligned}
$$

The value of 0.2 for the air-filled porosity is the average of landfill gas-filled porosities observed in other studies of similar nature (e.g., Cestaro et al., 2003). Change in storage is estimated from the temporal changes in $\mathrm{CH} 4$ concentrations from gas sampling wells or, if they are not available, from the changing $\mathrm{CH} 4$ concentrations in

The accuracy of this equation is mainly influenced by the temporal sampling density of the methane concentrations. Higher accuracy of the estimation can be obtained by the use of intensive sampling densities.

\section{Methane Generation}

The mass balance system is a measure of generated methane carried out with the help of identification and quantification of the methane pathways. Through intensive field measurements and calculations, methane pathways are quantified. Ultimately methane generated from the landfill is obtained by summing all the pathways. Such an approach provides an improved methodology to evaluate the actual methane generation and percent of recovery efficiency at field scale. However, still it has to be clear that LFG recovery and its efficiency are influenced by many complex and interrelated factors including atmospheric conditions and LFG dynamics. 


\subsubsection{Empirical Methane Generation Model}

The other method of quantifying the generated methane is through the use of empirical methane generation models. Different empirical methods of LFG generation models are discussed in section "3.6 Estimation of LFG Generation". Using one of these models with inputs specific to the type of landfill, waste type and composition, climatological location, etc., methane generation from a specific landfill site can be calculated. The result computed using this empirical model can be verified and validated using the result obtained from mass balance equation. This method is a gross simplification of the factors that interact within the landfill system and gas generation. However, the methodology is still applicable due to its simplicity in application. 


\section{LANDFILL GAS EXTRACTION}

\subsection{GENERAL}

Gas extraction can commence immediately after the completion of the use of the landfill. Basically, upon construction or closure of a landfill, facilities are required to reduce methane migration and collection of methane either from the point of environmental concern or energy recovery purpose. LFG has a calorific value about half that of natural gas when burnt as a fuel. The reason for half calorific value is attributed to the fact that there is about $60 \%$ methane, which is combustible, in landfill gas. The calorific value of LFG is $37 \mathrm{GJ} / \mathrm{t}$, while that of natural gas is $50 \mathrm{GJ} / \mathrm{t}$.

The gas utilization system must be designed at a capacity that will not require more fuel than the minimum gas production rate. Alternatively, modular power systems can be installed and then taken offline with the rise and fall of gas production. Because of the massive size and relatively slow gas production in a landfill, diurnal variations in gas production typically are not seen and the gas utilization system design does not need to consider them (CH2M Hill, 2002).

\subsection{ASSESSMENT OF GAS PRODUCTION}

Assessment of gas generation and its rate is essential in deciding as to which method of gas collection and usage is most suitable for a particular site. Accordingly, it assists in evaluating whether a proposed design and construction method of gas collection will meet its objectives in terms of capacity. Basically, there are two ways of determining the LFG and methane production from a landfill. The first technique employs the use of mathematical models, while the second one requires site investigations based on pumping test trials, which are intended to identify the probable behavior of the gas in 
the landfill. Pumping test trials are very crucial if energy recovery and utilization are part of the gas collection scheme.

\subsubsection{Pre-Installation Assessment}

Prior to installing any gas collection system, it is important to collect pertinent information about the landfill site and learn every aspect in detail. The purpose of the task is to have a clear understanding of the type of problems. In order to achieve a realistic gas yield and production rate, it is necessary to collect the following information:

i) Period, method and rate of landfilling and Mass of waste in place,

ii) Landfill site dimensions and its cells,

iii) Type of waste and composition (i.e. domestic, industrial, commercial, inert and hazardous),

iv) Waste compaction, density and moisture content,

v) Internal temperature and $\mathrm{pH}$ of the waste,

vi) Site geology including any borehole logs, if available,

vii) Type of capping, daily cover, lining material

viii) Gas monitoring results if available,

ix) Meteorological conditions and rainfall data,

x) Water table and groundwater conditions and usage with seasonal variations,

xi) Topography and surface water run-off, etc.

\subsubsection{Modeling of LFG and Methane Production}

Once the above mentioned information as listed on section 4.2.1 are collected, the next step is estimation of the gas generation rates using one of the commonly used modeling techniques. Although methane generation rate (Lo) varies according to the type and condition of the waste, studies have shown that an average figure for gas yield of about $150 \mathrm{~m}^{3}$ for every wet tone (Eden, 1994). U.S. EPA recommends methane generation rate of $170 \mathrm{~m}^{3} / \mathrm{Mg}$ of waste placed in the landfill. Of this it is stated that about $70-80 \%$ would be recoverable. Though researched for years, practical measures of collection efficiency are lacking. Instead, a default efficiency of $75 \%$ based on surveys of industry 
estimates is commonly used, for example, by U.S. EPA (Huitric and Kong, 2006). Entering the required gas production parameters into the model, results in a gas production curves with exponential decay. These curves in conjunction with the expected recovery efficiency are useful tools for initial assessment and sizing of the required gas collection system, that could be used during planning stage.

\subsubsection{Pumping Test for LFG}

Pumping trial test for LFG is usually carried out after all the required data are gathered; also after estimation of the rate of gas generation is undertaken. The common method is conducting trial test in a small part of the site and then to extrapolate the results to incorporate the entire landfill site. At least two wells have to be drilled in the site in order to allow for possible blinding of extraction wells and to collate representative data from the site.

The main objective of the pumping test is to verify that the gas emission estimation carried out by the model is realistic and that the required design and construction of as collection facility under consideration are of the right magnitude and suitable for the entire system. Beside the probable quantity of gas to be collected, the data gathered during the pumping trial test give good information on the constituents and quality of the gas being produced. The objectives of pumping trial test could be summarized as follows:

i) Quantifying probable landfill gas production rates over a period of time while logging seasonal variations of collection. Besides, gas constituents and quality will be identified. 
ii) Investigation of the radius of the zone of influence between extraction wells. This is obtained using a number of piezometers around the test wells. Accordingly, the optimum spacing of wells can be decided.

iii) Defining well-head gas flow characteristics. These describe the behavior of individual wells under passive and active conditions and assists in determining the need for blower and its capacity for inducing pressure gradient.

iv) Distinguishing the required abstraction pressures, which in turn permit the correct sizing of the abstraction equipment.

v) Investigating the effect of active extraction on the incidence of far-field migration from the boundaries of a landfill site. This is of particular significance where the landfill site is located within or close to residential or sensitive areas.

\subsection{ATMOSPHERIC AND LANDFILL PRESSURES}

On previous sections it has been noted that gas transport within the landfill occurs principally by either convective or diffusive mechanism or both occurring simultaneously. During convective transport system gas flows because of pressure gradient; from higher pressure to lower pressure. Atmospheric pressure prevailing around the surface of the landfill has a significant influence on both the quantity and quality of gas collection system. The variations in atmospheric pressure have a profound negative impact on the efficiency of gas recovery process.

LFG tends to be contained within the landfill when the atmospheric pressure over the surface of the landfill is relatively more to that of pressure exerted by the gas in the landfill. The gas requires higher pressure than that of the atmosphere to push itself out of the landfill. Air might be forced into the landfill, if the landfill does not generate gas at a sufficient high rate. This phenomenon is critical for passive gas collection systems, 
in which the scheme is entirely dependent on higher pressure exertion from the gas in the landfill. Otherwise collection of the gas from the landfill will be either nil or minimal during situations when higher atmospheric pressure is practiced.

If active gas extraction system is used to collect gas from the landfill, the continuous withdrawal of the gas especially during periods of rapidly increasing atmospheric pressure can produce a vacuum in the landfill. Thus, it is possible for air to permeate into the landfill even on properly operated and managed landfill gas systems. This can cause low nitrogen-air to blend with the recovered gas creating a low quality gas. In such situations where a high BTU gas recovery is required, significant portions of the methane capture must be sacrificed to prevent air from infiltrating into the landfill.

The pressure inside the landfill is not constant; it constantly changes in response to the atmospheric pressure. When a decreasing atmospheric pressure is observed, the landfill internal pressure may exhibit greater pressure than the external pressure, thus causing a temporary increase in the flow rate of gas from the landfill. Conversely, periods of increasing atmospheric pressure could yield less gas to be vented. As a result, proper operation and management of the collection system, especially the way the blower functions is important.

\subsection{COLLECTION STRATEGY}

Basically, there are two gas collection strategies, namely, passive and active.

\subsubsection{Passive Gas Collection}

The basic principle of a passive collection system is that gas flow will occur as a result of the natural pressure gradient and/or convection mechanisms. These systems are provided with a barrier to intercept lateral gas migration and channel the gas to a collection point. The efficiency of a passive collection system depends on landfill cap, 
daily cover, lining material, barriers, etc., which render a good containment of the LFG within the landfill and prevent the gas from direct emission to the ambient air. A passive system makes use of venting; and in the event that the vent is blocked by moisture or frost, the gas seeks other escape routes including moving into surrounding formations. Since passive collection systems rely on natural pressure gradients and gas concentrations to drive gas away to the collection system, generally, they have lower collection efficiencies than active systems.

Passive systems are not considered reliable enough to provide an exclusive means of protection (USACE, 1995). Passive venting systems raise the potential for nuisance odor problems due to the fact that there is no control on the gas flows and no positive system for odor management.

Compared to active collection systems, the construction of passive systems is less complex since the collection well is under positive pressure. Air infiltration from the atmosphere is not as great a concern in passive systems. Besides, passive systems do not require well structured and intricate well head assemblies, because control and operation of the system are usually at minimum. Table 4.1 presents comparison among different gas collection systems.

\subsubsection{Active Gas Collection}

Active collection systems operate by inducing negative pressure, vacuum, within the collection well resulting in gas flow from the landfill to the wells. The applied vacuum creates a zone of negative pressure generating a pressure gradient towards a collection point which is either a well or horizontal collector pipe. Active collection systems have the capability for a strong and mechanically induced pressure gradient which is essential for proper and controlled gas flows. 
The basic operating procedure, during active collection system, is to exert a vacuum so as to extract the gases from the waste in a flow rate the same as to the rate of gas generation within the influence area of the well or trench. The ideal way of doing this is to establish a neutral pressure/vacuum gradient continuously over the entire surface of the landfill. Basically, active systems are utilized where there is a need for a higher degree of system reliability.

Table 4.1: Comparison of various gas collection systems

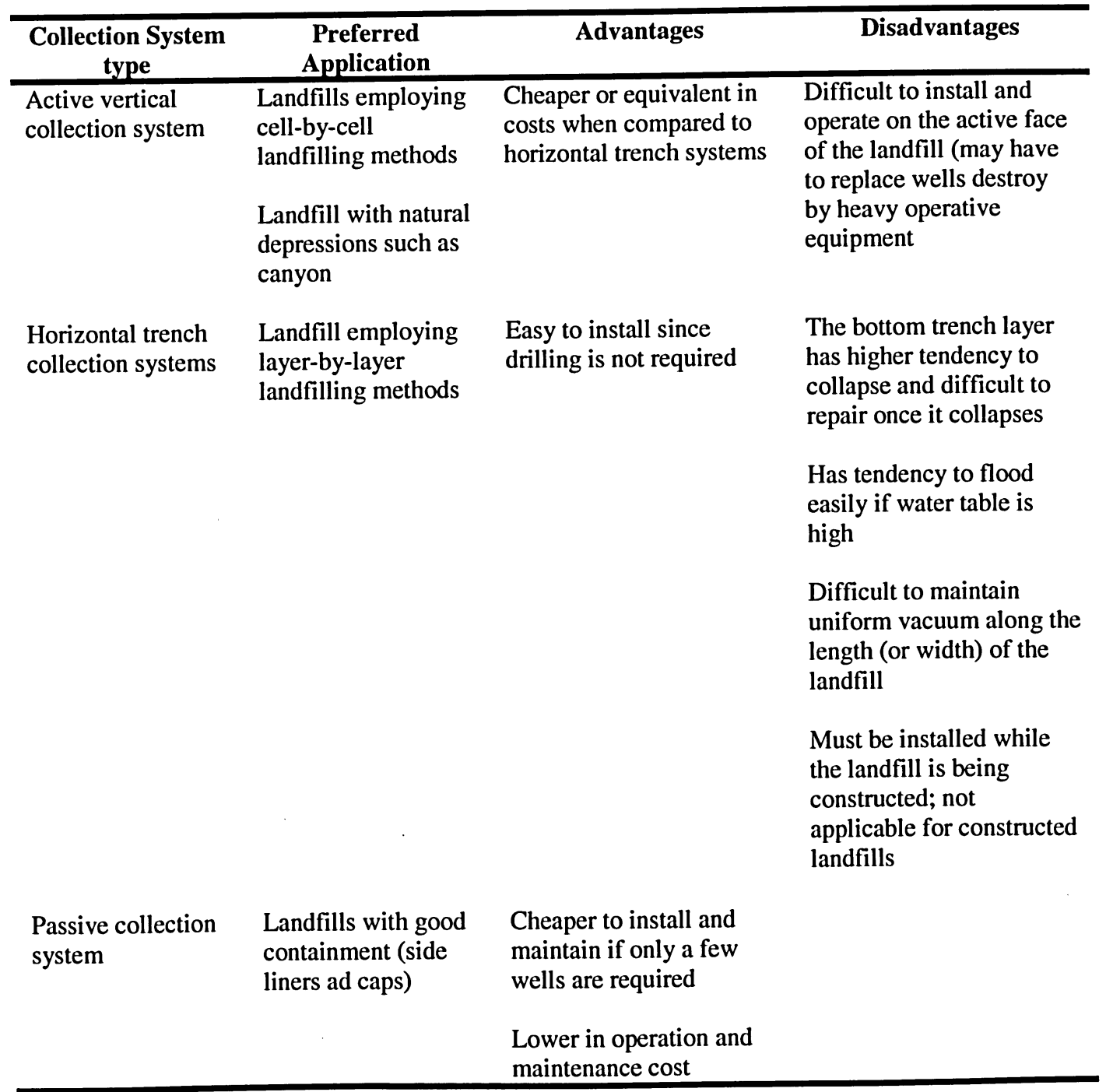

(Source: USACE, 1983, cited by USACE, 1995) 


\subsection{LFG COLLECTION SYSTEM}

A typical LFG collection system is comprised of the following components:

- LFG collection fields,

- Collection piping (laterals, sub-headers, headers, etc.),

- Condensate management and disposal system,

- Blower system and related appurtenances, (for active collection system) and

- Utilization and Flaring of LFG

\subsubsection{LFG Collection Fields}

Landfill gas collection fields are installed as networks to capture the gas from the landfill. They include a network of vertical LFG extraction wells and/or horizontal LFG collection trenches (see Figures 4.1, 4.2 and 4.3). Collection wells are created by incorporating perforated pipes, surrounded by gravel, natural stone or crush aggregate with a low calcareous content. The vertical collection wells can either be built during waste placement period or be drilled into the waste material of the landfill after closure of the landfill, using different design and construction techniques, which are dependent on site-specific conditions including depth of waste, gas generation rate, rate of waste infill, etc.

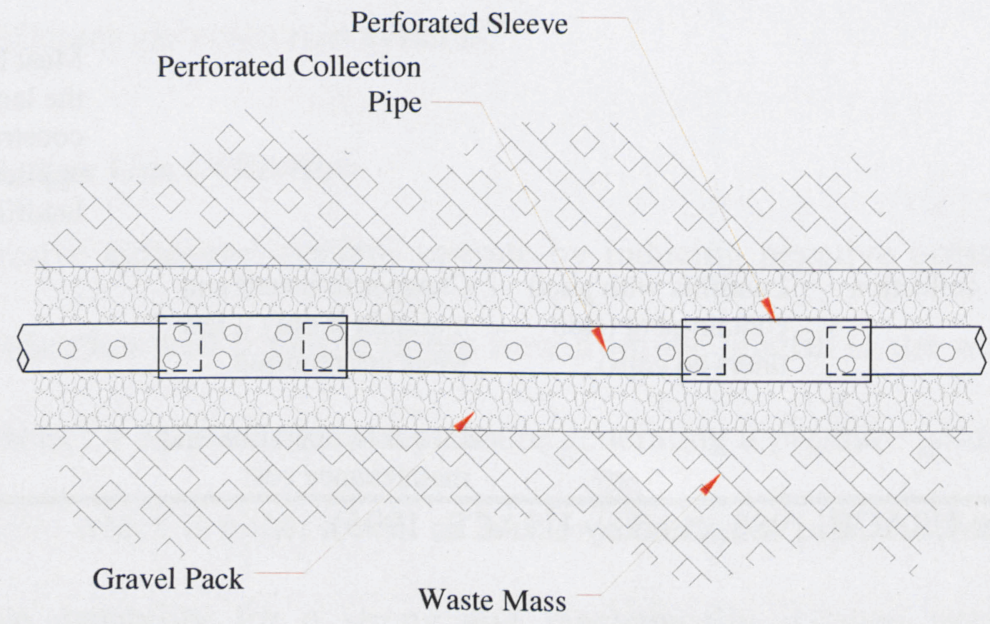

Figure 4-1: Typical horizontal gas collection trench (Profile-View) 


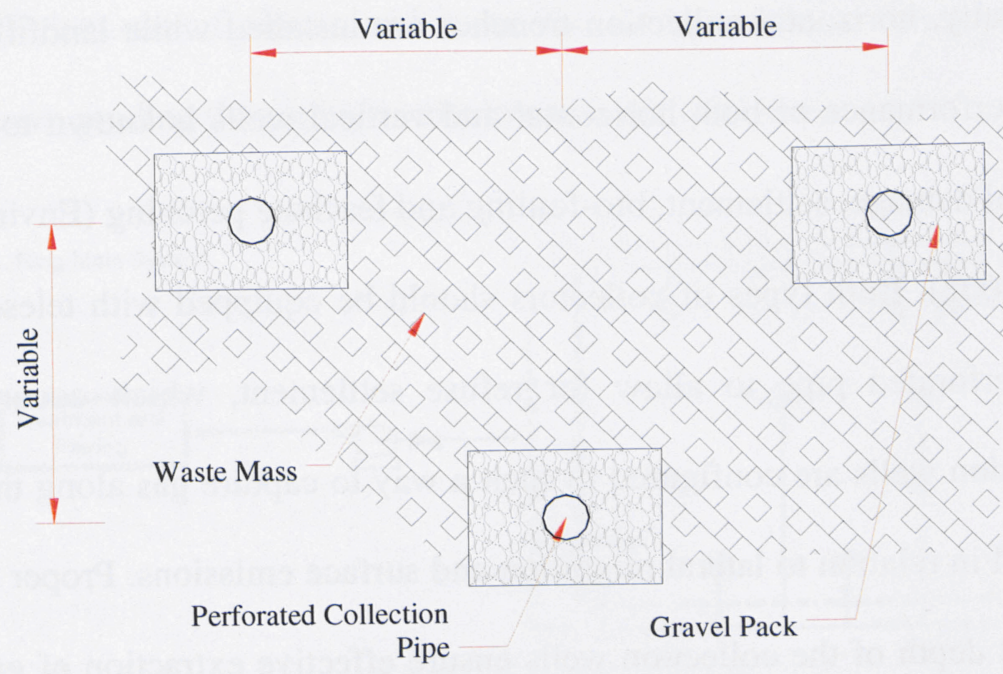

Figure 4-2: Typical horizontal gas collection trench (Cross-Section) (Source: Conestoga, 2004, Handbook for the Preparation of Landfill Gas to Energy Projects, The World Bank)

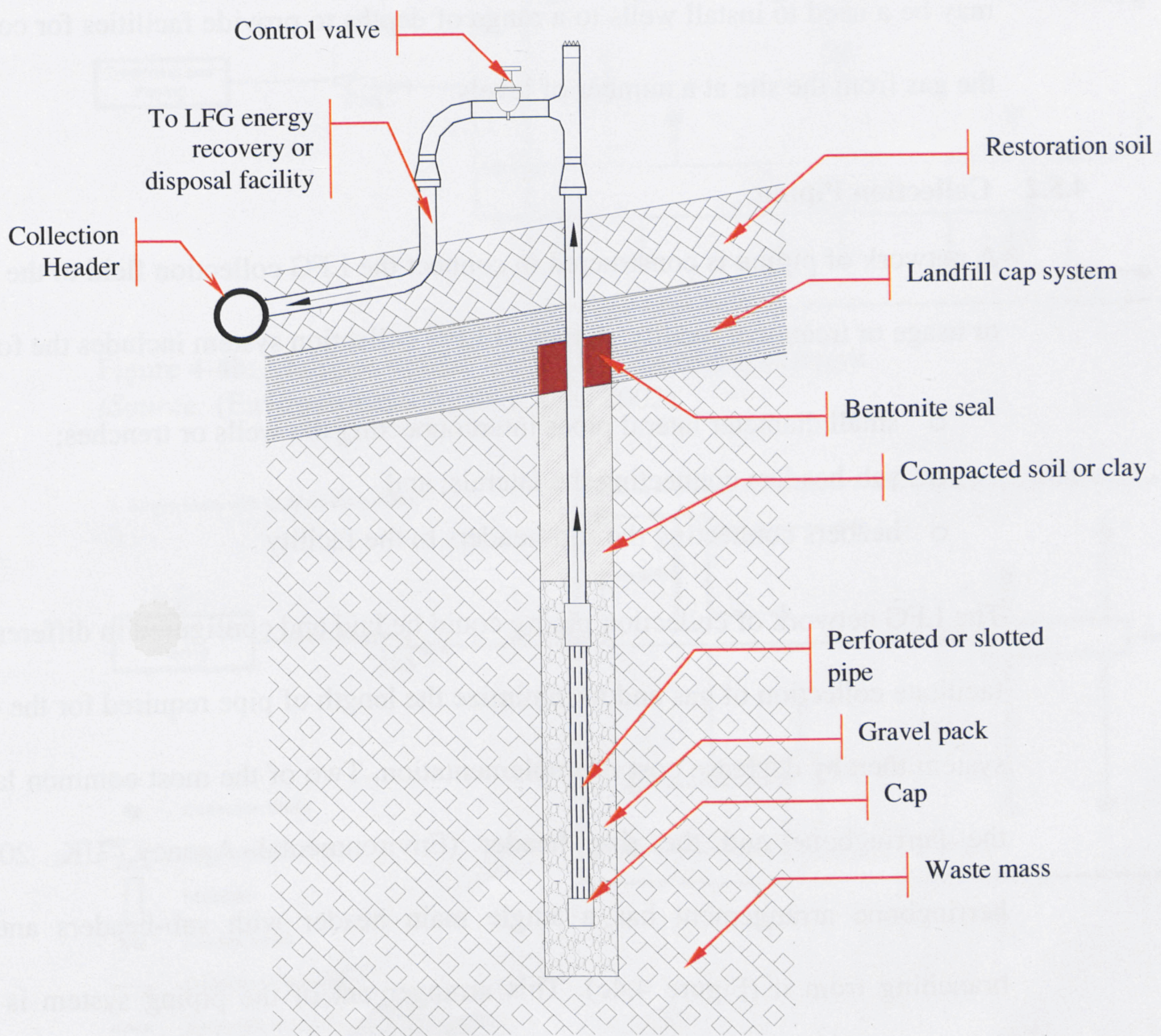

Figure 4-3: Typical vertical gas collection well

(Source: USACE, 1983) 
Generally, horizontal collection trenches are installed while landfilling is in progress. The performance of both horizontal and vertical wells is known to deteriorate due to general damage, settlement, bio-fouling and leachate perching (Environmental Agency, UK, 2002). Both types of collectors should be equipped with telescoping sections of non-perforated pipe to allow for refuse settlement, which occurs over time. Gas collection wells are configured in such a way to capture gas along the perimeter of the landfill in relation to lateral migration and surface emissions. Proper placement and the correct depth of the collection wells ensure effective extraction of gas from the waste.

The depth, spacing and layout will be dictated by the internal and external geometry of the landfill site, particularly in land raise or deeper landfills. In such instances there may be a need to install wells to a range of depths to provide facilities for collection of the gas from the site at a number of levels.

\subsubsection{Collection Piping}

A network of piping is constructed to connect the LFG collection field to the LFG flare or usage or treatment facility. A typical LFG collection system includes the following:

- small diameter lateral pipes interconnecting the wells or trenches;

- sub-headers connecting the laterals; and

o headers connecting the sub-headers to the facility

The LFG network of collection piping could be laid and configured in different ways to facilitate collection of gas and to minimize the length of pipe required for the collection system thereby decrease cost of implementation. Two of the most common layouts are the herringbone and the ring header (Environmental Agency, UK, 2002). The herringbone arrangement has a single main header with sub-headers and headers branching from it (Figure 4.4c). This arrangement of the piping system is the most 
efficient use of piping, and it can be laid to minimize the quantity of condensate, by down grading the piping works towards the LFG wells.

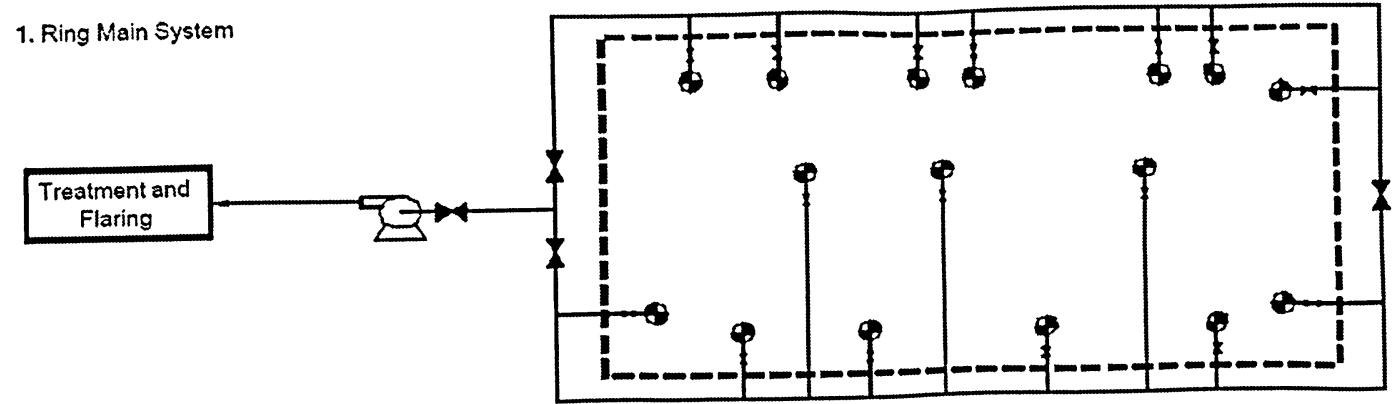

Figure 4-4a: Ring Main LFG collection network

(Source: (Environmental Agency, UK, 2002)

2. Muttiple Header System

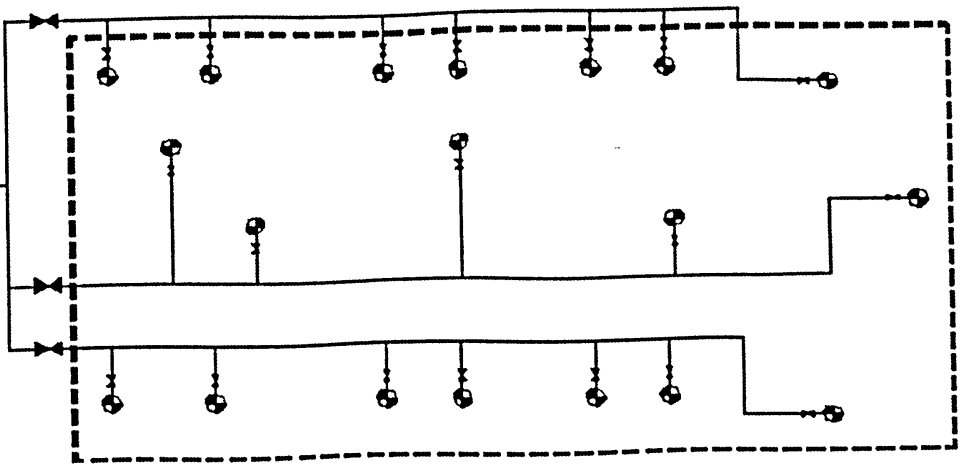

Figure 4-4b: Multiple Header Main LFG collection network

(Source: (Environmental Agency, UK, 2002)

3. Single Main with Outfield Regulation
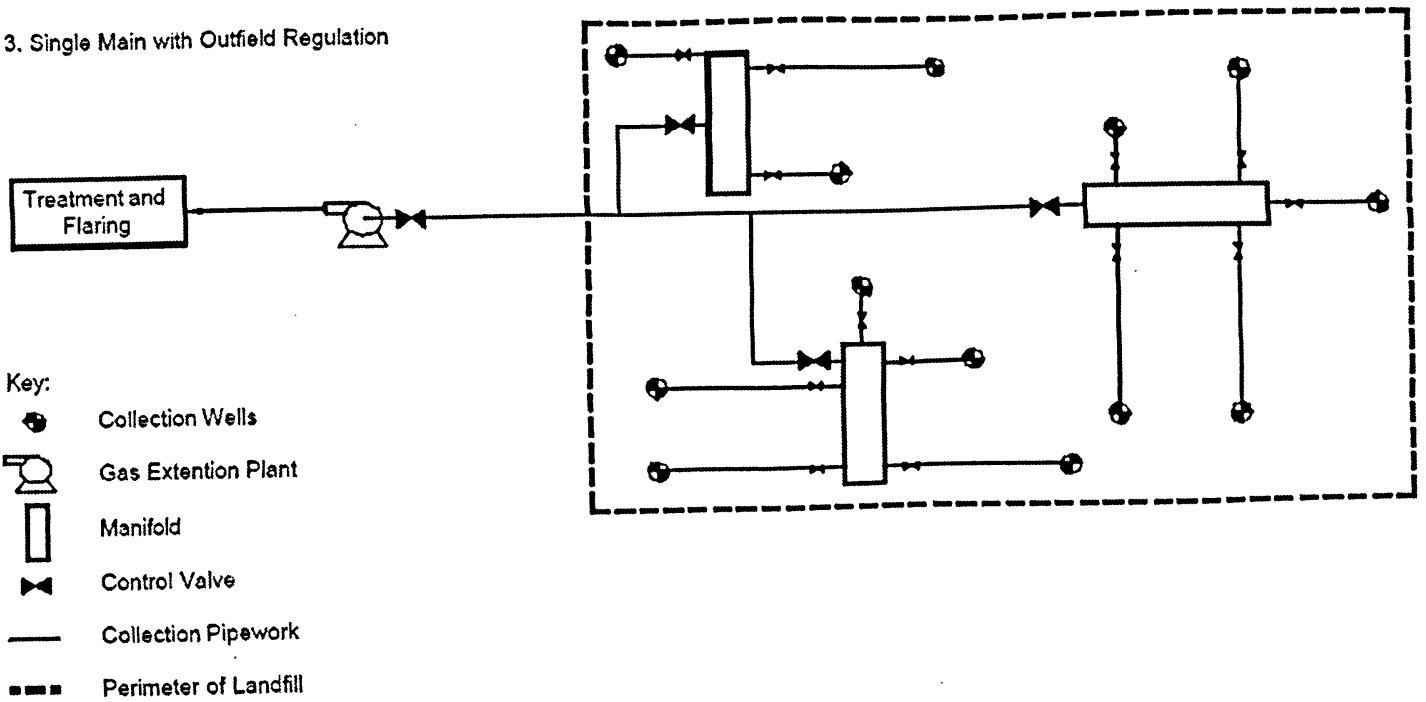

Figure 4-4c: Single Main with outfield Regulation collection network (Source: Environmental Agency, UK, 2002) 
The advantage of ring header (Figure $4.4 \mathrm{a}$ ) is that it can be used where availability of land for header construction out of the perimeter of the waste is limited. Usually, ring headers are fitted with valves in order to assist with isolation of portions of the site. Multiple header systems (Figure 4.4b) are mainly utilized wherever the landfill is large and deep and that has a long active site life. In such a way it facilitates the segregation of methane-rich gas that is found in the deeper portions of the site from the gas captured near the surface, which may be diluted because of air intrusion.

The collection piping system can be installed either above or under the ground based on site-specific conditions and cost parameters. Piping system above grade are the least expensive to construct. It is also important to note that high density polyethylene (HDPE) piping is highly recommended for most of the LFG piping and its price is largely controlled by the relative cost of petroleum and the proximity to suitable pipe manufacturing facilities (Conestoga Rovers, 2004, the World Bank - ESMAP).

\subsubsection{Condensate Drop-Out and Disposal System}

It has been noted earlier that one of the constituents of LFG is vapor and that the LFG is extremely moist. During anaerobic decomposition and when landfill gas is generated, the resulting gas mixture arises at a temperature typically in the range 30 to $40^{\circ} \mathrm{C}$ with a relative saturation at or approaching $100 \%$. When the collected gas flows through the piping network, it cools down letting the water vapor to form condensate, resulting in condensate accumulation within the pipe-works.

Condensate causes a reduction in the effectiveness of the collection pipes. It can also lead to complete blockages of the collection system and major disruptions. Hence, control measures have to be integrated into the management system so that the accumulation of condensate is avoided. The basic solution to the problem is to purge 
condensate accumulation in the collection system by utilizing well head de-watering, low point drainage through water-sealed traps, and collection and disposal at either a knockout vessel or at one or a series of drained manifolds.

Effective control approach depends on laying pipe runs to fall towards drainage sumps and having a minimum gradient of $2 \%$ (see Figure 4.5). If such falls cannot be achieved, due to any reason, then the pipe-work can be stepped to give a 'saw-tooth' alignment.

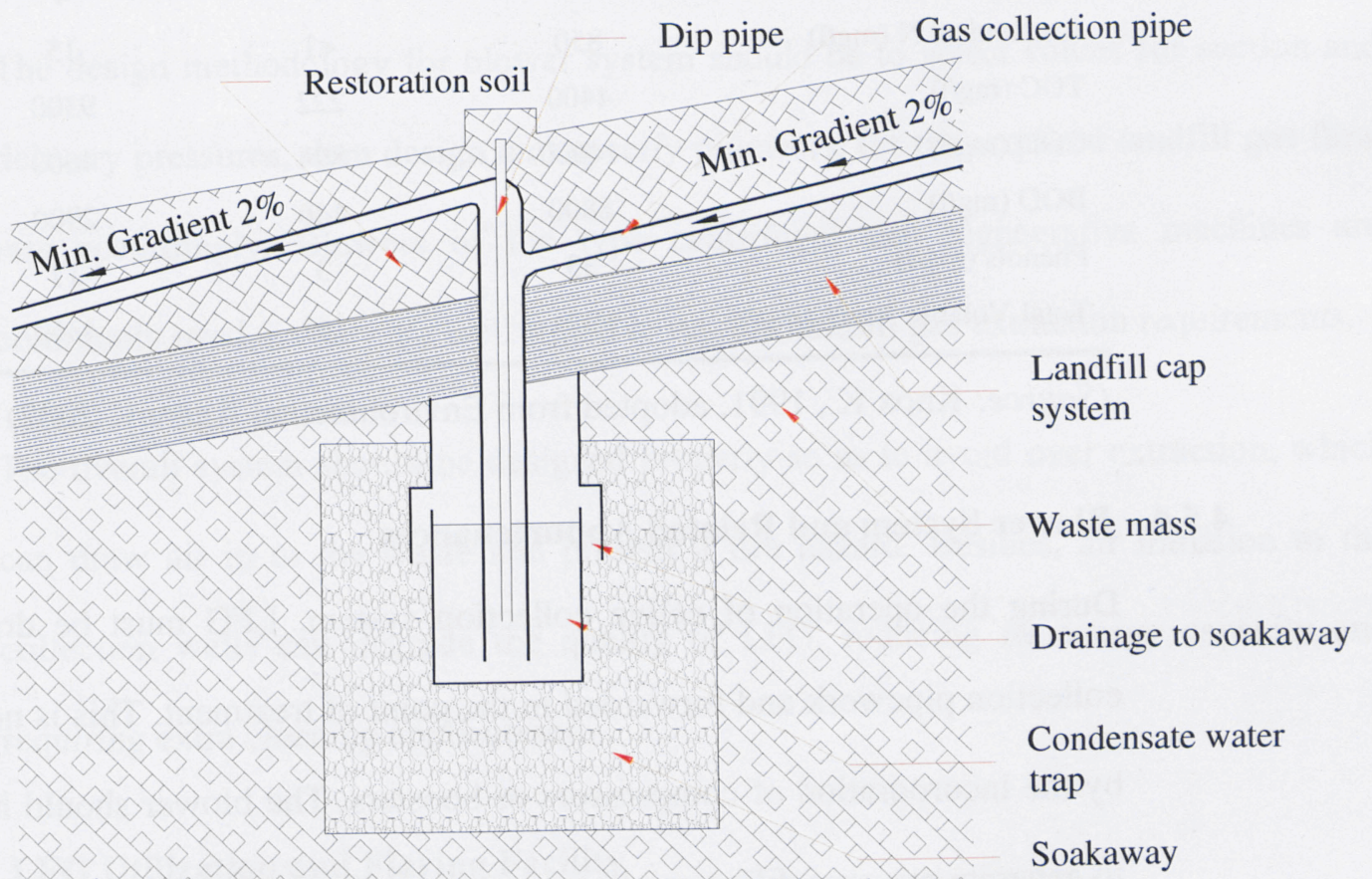

Figure 4-5: Typical condensate trap and collection pipe-works (Source: Environmental Agency, UK, 2002)

When the sump is filled up with condensate, it overflows to a soakaway pit packed with loose material or crashed stone or gravel and ultimately draining the condensate into the waste mass.

In case the condensate is removed from the sump using mechanical system like pump, it should be disposed in an environmentally sound manner, reducing the detrimental effects that the corrosive condensate may have on the LFG handling equipment. 
Condensate is generally more concentrated than leachate and may be considered a hazardous liquid waste in some jurisdictions (Christensen et al., 1989). Table 4.2 gives chemical properties of condensates from landfill gas.

Table 4.2: Typical characteristics of landfill gas condensate

\begin{tabular}{|c|c|c|c|c|}
\hline Component & Planint & Tlare & Gas Fiel & Drains \\
\hline (Parameter) & $\begin{array}{c}\text { Typical Upper } \\
\text { Values } \\
\end{array}$ & $\begin{array}{l}\text { Typical Lower } \\
\text { Values }\end{array}$ & $\begin{array}{c}\text { Typical Upper } \\
\text { Values }\end{array}$ & $\begin{array}{l}\text { Typical lower } \\
\text { values }\end{array}$ \\
\hline$\overline{\mathrm{pH}}$ & $\overline{7.6}$ & 4.0 & 3.9 & 3.1 \\
\hline Conductivity $(\mu \mathrm{S} / \mathrm{cm})$ & 5700 & 76 & 340 & 200 \\
\hline Chloride (mg/l) & 73 & 1 & 4 & $<1$ \\
\hline Ammonical N (mg/l) & 850 & $<1$ & 15 & 3 \\
\hline TOC (mg/l) & 4400 & 222 & 9300 & 720 \\
\hline $\mathrm{COD}(\mathrm{mg} / \mathrm{l})$ & 14000 & 804 & 4600 & 4600 \\
\hline BOD (mg/l) & 8800 & 446 & 2900 & 2900 \\
\hline Phenols (mg/l) & 33 & 3 & 17 & 4 \\
\hline Total Volatile Acids (mg/l) & 4021 & 141 & 4360 & 730 \\
\hline
\end{tabular}

(Source: Knox K., 1991, adopted from Environmental Agency, 2002)

\subsubsection{Blower System and Related Appurtenances}

During the operation of active collection system, LFG must be drawn through the collection pipework and forwarded to the point of treatment. This is normally achieved by the incorporation of compressors or boosters. The blower should have the capacity to generate pressure differential between the collection wells and the surrounding waste mass. Pressures losses from the collection wells up to the inlet of the compressor are called 'suction' losses, while from the exit of the compressor to the point of treatment as the 'delivery' losses. Basically, the magnitude of the suction and delivery losses is a function of the:

- gas flow rate;

- Pressure demand for a flare or utilization system being supplied with LFG.

- length and internal diameter of the pipes;

- smoothness of the pipes; 
- junctions and connection arrangements; and

- viscosity of the gas mixture.

The blower system includes all components that are used to generate and apply the vacuum to collect the LFG and supply it for its subsequent end use. The blower system components include:

- valves and controls as required for safe operation (e.g., a flame arrestor);

- LFG flow metering and recording; and

- blowers or compressors to meet capacity requirements.

The design methodology for blower system should be to select values for suction and delivery pressures, then design and specify pipework for the required landfill gas flow rate accordingly. Blowers of the type centrifugal and regenerative machines are commonly used, as they are well suited to typical landfill gas extraction requirements.

The overall system should be designed properly so as to avoid over extraction, which can draw air in to the waste and present a fire hazard. Besides, air intrusion to the collection wells can degrade the quality of LFG, reducing its energy capacity and requiring extra cleaning applications.

\subsubsection{LFG Utilization and Flaring Facility}

Both utilization and flaring recover the energy content of the LFG and form an off gas, which is environmentally acceptable for direct discharge to atmosphere.

A. Utilization: In many cases where large municipal landfills exist, LFG is extracted as an energy resource. Generally, the collection of gas for energy recovery purposes has been limited to large landfills with over 1 million tons of solid waste in place (USACE, 1995). There are a number of technologies available to recover the energy from the LFG and potentially provide a supplementary source of income to the landfill through 
the sale of LFG related products. However, the main LFG energy recovery systems are focused on the following four points:

- Use of LFG to fuel gas turbine;

- Generation of electricity using internal combustion engine with LFG;

- Use of LFG directly as a boiler fuel; and

- Upgrading the gas quality to pipeline quality for utility distribution systems.

Typical LFG contains approximately $4,450 \mathrm{~K} \mathrm{cal} / \mathrm{m}^{3}$ (3500 Btu per standard cubic foot) of energy whereas pipeline-quality gas contains $6,900 \mathrm{~K} \mathrm{cal} / \mathrm{m}^{3}(1,000 \mathrm{Btu} / \mathrm{scf})$ (USACE, 1995). Apart from the waste composition, type and landfill design and environment, the energy content of LFG varies widely depending upon the performance of the gas collection system and the stage of decomposition within the landfill. The purification and cleaning of LFG to pipeline quality and as vehicle fuel will be discussed in Section-5. Depending upon the application and utilization, the raw LFG collected from the landfill may require some level of purification prior to being utilized. LFG can be classified into three categories, shown in Table 4.3, based on the level of pretreatment or processing prior to utilization (Conestoga Rovers, 2004, the World Bank - ESMAP). These are:

Table 4.3: LFG classification according to the level of treatment

Classification

Low-grade LFG fuel

Medium-grade fuel

High-grade fuel
Requires minimal processing, involving condensate removal chamber(s) as part of the LFG collection system and moisture knockout pots to reduce the amount of moisture in the gas stream.

Additional gas treatment devices required to extract more moisture (with contaminants) and finer particulate matter. The process typically involves compression and refrigeration of LFG and/or chemical treatment or scrubbing to remove additional moisture and trace gas compounds such as mercaptans, sulfur compounds, siloxanes, and volatile organic compounds.

Involves extensive gas pretreatment to separate the carbon dioxide and other major constituent gases from the methane and to remove impurities including mercaptans, sulfur compounds, hydrogen sulfide and volatile organic compounds, and gas compression to dehydrate the gas. 
Low and medium grade LFG fuels have a heating value of approximately $16.8 \mathrm{MJ} / \mathrm{m} 3$.

This heat value is roughly one-half the heating value of natural gas. While high grade

LFG fuel, which has been additionally treated and processed has a higher heating value of $37.3 \mathrm{MJ} / \mathrm{m} 3$, and can be substituted directly for natural gas in pipeline applications.

Table 4.4 gives the application and utilization of the LFG based on its grade.

Table 4.4: LFG utilization based on its grade

\begin{tabular}{|c|c|}
\hline Low-grade LFG fuel & $\begin{array}{l}\text { - Heating: on-site or off-site furnace, drying kiln, or boiler } \\
\text { - } \frac{\text { Boiler / Steam Turbine: to produce steam for heating or }}{\text { electricity generation }} \\
\text { - Microturbine: electrical power generation or heat for } \\
\text { combined heat and power applications }\end{array}$ \\
\hline Medium-grade fuel & $\begin{array}{l}\text { - Heating: used in industrial boilers, dryers, kilns, or gas } \\
\text { furnaces } \\
\text { - } \frac{\text { Reciprocating Gas Engines: electricity generation }}{\text { - } \text { Gas Turbines: electricity generation }} \\
\text { - } \frac{\text { Combined Cycle Systems: using gas turbine and steam }}{\text { turbine for electricity generation }}\end{array}$ \\
\hline High-grade fuel & $\begin{array}{l}\text { - Pipeline Quality Gas: direct substitute for natural gas for natural } \\
\text { gas utility and industrial users } \\
\text { - } \frac{\text { Commercial Sale of Carbon Dioxide: largest use of carbon }}{\text { dioxide is in the food processing and beverage industries }} \\
\text { - Chemical Products Production: for production of methanol, } \\
\text { fertilizers, fuel cells } \\
\text { - Fuel Cells: for production of hydrogen (for energy purpose) } \\
\text { - Vehicle Fuel: Compressed LFG (CNG) and Liquefied LFG } \\
\text { (LNG) }\end{array}$ \\
\hline
\end{tabular}

B. Flaring: In the absence of any utilization of LFG, the gas is flared. Besides, flares are also employed as a backup facility to treat gas in periods of utilization downtime. LFG flaring results in conversion of methane, found in LFG, to carbon dioxide and water. The combustion of LFG also guarantees the destruction of the trace compounds in LFG. Table 4.5 gives the stack emission from landfill gas combustion system. The collection and flaring of LFG is an effective means of LFG management and disposal 
in environmentally sound manner, which also reduces odor and migration problems. In addition, flaring LFG converts the methane in LFG to carbon dioxide, effectively reducing its GHG (greenhouse gas) potential. It is advisable to incorporate LFG flaring facility as a backup with utilization systems, in that it can be used whenever there are lengthy downtimes during equipment maintenance or system breakage. The capacity of the flare system must be compatible with the operational parameters of the site over time, and this is particularly important where they are used in conjunction to utilization as standby or control for excess gas.

Table 4.5: Stack emissions after landfill gas combustion.

\begin{tabular}{cc}
\hline Constituents & Volume \\
\hline $\mathrm{CO}_{2}$ & $66.7 \%$ \\
$\mathrm{H}_{2} \mathrm{O}$ & $15.6 \%$ \\
$\mathrm{~N}_{2}$ & $17.7 \%$ \\
$\mathrm{CO}$ & $24 \mathrm{ppmv}$ \\
$\mathrm{NO}_{x}$ & $21 \mathrm{ppmv}$ \\
$\mathrm{SO}_{2}$ & $33 \mathrm{ppmv}$ \\
$\mathrm{HC}$ & $2 \mathrm{ppmv}$ \\
\hline
\end{tabular}

(Source: Natural Resources Canada, 2007)

Flaring of landfill gas is either done in open-flame flares (candle flare) or closed flares. An open-flame flare or candle flare are historically the first generation of flares. The open-flame flare was mainly used for safe disposal of combustible gas when emission control had not been a requirement. With the use of open flame flares, there is no reliable means to monitor for dioxins or other toxic emissions.

Enclosed flares differ from open flares in that both LFG and air flows are controlled. Enclosed flares involve enclosing the flame in an insulated cylindrical shroud. Some enclosed LFG flares have exit temperatures of around $1400^{\circ} \mathrm{F}$. While LFG is pushed through the flame arrestor and burner tips by a blower, the flare stack pulls or drafts the air through air dampers and around burner tips. The stack acts as a chimney, so its 
height and diameter are critical in developing sufficient draft and residence time for efficient operation. The optimal stack height will depend on the exit velocity, the pollutant loading, the retention time required (typically 0.3 seconds at 1000 degrees centigrade), location of the flare in relation to receptors and the surrounding topography.

\subsection{RADIUS OF INFLUENCE OF EXTRACTION WELLS}

The spacing of LFG extraction wells is basically determined from the radius of influence of individual wells. This radius is described as the distance from the center of a well to a point away from the well where the steady-state-pressure gradient resulting from the blower is 0.1 inch of water (USACE, 1995). As a consequence, any LFG generated beyond the radius of influence would not be collected by the extraction wells. Current evidence indicates the radius of influence of a well tends to change as the availability of gas within the vicinity of the well changes. For this reason, it is not possible to define a single radius of well influence (Prosser, 1985). Therefore, in order to obtain a representative well spacing for the landfill, several pump tests should be performed so that waste compaction variability and difference in gas availability can be taken into consideration.

Conducting pumping test trials is a very costly venture. Hence, there are several theoretical models developed to estimate the vacuum radius of influence relationship. Typical negative pressures at the well head range from about 127 to $380 \mathrm{~mm}$ of water column. Typical well spacing ranges from approximately 15 to $100 \mathrm{~m}$, depending on the radius of influence for each well (Environmental Agency, UK, 2002). 
The desired method for determining effective well spacing at a specific landfill is to use field measurement data. Pump tests with monitoring probes at incremental distances from the test well will indicate the influence of a given negative pressure at that location.

The EPA Methods specified in the New Source Performance Standards (NSPS) draft rule (March 1991) use Darcy's law to establish the vacuum/radius of influence relationship. Knowledge of the following parameters are essential in order to realistically come up with the radius of influence:

- daily and final cover materials used in landfill construction,

- gas properties including density and viscosity,

- permeability of the porous media (both the refuse and cover), and

- gas pressure within the landfill

Since extensive data are rarely available or accurately obtained, EPA recommends a default maximum radius of influence of $60 \mathrm{~m}$ in revisions for publication of the final NSPS scheduled for December 1994. Use of this default parameter or the theoretical modeling is generally acceptable for estimating the radius of influence.

As noted above, use of the theoretical models based on Darcy's Law requires estimation of several parameters. The parameters required include:

- intrinsic permeability of the refuse,

- current gas production rate of the landfill,

- static pressure at the wellhead,

- viscosity of the LFG,

- radius of the extraction well;

- length of well screen (slotted or perforated part); and

- radius of influence of the well borehole. 
Of these parameters, the intrinsic permeability of the refuse is the most difficult to predict. This parameter can vary several orders of magnitude between and within a landfill. This parameter has a large impact on the radius of influence predicted by the methodology. When the model is used for prediction of the radius of influence about a well, it is recommended that the model be used to solve the refuse intrinsic permeability to verify that the remaining parameters used predict a value for the intrinsic permeability which falls within a common range of intrinsic permeabilities for refuse $\left(1 \times 10^{-7}\right.$ to $\left.1 \times 10^{-12} \mathrm{~cm}^{2}\right)$.

The static pressure at the well head is the difference between landfill internal pressure and the atmospheric pressure and is the design vacuum pressure at the well head. The magnitude of the static pressure is a function of how much LFG is being produced and how impervious the capping materials are to gas migration. Where gas production rates are high and the landfill cover impervious, static pressures at the wellheads can be as high as $375 \mathrm{~mm}$ water column (wc). It is more common for wells to have static pressures in the range of 180 to $255 \mathrm{~mm}$ wc.

Viscosity of the LFG will be a function of the composition, the pressure and the temperature of the LFG. The viscosity can generally be approximated assuming the gas is composed of $50 \% \mathrm{CH}_{4}$ and $50 \% \mathrm{CO}_{2}$. At $0^{\circ} \mathrm{C}$ and at atmospheric pressure, a $50 \%$ $\mathrm{CH}_{4}$ and $50 \% \mathrm{CO}_{2}$ gas has a viscosity of $1.21 \times 10^{-5} \mathrm{~Pa}$. sec.

The intrinsic permeability can be computed as follows:

$$
K_{i}=\frac{P_{v} * R^{2} * \ln \left(\frac{R}{r}\right) * \mu_{L F G} * \rho_{R E F} * Q * E_{a}}{M *\left(P_{1}^{2}-P_{v}^{2}\right) *\left(\frac{W D}{L}\right)}
$$

where, 


$$
\begin{aligned}
& \mathrm{ki}=\text { intrinsic permeability of refuse, } \mathrm{cm}^{2} \\
& \mathrm{P}_{1}=\text { gage internal landfill pressure, } \mathrm{Pa} / \mathrm{m}^{2} \\
& \mathrm{P}_{\mathrm{v}}=\text { gage vacuum pressure at wellhead, } \mathrm{Pa} / \mathrm{m}^{2} \\
& \mathrm{R}=\text { radius of influence, } \mathrm{m} \\
& \mathrm{r}=\text { radius of well borehole, } \mathrm{m} \\
& \mu_{\mathrm{LFG}}=\text { viscosity of } \mathrm{LFG}, \mathrm{Pa} . \mathrm{sec} \\
& \rho_{\mathrm{REF}}=\text { refuse density, } \mathrm{kg} / \mathrm{m}^{3} \\
& \mathrm{Q}=\text { LFG generation rate, } \mathrm{m}^{3} / \mathrm{sec} \\
& \mathrm{Ea}=\text { efficiency of collection system, }(1=100 \%) \\
& M=\text { Landfill capacity, } \mathrm{Mg} \\
& \mathrm{WD}=\text { Well screen length, } \mathrm{m} \\
& \mathrm{L}=\text { Landfill depth, } \mathrm{m}
\end{aligned}
$$

For the design purpose, a value of 1.0 is normally used for the efficiency, Ea, of collection system.

\subsection{DESIGN CONSIDERATIONS FOR LFG EXTRACTION SYSTEM}

Generally, the design consideration for LFG extraction process undergoes two important stages. The first stage focuses on assessments to determine the technical and economical viability of the overall LFG recovery system; while the second stage stresses on the design of a full-fledged LFG extraction system.

\subsubsection{Stage-1: Assessment and Investigation}

Assessment and investigation activities are mainly comprised of the following steps:

- Collection of existing data,

- perform interviews and preliminary site inspections,

- review and analysis of base data and information,

- carryout screening process, and 
- undertake field tests.

Existing site data include waste volumes, waste type, gas data, leachate data and groundwater data, closure date, etc. The information of the site assist in establishing a data base for conducting design calculations.

Inspection of the site and its surroundings will aid in verifying the data collected and at the same time configuring the conceptual design of the LFG collection and recovery system. To help with the setup of the preliminary design activities, the screening process has to take into account recovery technique; regulatory requirements for collection and treatment; comparative cost; and advantages and disadvantages of each technique.

LFG quality and quantity of the specific landfill site are required to undertake a proper design of LFG collection and treatment systems. If the landfill site under consideration is an existing one data collection can be undertaken as described in Section 4.2 (Assessment of Gas Production). However, if the landfill is new, then certain assumptions must be made on the chemical and physical characteristics of the gas based on historical data from similar installations around the locality. In any case, for existing landfills, pilot scale field testing should be conducted to determine a number of parameters including characterization of the gaseous emission as listed below:

- a measure of the pressure distribution associated with an applied vacuum,

- gas flow rates,

- contaminant concentrations and recovery rates,

- gas-phase permeabilities at the site, and

- moisture removal rates. 
Ones all the required investigation and assessment are carried out, an LFG control and treatment system that meets the needs of a specific landfill site conditions could be decided. Following this investigation, the following step is detail design of the system

\subsubsection{Stage-2: Design Stage}

The primary design elements of the LFG management system include gas collection and treatment. Presented below are design considerations of these systems.

\subsubsection{LFG Collection Wells}

It has been discussed earlier that there are two types of LFG collection systems; passive collection and active collection. Passive collection system makes use of either vertical wells or trenches to collect LFG. Basically, passive systems rely on natural pressure gradient and concentration differences and their efficiency is dependent mainly on good containment of the LFG. Typically the wells and trenches use vent pipes which either discharge the gas to the atmosphere after flaring or to a treatment facility. Since the objective of this paper is focused principally on LFG extraction with the purpose of purifications to high grade fuel, then the emphases is on active collection systems.

Active collection wells utilize mechanical blower or compressor to generate a vacuum and pressure gradient thereby facilitate LFG flow to the gas extraction wells or collection trenches. The gas is then piped to a flare, cogeneration unit or other treatment system. An effective collection system should be designed and configured so as to:

- handle the maximum LFG generation rate,

- effectively collect LFG from all areas of the landfill, and

- provide the capability to monitor and adjust the operation of individual extraction wells and trenches. 
Air intrusion is a major concern in the design of the active LFG collection system. Air intrusion may naturally permeate through the landfill cover and into the refuse.

\subsubsection{Extraction Well Construction}

The construction of LFG extraction wells includes the installation of the wells around the perimeter and into the center of the landfill so as to effectively capture LFG. Extraction wells are usually constructed of PVC, HDPE, fiberglass, stainless steel, or other suitable nonporous material. Pipe diameters vary but generally are not smaller than $50 \mathrm{~mm}$ in diameter and not larger than $300 \mathrm{~mm}$ in diameter. It is recommended that the bottom $3 / 4$ of the pipe be perforated with $12 \mathrm{~mm}$ diameter holes spaced at 90 degrees every $150 \mathrm{~mm}$. Slotted pipes having equivalent perforations (opening space) is also suitable. Wells are typically constructed in 30 to $100 \mathrm{~cm}$ diameter boreholes.

Upon insertion of the casing into the borehole, the remainder of the well excavation is backfilled with crushed stone. The crushed stone gives the extraction well a larger effective diameter from which gas can be drawn into. Wells are typically constructed to $75 \%$ of the landfill's total depth in order to avoid damaging the liner. The screened interval of an LFG extraction well typically extends from the bottom of the well to a point at least $150 \mathrm{~cm}$ below the landfill surface. Slip couplings are also used for deep wells to account for differential settlement within the landfill. Slip couplings should be designed to withstand circumferential pressure without collapsing. Each well head is typically designed with a butterfly or ball valve for regulating the applied pressure to the wellhead.

\subsubsection{Spacing and Number of Wells}

Well spacing is usually fixed after undertaking trial pumping tests. Typical well spacing ranges from approximately 15 to $100 \mathrm{~m}$, although it depends on the radius of 
influence for each well. EPA has established a default maximum radius of influence of $60 \mathrm{~m}$ in revisions for publication of the final NSPS scheduled for December 1994. Use of this default parameter or the theoretical modeling is generally acceptable for estimating the radius of influence (cited at USACE, 1995).

Typically, well radius of influence and spacing, and landfill geometry influence the number of extraction wells to be installed. For effective gas capture and control, some overlap of influence zone is advisable.

\subsubsection{Equipment for Gas Flow Transport}

Gas moving equipment in this context is composed of pipeline header system and compressors and blowers. A pipeline header system conveys LFG flow from the well or trench system to the blower or compressor facility. A typical header pipe material is made up of PVC or HDPE; and it is generally 150 to $600 \mathrm{~mm}$ in diameter, although it depends on the flow rate through each section of the pipe. The size and type of blower is a function of the total gas flow rate, total system pressure drop, and vacuum required to induce the pressure gradient.

\section{A. Header Pipeline:}

Collection header pipes are connected to the gas extraction wells by means of flexibletube-laterals. The flexible tubing allows some movement between the two systems, which prevents breakage or dislodging of the pipes during settlement. The header pipe is often installed, in colder climates, above the low permeability layer of the capping system; while in warmer climates, it can be installed above the surface of the landfill. The exposed collection header is favorable with respect to ease of maintenance.

Vertical stresses in landfills cause landfill settlements. The vertical stresses are mainly as the result of the refuse and cover materials, and due to the biological decomposition 
of the waste material, which give way to settlement. Differential settlements can cause structural damage to the piping in the form of sags and breaks. From the point of landfill settlement and its consequences, a collector header that is not buried will be easier to repair.

Sizing of LFG headers is undertaken in accordance with the design flow rates generated from the well system. Each section of the header should be designed to transmit the design volumetric flow rate at a velocity that will minimize friction losses and condensate losses in the header system. The first step in estimating the diameter of the header is to estimate the flow rate through each section of header. This calculation will provide an estimate of gas flow rate per linear meter of pipe. The gas flow from each well can then be estimated by multiplying the length of well screen of each well by the flow rate per linear meter of screen. The diameter of each header pipe can then be calculated using the following equation (Martin and Fujii, 1985, cited by USACE, 1995):

$$
D=1.414 *\left(\frac{W^{0.408}}{\rho^{0.343}}\right)
$$

where,

$$
\begin{aligned}
& \mathrm{D}=\quad \text { Diameter of header, } \mathrm{cm}^{2} \\
& \mathrm{~W}=\quad \text { flow rate, }(1,000 \mathrm{lb} / \mathrm{hr}) \\
& \rho=\quad \text { gas density }\left(\mathrm{lb} / \mathrm{ft}^{3}\right) \\
& 1.414=\text { conversion factor }
\end{aligned}
$$

In general, pipe diameters of the header system should be no less than $100 \mathrm{~mm}$ in diameter; a $150 \mathrm{~mm}$ diameter is typical. Piping headers must be designed and constructed in a manner not to allow condensate to accumulate inside them. A 
minimum header slope of $2 \%$ is often used. Condensate sumps should be located at all low points in the header system to prevent clogging of the header.

\section{A. Compressors and Blowers}

There are a number of compressors and blowers available, used to remove LFG from landfills. Among them multistage centrifugal blowers, regenerative blowers, rotary lobe compressors, and liquid ring vacuum compressors are the most common. The selection of the right LFG compressors and blowers is a function of gas quality, peak gas flow rates, design vacuum pressure, and the pressure required for in-line processing of the gas. They should be designed to accommodate for peak LFG flow rate over the life of the LFG project. Sizing of a blower/compressor is based on:

- Total flow (Q) for the entire landfill;

- Design operating pressure; and

- Estimated head-loss in the system.

Pipe losses can be calculated using Darcy-Weisbach equation (Eq. 4-3) and the Moody Diagram for friction factor in the pipe versus Reynold's number and relative roughness.

$$
h_{f}=f * \frac{L}{D} * \frac{V^{2}}{2 g}
$$

where,

$$
\begin{array}{ll}
h_{f}= & \text { head loss due to friction } \\
f= & \text { Darcy friction factor } \\
L= & \text { length of pipe } \\
D= & \text { diameter of the pipe } \\
V= & \text { velocity of the flow, } \\
g= & \text { standard constant for acceleration due to gravity. }
\end{array}
$$

Selection of blowers should be based on the following:

- simplicity of installation;

- long-life expectancy; 
- cost effectiveness;

- minimum maintenance;

- variable load capacity;

- a low gas leakage rating under operating conditions; and

- safety of operation.

\subsubsection{Condensate Control System}

Condensate management should be one of the key design elements of a LFG system. The main component of condensate control is water scrubber or knockout vessels. They are employed to remove liquids, with the prime purpose of preventing corrosion or line freeze-ups. Condensates, if not removed they get collected in the bottom part of the collection systems and plug the pipes, preventing gas flow and ultimately resulting in inefficient gas extraction system.

Condensate sumps and traps must continuously drain condensate from the system under both negative and positive operating pressures while maintaining an air-tight seal between the collection system and the atmosphere. A check valve is usually installed at the outlet of the trap to prevent air or water flow back into the pipe. The water traps should be able to withstand a minimum of 12 inches of water column more than the anticipated design vacuum in the system. They are generally installed at the lowest points in the collection header system. The quantity of condensate generated is dependent on the temperature and moisture content of the extracted LFG and the ambient air temperature. Site specific samples of the LFG can be collected and analyzed for their moisture content and temperature. If trial pumping test is not available, estimates can be made assuming the LFG is saturated with moisture. Inserting temperature probes into the landfill could give the site-specific temperature of the gas. It can also be quantified based on literature values for landfills similar in composition, age and dimension. The estimation of the generated condensate can be 
computed under the assumption that the condensate is similar in density to water and LFG similar to air. Accordingly, the volume of condensate can be calculated using psychometric charts (developed for properties of steam), concentration of condensate in LFG, humidity of the moist air, specific volume of the moist air.

Landfill gas is rarely saturated and the header piping system's ambient temperature is basically higher than the ambient temperature of the surrounding soils or air. As a result, the magnitude of the condensate estimated using this approach yields a conservative value. It is suggested to carryout a thermodynamic balance of the system, in case a higher degree of accuracy is required (USACE, 1995).

Condensate removal in a knock-out pot occurs generally due to pressure drop. The estimation for the quantity of condensate that forms as a result of a pressure drop can be performed using the following equation.

$$
Q_{\text {cond }}=\frac{0.0203 * Q_{T O T}}{760-1.87 * \Delta P_{T O T}}
$$

where,

$$
\begin{array}{ll}
Q_{\text {cond }}= & \text { flow rate of condensate, } \mathrm{m} / \mathrm{min}^{3} \\
Q_{T O T}= & \text { total gas flow rate, } \mathrm{m} / \mathrm{min}^{3} \\
\Delta P_{T O T}= & \text { total pressure drop, } \mathrm{N} / \mathrm{m}^{2}
\end{array}
$$

Disposal of LFG condensate could be carried out using one or combination of the following options:

- disposal at a treatment plants through sewer lines or after transportation using tank trucks,

- treatment at site,

- inserting it back into the landfill,

- treatment lagoons, and

- LFG flare. 


\section{PURIFICATION OF LANDFILL GAS}

\subsection{GENERAL}

Presently, there are more than 1100 full-scale landfill gas recovery projects worldwide, including approximately 180 in Germany, 150 in the UK, 135 in Italy, and more than 350 in the US (Willumsen, 2003). Landfill gas is used on-site to generate electricity using internal combustion engines or gas turbines. It is also utilized to produce a substitute natural gas suitable for compression or pipeline transport vehicle use, but only after undergoing certain purifications and treatments. Electrical projects range from smaller microturbines to a large $25 \mathrm{MW}$ steam turbine [the City of Montreal electricity generation from landfill, Quebec, Canada (Natural Resources Canada, 2007)].

LFG is approximately $50 \%$ methane and $50 \%$ carbon dioxide. Besides, it is a moist gas with variable concentrations of a number of trace gases (like $\mathrm{H}_{2} \mathrm{~S}$ ) that require purification prior to utilization. With its $50 \%$ methane content, LFG can be considered a low to medium grade fuel, which can be used for on-site generation of electricity and heat. Based on the intended use and application, the raw LFG may require some level of purification and treatment. Production of pipeline quality gas involves the removal of carbon dioxide and other gases that are present in LFG. This would result in a gas that is approximately 98 percent methane by volume (Conestoga Rovers, 2004, the World Bank - ESMAP).

Purified high grade fuel LFG can be utilized in a number of applications including direct fuel, use for heating, electrical generation, commercial chemical byproducts, pipeline quality as natural gas substitute, vehicle fuel, etc. High grade LFG can be 
compressed under high pressure to give the equivalent of CNG (compressed natural gas); or under low temperature it gives a product similar to LNG (liquefied natural gas).

As discussed in the previous sections, LFG can be classified into three categories, based on the level of pretreatment and processing prior to utilization. These classifications are low, medium, and high-grade fuels. Based on these classifications, the various applications and utilization options of the LFG fuel grades are given in Figure 5.1.

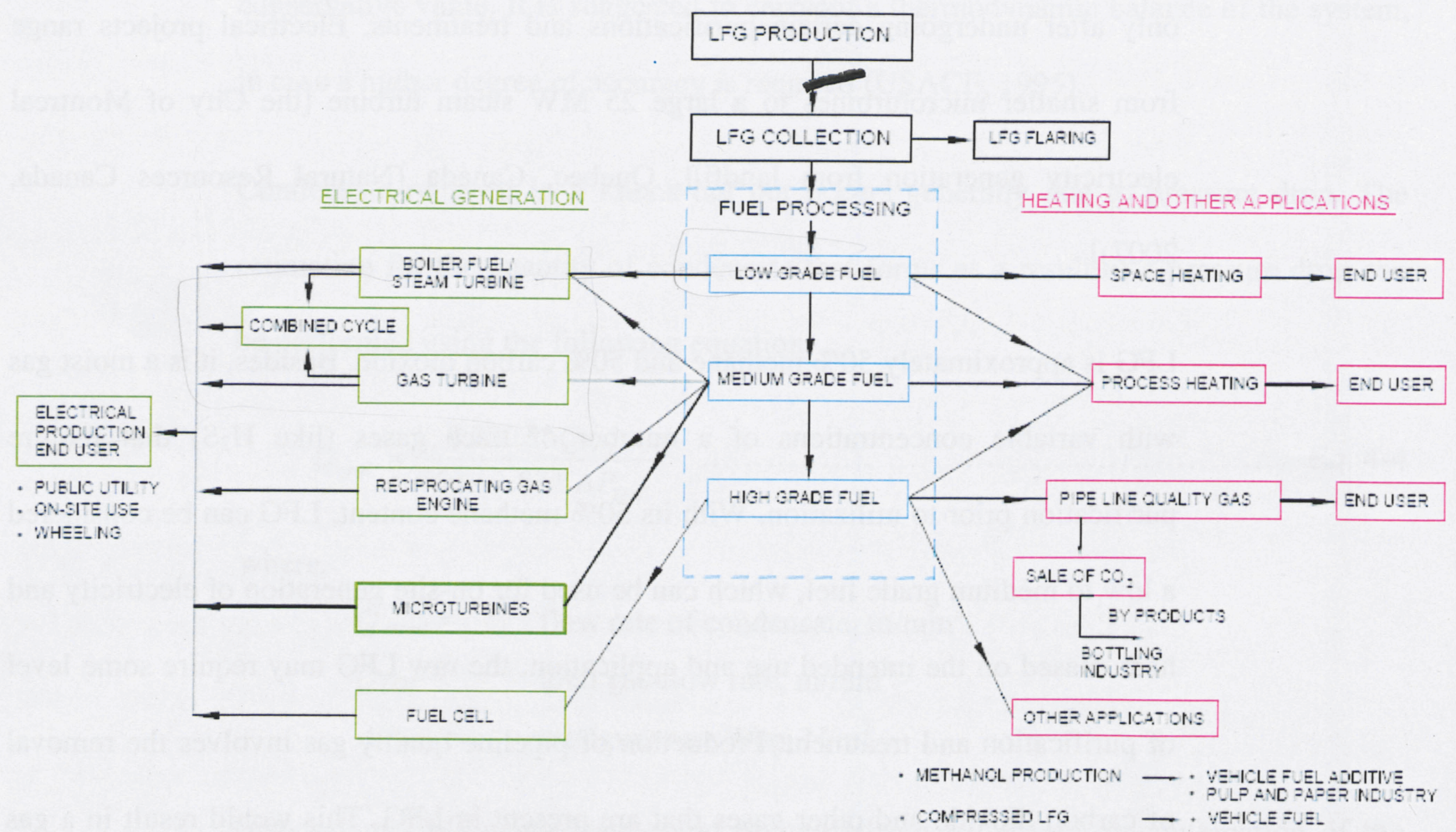

Figure 5-1: LFG classification and use according to fuel grade.

(Source: Conestoga, 2004, the World Bank - ESMAP)

The processes of purification and treatment of landfill gas discussed below are mainly collected as is from different sources and are compiled in this report. Further detail with respect to LFG purifications, the reader is referred to those readings. The sources are 
Conestoga Rovers, 2004; Ferreira, 2004; Hagen et al., 2001; Kapdi, 2004; and Krich et al., 2005.

Accordingly, the LFG treatment and processing discussion on this paper is focused on producing high-grade-fuel LFG. The purification processes discusses the following removal items:

- Removal of moisture and particles

- Removal of trace gases:

- sulfur compounds,

- halogen compounds,

- siloxanes

- Carbon dioxide stripping

Table 5.1 gives a number of essential purification steps for landfill gas and in comparison with sewer gas from biological wastewater treatment plant (Pilarczyk et al., 1987).

Table 5.1: Purification steps and utilization of sewer and landfil gases

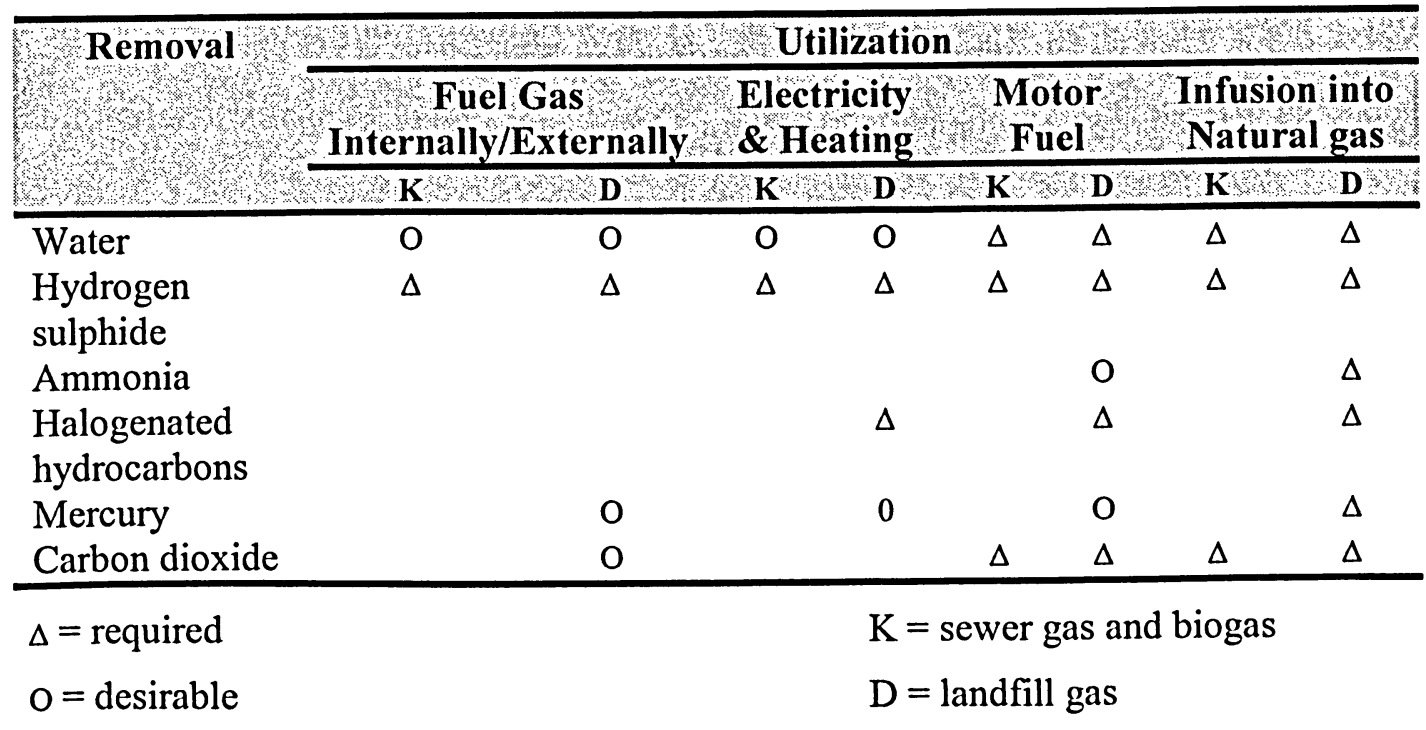

(Souce: Pilarczyk et al., 1987) 


\subsection{REMOVAL OF HYDROGEN SULPHIDE}

Hydrogen sulphide is highly corrosive and it has unpleasant odour; as a result, $\mathrm{H}_{2} \mathrm{~S}$ is typically removed first, even though some technologies allow for concurrent removal of $\mathrm{H}_{2} \mathrm{~S}$ and $\mathrm{CO}_{2}$. Minor quantities of mercaptans (organic sulfides) are also produced, but are removed along with $\mathrm{H}_{2} \mathrm{~S}$. Even in low concentrations, $\mathrm{H}_{2} \mathrm{~S}$ can cause serious corrosion in gas pipelines and gas conversion and utilization equipment as well as result in unpleasant odors and damage to the metal siding and roofing of buildings (Mears, 2001).

Hydrogen sulphide $\left(\mathrm{H}_{2} \mathrm{~S}\right)$ can be removed by a variety of processes, each of which is described below:

- Air injected into a gas digester

- Iron chloride added to the digester influent

- Reaction with iron oxide or hydroxide (iron sponge)

- Use of activated-carbon sieve

- Water scrubbing

- Sodium hydroxide or lime scrubbing

- Biological removal on a filter bed

\subsubsection{Air/Oxygen Injection}

When air is injected into the gas that collects on the surface of the digester, thiobacilli bacteria oxidize sulfides contained in the gas, reducing $\mathrm{H}_{2} \mathrm{~S}$ concentrations by as much as $95 \%$ (to less than $50 \mathrm{ppm}$ ) (Ferreira, 2004). The injection ratio is typically a $2 \%$ to $6 \%$ air to gas ratio (a slight excess of $\mathrm{O}_{2}$ over the stoichiometric requirement). The byproduct of this process is hydrogen and yellow clusters of elemental sulfur. The addition of the proper proportion of air presents significant control problems. Without 
careful control over the amount of air injected, this process can result in the accidental formation of explosive gas mixtures.

\subsubsection{Iron Chloride Injection}

Iron chloride reacts with $\mathrm{H}_{2} \mathrm{~S}$ to form iron sulfide salt particles. Iron chloride can be injected directly into the digester or into the influent mixing tank. This technique is effective in reducing high $\mathrm{H}_{2} \mathrm{~S}$ levels, but less effective in maintaining the low and stable $\mathrm{H}_{2} \mathrm{~S}$ levels needed for vehicular fuel applications. This process needs to be complemented with another removal method to reduce $\mathrm{H}_{2} \mathrm{~S}$ level.

\subsubsection{Iron Oxide or Hydroxide Bed}

Hydrogen sulfide reacts endothermically with iron hydroxides or oxides to form iron sulfide. A process often referred to as "iron sponge" makes use of this reaction to remove $\mathrm{H}_{2} \mathrm{~S}$ from gas. Iron sponge (steel wool), however, has a relatively small surface area, which results in low binding capacity for the sulfide. Because of this, wood chips impregnated with iron oxide have been used as preferred reaction bed material. The iron-oxide impregnated chips have a larger surface-to-volume ratio than steel wool and a lower surface-to-weight ratio due to the low density of wood. Roughly 20 grams of $\mathrm{H}_{2} \mathrm{~S}$ can be bound per 100 grams of iron-oxide impregnated chips (Kirch et al., 2005). The optimal temperature range for this reaction is between $25^{\circ} \mathrm{C}$ and $50^{\circ} \mathrm{C}$. The reaction requires water; therefore, the LFG should not be dried prior to this stage. Condensation in the iron sponge bed should be avoided since water can coat or "bind" iron oxide material, somewhat reducing the reactive surface area.

The iron oxide can be regenerated by flowing oxygen (air) over the bed material. Typically, two reaction beds are installed, with one bed undergoing regeneration while 
the other is operating to remove $\mathrm{H}_{2} \mathrm{~S}$ from the LFG. Applications requiring both $\mathrm{H}_{2} \mathrm{~S}$ and $\mathrm{CO}_{2}$ removal and compression of the biomethane gas, the iron sponge technology using iron-impregnated wood chips appears to be the most suitable.

\subsubsection{Activated Carbon Sieve}

In pressure-swing adsorption systems, $\mathrm{H}_{2} \mathrm{~S}$ is removed by activated carbon impregnated with potassium iodide. The $\mathrm{H}_{2} \mathrm{~S}$ molecule is loosely adsorbed in the carbon sieve; selective adsorption is achieved by applying pressure to the carbon sieve. Typically, four filters are used in tandem, enabling transfer of pressure from one vessel to another as each carbon bed becomes saturated. This process typically adsorbs $\mathrm{CO}_{2}$ and water vapor in addition to $\mathrm{H}_{2} \mathrm{~S}$. To assist in the adsorption of $\mathrm{H}_{2} \mathrm{~S}$, air is added to the gas, which causes the $\mathrm{H}_{2} \mathrm{~S}$ to convert to elementary sulfur and water. The sulfur is then adsorbed by the activated carbon. The reaction typically takes place at a pressure of around 100 to $115 \mathrm{psi}$ and a temperature of 50 to $70^{\circ} \mathrm{C}$. The carbon bed has an operating life of 4,000 to 8,000 hours, or longer at low $\mathrm{H}_{2} \mathrm{~S}$ levels. A regenerative process is typically used at $\mathrm{H}_{2} \mathrm{~S}$ concentrations above $3,000 \mathrm{ppm}$.

\subsubsection{Water Scrubbing}

Water scrubbing is a well-established and simple technology that can be used to remove both $\mathrm{H}_{2} \mathrm{~S}$ and $\mathrm{CO}_{2}$ from LFG, because both of these gases are more soluble in water than methane is. Likewise, $\mathrm{H}_{2} \mathrm{~S}$ can be selectively removed by this process because it is more soluble in water than carbon dioxide. However, the $\mathrm{H}_{2} \mathrm{~S}$ desorbed after contacting can result in fugitive emissions and odor problems. Pre-removal of $\mathrm{H}_{2} \mathrm{~S}$ (e.g., using iron sponge technology) is a more practical and environmentally friendly approach. 


\subsubsection{Biological Filter}

A biological filter combines water scrubbing and biological desulfurization processes. Biological scrubbing techniques utilize sulphur oxidizing bacteria, thiobacillus, for removing hydrogen sulphide from biogas. As with water scrubbing, the biogas and the separated digestate meet in a counter-current flow in a filter bed. The biogas is mixed with $4 \%$ to $6 \%$ air before entry into the filter bed. The filter media offer the required surface area for scrubbing, as well as for the attachment of the desulfurizing bacteria ( $\mathrm{H}_{2} \mathrm{~S}$ oxidizing).

Nishimura and Yoda (1997) studied a full scale bio-scrubber for removing hydrogen sulphide. According to their studies, the full scale bio scrubber showed more than $99 \%$ removal efficiency when treating $\mathrm{H}_{2} \mathrm{~S}$ with concentration of $2000 \mathrm{ppm}$.

\subsection{REMOVAL OF WATER VAPOR}

The biological decomposition of the waste mass on landfill is an exothermic process. Hence, the generated LFG is warm and is apparently saturated with water vapor. The moisture content of LFG, on top of the constituents like carbon dioxide, hydrogen sulfide, and VOCs, creates a potentially corrosive gas because of creation of acid solutions. Moisture reduction techniques that can be applied include moisture separators, mist eliminators, direct cooling, compression followed by cooling, absorption, and adsorption.

The amount of saturated water vapor in a gas depends on the prevailing temperature and pressure within the landfill. Moisture removal is especially important if the $\mathrm{H}_{2} \mathrm{~S}$ has not been removed from the gas because $\mathrm{H}_{2} \mathrm{~S}$ and water vapor react to form sulfuric acid $\left(\mathrm{H}_{2} \mathrm{SO}_{4}\right)$, which can result in severe corrosion in pipes and other equipment that comes 
into contact with the gas. Even if the $\mathrm{H}_{2} \mathrm{~S}$ has been removed, water vapor can react with $\mathrm{CO}_{2}$ to form carbonic acid $\left(\mathrm{H}_{2} \mathrm{CO}_{3}\right)$, which is also corrosive. When water vapor condenses within a system due to pressure or temperature changes, it can result in clogging of the pipes on top of the corrosion problems.

A number of techniques can be used to remove condensation from a pipe, including tees, U-pipes, or siphons. The simplest means of removing excess water vapor in LFG is through refrigeration. In a refrigerator unit, water vapor condenses on the cooling coils and is then captured in a trap. The dew point of LFG is close to $1.7^{\circ} \mathrm{C}$. Scrubbing of the gas to remove $\mathrm{H}_{2} \mathrm{~S}$ prior to refrigeration would significantly lengthen the life of the refrigeration unit.

Moisture separators function by swirling gas through a large cylinder, slowing down the gas velocity and allowing moisture in the form of droplets to collect on the walls of the cylinder. Mist eliminators, or coalescing filters, are typically used in conjunction with a moisture separator to collect droplets too small to have been intercepted by the separator. These are typically constructed of a wire mesh screen through which the LFG passes. Mist eliminators also intercept particulate matter entrained within the water droplets. In combination with moisture separators it removes $99.9 \%$ of the liquids.

Adsorption techniques use a granular solid material, which has an affinity for water. In this process, the water "sticks" to the granular material as the gas passes. Examples of this media include silica gel, alumina, and silicates known as molecular sieves. This technique is sometimes used in conjunction with absorption in systems such as packed towers, plate columns, spray towers, and venturri scrubbers. Over time, contamination of the specialized media employed in these systems causes reduced efficiency and 
replacement is required. Absorption uses a liquid with a high affinity for water. The LFG to be absorbed is either introduced to the bottom of a column of absorbing medium, or the medium is sprayed onto the LFG stream. The water is removed from the gas through a process of physical and chemical reactions with the absorbing medium. The success of this process depends on the specific absorbing medium and the LFG characteristics.

\subsection{PARTICULATE REMOVAL}

The solid particles carried within the LFG stream must be removed in applications for use of medium to high-grade fuel to avoid damage to the blower systems and other equipment components. The majority of the fine particulate matter is entrained within the moisture droplets in the gas. Therefore, moisture removal serves the dual purpose of also removing the particulate matter. Particulate filters can also be used to reduce particulate content of the gas but these filters require a high level of maintenance and must be frequently cleaned and/or replaced.

\subsection{REMOVAL OF CARBON DIOXIDE}

The problem of having carbon dioxide in LFG is that it reduces the overall energy content of the gas. Besides, it creates a corrosive liquid when combined with water vapor. By removing carbon dioxide from LFG, the heating value of LFG is augmented, while collating the carbon dioxide for other end products in food processing industry. The technologies available for removal of $\mathrm{CO}_{2}$ from LFG are typically used for larger scale applications such as upgrading natural gas from "sour" gas wells, sewage treatment plants, and landfills. The following processes can be considered for $\mathrm{CO}_{2}$ removal from LFG. The processes are presented roughly in the order of their current availability for and applicability to gas upgrading: 
- Water scrubbing

- Pressure swing adsorption

- Chemical scrubbing with glycols

- Cryogenic separation

\subsubsection{Water Scrubbing}

Water scrubbing is the most applicable $\mathrm{CO}_{2}$ scrubbing process because of its simplicity and low cost. When water scrubbing is used for $\mathrm{CO}_{2}$ removal, the gas is pressurized, typically to 150 to $300 \mathrm{psig}$ (psi gauge) with a two-stage compressor, and then introduced into the bottom of a tall vertical column. The raw LFG is introduced at the bottom of the column and flows upward, while fresh water is introduced at the top of the column, flowing downward over a packed bed. The packed bed (typically a highsurface-area plastic media) allows for efficient contact between the water and gas phases in a countercurrent absorption regime. Water often pools at the bottom of the contact column and the gas first passes through this water layer in the form of bubbles. The $\mathrm{CO}_{2}$ saturated water is continuously withdrawn from the bottom of the column and the cleaned gas exits from the top.

A purity of about $95 \%$ methane can be readily achieved with minimal operator supervision in a single pass column. After scrubbing, the water can be regenerated (i.e., stripped of $\mathrm{CO}_{2}$ by contacting with air at atmospheric pressures, either in a packed bed column similar to the one used for absorption, or in a passive system such as a stock pond). In addition to being a simple, well-established, and relatively inexpensive technology, water scrubbing typically loses relatively little $\mathrm{CH}_{4}$ (less than $2 \%$ ) because of the large difference in solubility of $\mathrm{CO}_{2}$ and $\mathrm{CH}_{4}$ (Kirch et al., 2005). 


\subsubsection{Pressure Swing Adsorption}

This approach uses a column filled with a molecular sieve (typically an activated carbon) for differential sorption of the gases, such that $\mathrm{CO}{ }_{2}$ and $\mathrm{H}_{2} \mathrm{O}$ adsorb preferentially, letting $\mathrm{CH}_{4}$ pass through. The process is operated under moderate pressures. Several columns, typically four, are operated sequentially to reduce the energy consumption for gas compression and the gas pressure released from one vessel is subsequently used by the others. The first column cleans the raw gas at about $90 \mathrm{psi}$ to an upgraded gas with a vapor pressure of less than $10 \mathrm{ppm} \mathrm{H}_{2} \mathrm{O}$ and $\mathrm{CH}_{4}$ content of $96 \%$ or more. In the second column, the pressure of $90 \mathrm{psi}$ is first released to approximately 45 psi by pressure communication with the fourth column, which was previously degassed by a slight vacuum. The pressure in the second column is then reduced to atmospheric pressure and the released gas flows back to the digester so that the $\mathrm{CH}_{4}$ can be recovered. The third column is evacuated from about 15 to about $1 \mathrm{psi}$. The desorbed gas consists predominantly of $\mathrm{CO}_{2}$ and is normally vented to the environment even though it contains some residual $\mathrm{CH}_{4}$. To reduce $\mathrm{CH}_{4}$ losses, the system can be designed so that desorbed gases recirculate to the pressure swing adsorption system or even the digester.

This process produces a water-free gas that is cleaner than gas produced by other techniques such as water scrubbing; however, it requires considerably more sophistication and increased process controls, including careful recycling of a fraction of the gas to avoid excessive $\mathrm{CH}_{4}$ losses. Another drawback is its susceptibility to fouling by contaminants in the gas stream. 


\subsubsection{Chemical Scrubbing with Polyethlylene Glycols}

Polyethylene glycol scrubbing, like water scrubbing, is a physical absorption process. Selexol is the main commercial process using this solvent, and it is used extensively in the natural gas industry as well as other applications. Carbon dioxide and $\mathrm{H}_{2} \mathrm{~S}$ have even greater solubility relative to methane in Selexol fluid than in water, which results in a lower solvent demand and reduced pumping. Selexol is typically kept under pressure, which improves its capability to absorb these contaminants. In addition, water and halogenated hydrocarbons (contaminants in landfill gas) are removed when scrubbing gas with Selexol. The major drawback is that the process is more expensive for small-scale applications than water scrubbing or pressure swing adsorption.

\subsubsection{Cryogenic Separation}

Because $\mathrm{CO}_{2}, \mathrm{CH}_{4}$, and contaminants all liquefy at very different temperature-pressure domains, it is possible to produce $\mathrm{CH}_{4}$ from LFG by cooling and compressing the gas to liquefy $\mathrm{CO}_{2}$ which is then easily separated from the remaining gas. The extracted $\mathrm{CO}_{2}$ also can be used as a solvent to remove impurities from the gas. Removal of this $\mathrm{CO}_{2}$ requires a follow-up membrane separation step, or $\mathrm{CO}_{2}$ wash process, mainly to remove impurities and produce some liquid $\mathrm{CO}_{2}$.

The economics of cryogenic separation still need to be assessed and further development is needed before cryo-separation can be considered ready for applications. A potential problem with cryo-separation is that its costs of separation tend to drop sharply with increasing scale and its cost-effectiveness at small scales has not been established. This process might be worth considering if the end objective is to produce liquefied biomethane (LBM), a product equivalent to liquefied natural gas (LNG). In 
this case, the refrigeration process needed for cryo-separation would likely be synergistic with the further cooling required for LBM production.

\subsection{TRACE GAS REMOVAL}

The trace gases normally removed from LFG are non-methane organic compounds (NMOCs), and volatile organic compounds (VOCs). These can be removed through the use of granular activated carbon (GAC), selective solvents, or iron sponge. GAC is the most commonly-used tool to deal with hydrocarbon and VOC treatment. One significant disadvantage of using GAC for LFG polishing applications is its high affinity for moisture. This can be mitigated by the implementation of a good moisture removal process prior to use of the GAC. Selective solvent processes use various solvents to selectively adsorb trace gases. Iron sponge processes can be used to remove hydrogen sulfide from the LFG. The system uses hydrated iron oxide supported on wood shavings to react and produce iron sulfide. 
CONCLUSIONS

The amount of energy recovered at municipal solid waste landfills is often characterized by high levels of uncertainty (Copty et al., 2004). Mainly, the uncertainties arise from the rate of LFG generation and the effectiveness of the gas collection system. Rate of landfill gas generation is dependent on the waste type and composition, landfill design and construction techniques, groundwater conditions, climatological factors, etc. These parameters affect the rate of waste stabilization and biological decomposition, which in turn affect the amount of gas produced within the landfill. Many complex factors, which are interrelated to each other including the dynamics of landfill gas and atmospheric conditions, influence the efficiency of LFG recovery systems. Besides, gas permeability, transport mechanism and flow patterns, which are dependent on the attributes of the physical property of the waste, type of daily cover, material of cell liners, diurnal groundwater levels, etc. also affect the effectiveness of the gas collection system. These factors and others, ultimately, affect the magnitude of gas that could be captured as well as the overall efficiency of the gas collection system.

Hence, intensive field investigation and rigorous data collection is required for proper characterization of the parameters that affect the amount of gas generated and recovered. It is obvious that the acquisition of site specific data from MSW landfills would help in developing better models of gas emission estimates. However, still, validation and verification of model results is difficult. This is mainly due to the reason that exact measure of the parameters is not well identified or lack accuracy. The development of methane pathways and budgets based on measured values may help resolve this issue to certain degree. But still, different approach in design, construction, and operation of landfills and also the variable nature of refuse composition are huge 
drawbacks in developing simple, versatile and accurate quantification methods. As a result, empirical models are valid and economical tools, which are sufficient for planning and design of gas generation potential of a landfill. Besides, modeling results in conjunction with the measure of the recovered gas could help in adjusting the rate of LFG generation. Whichever model is used, it is a good practice to undertake sensitivity analysis in order to identify a number of potential results and ultimately distinguish and analyze the parameters that show the greatest influence on the magnitude of the generated LFG.

The most important constituent of landfill gas is methane, which is the principal energy source. Though it depends on many factors, methane makes up 35 to $60 \%$ of landfill gas. Besides methane, LFG is usually saturated with moisture and it also has a number of impurities with variable concentrations including carbon dioxide, hydrogen sulphide, etc. The impurities cause a number damages to the purification and utilization equipment, while reducing LFG's energy value by almost $50 \%$ of that of pure methane or natural gas. Depending on the requirement of specific application, these impurities, therefore, need to be removed so that pure methane with relatively higher energy value is obtained.

LFG can be used for heating purpose or generation of electricity, without any additional purification. Many researchers in this field note that the economic return on investment for projects involving the sale of methane from landfill gas is greater than the return of an electric power project from landfill gas. As a result, there is a significant opportunity to increase LFG recovery and purification prior to utilization. LFG purification technology is a well set up system with a very wide applications. However, the ultimate purification and upgrading of LFG is dependent on the economics of the overall system starting from operation of the collection system to 
purification and upgrading of LFG to biomethane. On top of the economics, it is also equally important to assess the conditions and availability of appropriate markets for different grade of biomethane. The benefits harnessed from proper gas collection system and proper purification techniques would generate revenue, which can provide an incentive to improve the design and operation of landfills, and to advance overall waste management system. Moreover, proper gas collection system and LFG management will assist in the protection of the environment from greenhouse gas emissions, which contribute to global warming. 


\section{REFERENCE}

Anthony, C., (1982), “The Biochemistry of Methylotrophs”, Academic Press, London.

Augenstein, D., and J Pacey, (1991), "Landfill Methane Models" 14th Annual Landfill Gas Symposium Proceedings, Research Triangle Park, 1991. Ed. SWANA. Triangle Research Park. 1991. III-87 - III-111.

Blaha, D., Bartlett, K., Czepiel, P., Harris, R., Crill, P., 1999. Natural and anthropogenic methane sources in New England, Atmospheric Environment 33, 243-255.

Bogner, J. and Spokas, K., (1993), "Landfill CH4: rates, fates, and role in global carbon cycle". Chemosphere 26, 366-386.

Boyle, W. C. (1977), "Energy Recovery from Sanitary Landfills A Review-" Microbial Energy Conversion. New York, NY: Pergamon Press.

Budvaris, S. (1989) (Ed) The Merck Index, $11^{\text {th }}$ Edition. Merck and Co Inc., Rahway, New Jersey.

Campbell, D.; Epperson, D.; Davis, L.; Peer, R.; Gray, W. (1991), "Analysis of Factors Affecting Methane Gas Recovery from Six Landfills”, Final Report. Jul 90-Jul 91, Radian Corp., Research Triangle Park, NC., 076365000, Environmental Protection Agency, Research Triangle Park, NC.

Cestaro, S., Cossu, R., Lanzoni, S., Raga, R., 2003. Analysis of pressure field in a landfill during in situ aeration for waste stabilization. In: Proceedings Sardinia 2003, Ninth International Waste Management and Landfill Symposium S. Margherita di Pula, Cagliari, Italy, 6-10 October. 
CH2M HILL, (2002), “Inventory Report for Potential Landfill Bioreactors" The California Energy Commission, CH2M HILL, 3 Hutton Centre Drive, Suite 200, Santa Ana, CA 92707

Christensen, Thomas H., and Peter Kjeldsen, (1989), "Basic Biochemical Processes in Landfills" in Sanitary Landfilling : Process, Technology and Environmental Impact ed. Thomas H. Chistensen, Raffaello Cossu, and Rainer Stegmann (Academic Press, New York, 1989) p.29

Conestoga-Rovers \& Associates (2004), "The World Bank ESMAP: Handbook for the Preparation of Landfill Gas to Energy Projects in Latin America and the Caribbean" Ref. No. 019399(6), January 2004, 651 Colby Drive, Waterloo, Ontario, N2V 1C2,

Copty N. K., Ergene D., and Onay T. T., (2004), "Stochastic Model for Landfill Gas Transport and Energy Recovery", Journal of Environmental Engineering, Vol. 130, No. 9, September 1, 2004, ASCE, ISSN 0733-9372/2004/9-1042-1049

De Visscher A. , De Pourcq I. , Chanton J., (2004), “Isotope fractionation effects by diffusion and methane oxidation in landfill cover soils", Department of Oceanography, Florida State University, Tallahassee, Florida, USA, JOURNAL OF GEOPHYSICAL RESEARCH, VOL. 109, D18111, doi:10.1029/2004JD004857, 2004

Doorn M., Pacey J., and Augenstein D., (1995): “Landfill Gas Energy Utilization Experience: Discussion of Technical and Non-Technical Issues, Solutions, and Trends", EPA600/R-95-035, prepared for the Air and Energy Engineering Research Laboratory, U.S. Environmental Protection Agency by E.H. Pechan and Associates, Inc. (Washington, DC, March 1995) 
Eden C. (1994), “Combined Landfill Gas and Leachate Extraction Systems”, UKPS Ltd, The Barclay Centre, University of Warwick Science Park, Coventry, England, Technical guidance note CPE07/94

Environment Agency (2002), "Guidance on the Management of Landfill Gas". Draft for Consultation, Environment Agency, Rio House, Waterside Drive, Aztec West, Almondsbury, BRISTOL, BS32 4UD, UK

Emcon Associates (1980), "Methane Generation and Recovery from Landfills", Ann Arbor Science Publishers, 1980.

Farquhar G. J. and Rovers F. A., (1973), "Gas Production During Refuse Decomposition" Department of Civil Engineering, University of Waterloo, Waterloo, Ontario, Canada

Ferreira, Paloma (2004): “THE USAGE OF BIOGAS IN FUEL CELL SYSTEMS” Centre for Energetic, Environmental and Technological Research Institute for Catalysis and Petrochemistry-Spanish Council for Scientific Research Madrid, Spain

Findikakis, A. N. and J. O. Leckie. (1979), "Numerical Simulation of Gas Flow in Sanitary Landfills". Proc. ASCE, Jour. Env. Eng., Vol. 105, No. EE5, pp. 927-945.

Hagen, M., E. Polman, A. Myken, J. Jensen, O. Jönsson, AB Biomil, and A. Dahl, (2001), "Adding gas from biomass to the gas grid", Final report, contract no: XVII/4.1030/Z/99-412. July 1999 - February 2001.

Ham, Robert K., and Morton A. Barlaz, (1989), "Measurement and Prediction of Landfill Gas Quality and Quantity" in Sanitary Landfilling : Process, Technology and Environmental Impact ed. Thomas H. Chistensen, Raffaello Cossu, and Rainer Stegmann (Academic Press, New York, 1989) p.155-158 
Ham, R. K.t et al. (1979). Recovery, Processing, and Utilization of Gas from Sanitary Landfills. Cincinnati, OH: U.S. EPA, EPA 600/2-79-001.

Hartz, K.E. (1980), “Studies of Methanogenesis in Samples from Landfills". Ph.D. Dissertation, University of Wisconsin-Madison. August, 1980.

Huitric L.R. and Kong D., (2006), “Measuring Landfill Gas Collection Efficiency Using Methane Concentrations", Solid Waste Management Department Los Angeles County Sanitation Districts Whittier, California, U.S.

Kapdi S.S., V.K. Vijay, S.K. Rajesh, Rajendra Prasad (2004), Biogas scrubbing, compression and storage: perspective and prospectus in Indian context", Centre for Rural Development and Technology, Indian Institute of Technology, New Delhi 110016 , India, ELSEVIER, Renewable Energy 30 (2005), pp. 1195-1202

Krich Ken, Don Augenstein,JP Batmale, John Benemann, Brad Rutledge, Dara Salour (2005), "Biomethane from Dairy Waste: A Sourcebook for the Production and Use of Renewable Natural Gas in California", Prepared for Western United Dairymen, Funded in part through USDA Rural Development, July 2005

Kotze, J. P., Thiel, P. G., and Hattingh, W. H. J. : 1969, Water Res. 3, 459. Pergamon Press, Great Britain.

Lim, K.T., (1995), “Mega-molecular dynamics on highly parallel computers: Methods and applications", PhD Dissertation. California Institute of Technology, Pasadena, California.

Ludwig, H., (1967), "Final Report in Situ Investigation of Gases Produced from Decomposing Refuse", Oakland, California. 
Martin, John and Fujii, Mark,(1985) "Evaluation of Horizontal Trenches for Landfill Gas Collection at Rossmans Landfill," Proceedings from GRCDA 8th International Landfill Gas Symposium, April 9, 1985.

McBean, E.A., F.A. Rovers, and G.J. Farquhar, (1995), Solid Waste Landfill Engineering and Design, New Jersey: Prentice Hall, 1995.

Moore, C. A. (1979), "Landfill Gas Generation, Migration, and Controls", CRC Critical Reviews in Environmental Control. November, 1979, pp. 157-183.

Natural Resources Canada (2007), "Production of 25 MW of Electricity Using Landfill Gas", Web site: oee.nrcan.gc.ca/ici, accessed June 25, 2007.

Nishimura S. and Yoda M., (1997), "Removal of Hydrogen Sulphide from an Anaerobic Biogas using a Bio-Scrubber", Wat. Sci. Tech. Vol. 36, No. 6-7, pp $349-356,1997$, Pergamon.

Parametrix, Inc.(1987), “Solid Waste Landfill Design Manual” 13020 Northup Way, Suite 8 Bellevue, Washington, Publication No. 87-13

Pfeffer, John T. (1992), "Solid Waste Management Engineering”, University of Illinois at Urbana-Champaign, Prentice Hall, Englewood Cliffs, New Jersey, USA.

Pilarczyk E., Henning K.-D., Knoblauch K., Bergbau-Forschung (1987), "Natural gas from Landfill Gases" Essen, Federal Republic of Germany, Resources and Conseruation, 14 (1987) 283-294 Elsevier Science Publishers B.V., Amsterdam

Prosser W. R, (1985), “The Effects of Atmospheric Pressure on the Availability of Gas from a Landfill", GC Environmental, Inc. 1230 N. Jefferson St., Suite J. Anaheim, CA 92807 
Ramaswamy, J. N., (1970), "Nutritional effects on acid and gas production in sanitary landfills", Ph.D. Thesis, West Virginia University, U.S.

Reinhart, D.R., and B. Al-Yousfi, (1996), "The Impact of Leachate Recirculation on Municipal Solid Waste Landfill Operating Characteristics." Waste Management \& Research 14 (1996): 337-346

Schumacher, M. M. (ed.). 1983. Landfill Methane Recovery. Park Ridge, NJ: Noyes Data Corporation.

Skinner, F. A., (1968), “The Ecology of Soil Bacteria" An International Symposium (Ed. by T. R. G. Gray and D. Parkinson), The University of Liverpool, University of Toronto Press.

Songohuga, O. (1969), “Acid, Gas and Microbial Dynamics in Sanitary Landfills”. Ph.D. Dissertation, University of West Virginia, Morgantown, West Virginia, 1969.

Spokas k., Bogner J., Chanton J.P., Morcet M., Aran C., Graff C., Moreau-Le Golvan Y., Hebe I., (2005), “Methane mass balance at three landfill sites: What is the efficiency of capture by gas collection systems", ELSEVIER, Waste Management 26 (2006) pp. $516-525$

Statistics Canada, (December 2005), "Human Activity and the Environment: Solid waste", retrieved from Website http://www.statcan.ca/Daily/English/051202/d051202b.htm, June 20, 2007.

Stone, R. (1978), "Preventing the Underground Movement of Methane from Sanitary Landfills", Civil Engineering. January, 1978, pp. 51-52. 
Tchobanouglous, G. et. al. (1977), “Solid Wastes, Engineering Principles and Management Issues", McGraw Hill, 1977

Tregoures, A., Beneito, A., Berne, P., Gonze, M.A., Sabroux, J.C., Pokryszka, Z., Savanne, D., Tauziede, C., Cellier, P., Laville, P., Milward, R., Arnaud, A., Levy, F., Burkhalter, R., (1999), “Comparison of seven methods for measuring methane flux at a municipal solid waste landfill site". Waste Management and Research 17, 453-458.

USACE, (1983), “TM 5-814-5: Sanitary Landfill”. U.S. Army Corps of Engineers, Washington,DC.

USACE (1995), “ETL 1110-1-160: Engineering and Design, LANDFILL OFF-GAS COLLECTION AND TREATMENT SYSTEMS", DEPARTMENT OF THE ARMY, Washington, DC 20314-1000, Engineering Technical Letter No. 1110-1-160, 17 April 1995

U.S. EPA (1978): “Municipal Sludge Landfill Process Design Manual”. Report No. EPA625/1-78-010/SW-705. Washington, DC: Office of Solid Waste.

U.S. EPA (1996): “Turning Liability into an Asset: A Landfill Gas-to-Energy Project Development Handbook', Landfill Methane Outreach Program Report No. EPA-430B-96-0004. U.S. Environmental Protection Agency, September 1996

U.S. EPA (2003), "Municipal Solid Waste in the United States: 2001 Facts and Figures", US Environmental Protection Agency. Available at http://www.epa.gov/epaoswer/nonhw/muncpl/msw99.htm

U.S. EPA (2005), “Landfill Gas Emissions Model (LandGEM) Version 3.02 User's Guide”, EPA-600/R-05/047, May 2005 
Weast, R. and I. Hodgeman. (1958), "Handbook of Chemistry and Physics", CRC Publishing.

Willumsen, H., (2003), "Landfill gas plants worldwide: number and types", Proceedings Sardinia '03 Waste Management and Landfill Symposium. CISA, University of Cagliari, Sardinia, Italy, 2003.

Wise M. G., J VAUN MCARTHUR, and LAWRENCE J. SHIMKETS (1999), "Methanotroph Diversity in Landfill Soil: Isolation of Novel Type I and Type II Methanotrophs Whose Presence Was Suggested by Culture-Independent 165 Ribosomal DNA Analysis", American Society for Microbiology, APPLIED AND ENVIRONMENTAL MICROBIOLOGY, Nov. 1999, p. 4887-4897 Vol. 65, No. 11

Wyton S. and Smith C., "The City of Calgary's Landfill Gas and Renewable Energy Assessment" Available at http://www.sustainablecommunities.fcm.ca/.. /General_Folder/SWANA_LFG_paper_SW-CJS_Rev_2.pdf. Retrieved on September 15, 2007. (Waste \& Recycling Services, The City of Calgary, and CH2M HILL Canada Limited Calgary, Alberta, Canada)

Zison, S.W., (1990), "Landfill Gas Production Curves, Myth vs. Reality" GRCDA '90 